University of Louisville

ThinkIR: The University of Louisville's Institutional Repository

8-2014

\title{
Measuring mindful interoception : development of the mindful interoception sampling task (MIST).
}

Samuel J. Dreeben

University of Louisville

Follow this and additional works at: https://ir.library.louisville.edu/etd

Part of the Psychology Commons

\section{Recommended Citation}

Dreeben, Samuel J., "Measuring mindful interoception : development of the mindful interoception sampling task (MIST)." (2014). Electronic Theses and Dissertations. Paper 371.

https://doi.org/10.18297/etd/371

This Doctoral Dissertation is brought to you for free and open access by ThinkIR: The University of Louisville's Institutional Repository. It has been accepted for inclusion in Electronic Theses and Dissertations by an authorized administrator of ThinkIR: The University of Louisville's Institutional Repository. This title appears here courtesy of the author, who has retained all other copyrights. For more information, please contact thinkir@louisville.edu. 


\title{
MEASURING MINDFUL INTEROCEPTION:
}

\section{DEVELOPMENT OF THE MINDFUL INTEROCEPTION SAMPLING TASK (MIST)}

\author{
By \\ Samuel J. Dreeben \\ B.A. Williams College, 2006 \\ M.A. University of Louisville 2011 \\ A Dissertation \\ Submitted to the Faculty of the \\ College of Arts and Sciences of the University of Louisville \\ in Partial Fulfillment of the Requirements \\ for the Degree of \\ Doctor of Philosophy \\ Department of Psychological and Brain Sciences \\ University of Louisville \\ Louisville, Kentucky
}

August 2014 



\section{MEASURING MINDFUL INTEROCEPTION:}

\section{DEVELOPMENT OF THE MINDFUL INTEROCEPTION SAMPLING TASK (MIST)}

$$
\text { By }
$$

Samuel J. Dreeben

B.A. Williams College, 2006

M.A. University of Louisville 2011

\section{A Dissertation Approved on}

June 18, 2014

by the following Dissertation Committee:

Paul Salmon, Ph.D., Dissertation Chair

Ken Linfield, Ph.D.

Keith Lyle, Ph.D.

Benjamin Mast, Ph.D.

Sandra Sephton, Ph.D. 


\begin{abstract}
MEASURING MINDFUL INTEROCEPTION:

DEVELOPMENT OF THE MINDFUL INTEROCEPTION SAMPLING TASK (MIST)
\end{abstract}

Samuel J. Dreeben

June 18, 2014

Sustained, non-evaluative, present moment interoception or "mindful interoception" (MI) is a central feature of many widely practiced clinical interventions, including mindfulness-based therapies, cognitive-behavioral therapies, focusing-oriented psychotherapy, and Gestalt therapy. However, to date, no valid measures of MI have been developed. The lack of such a measure has precluded attempts to discern A) to what extent MI ability changes as a function of MI-based therapies, B) if change in MI mediates symptom reduction, and C) if individual differences in MI ability are associated with anxiety, mindfulness, and other hypothetically related constructs.

The purpose of the current study was to develop and validate the first such measure of MI, the Mindful Interoception Sampling Task (MIST). The MIST is a behavioral measure of MI, in which participants focus attention on sequential regions of the body and are periodically prompted to report whether their attention has wandered. Higher scores on the MIST are thus hypothetically reflective of lower levels of MI. 
One hundred eight participants were recruited from undergraduate psychology courses for this study. Participants were administered the MIST and the Schandry heartbeat detection task, a widely used behavioral measure of interoception. A battery of questionnaires was also administered, and resting heart rate and blood pressure were recorded.

Results of this study indicate the MIST is a valid behavioral measure of mindfulness, the first of its kind. Further research is still needed to determine whether the MIST specifically measures MI. Current findings, however, do suggest the newly identified construct of MI is an important and promising focus of clinical research. 


\section{TABLE OF CONTENTS}

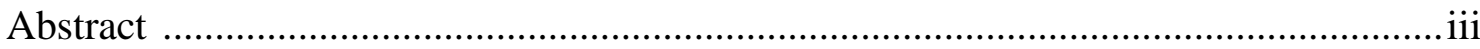

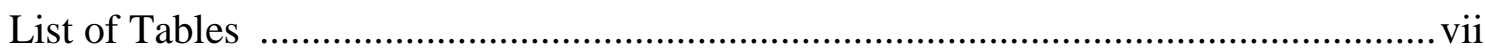

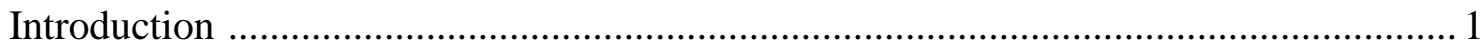

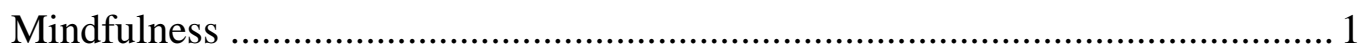

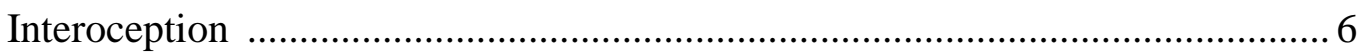

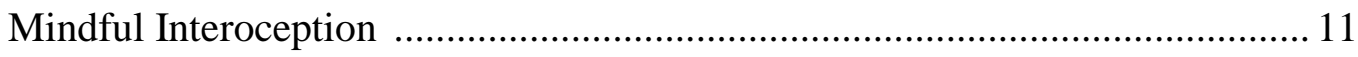

Measuring Mindful Interoception …………................................................ 18

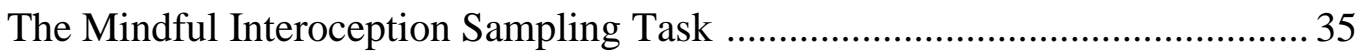

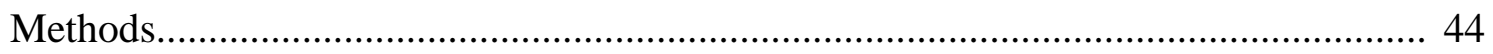

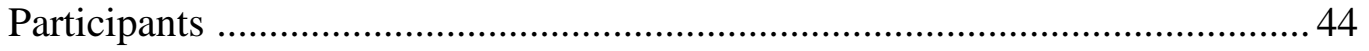

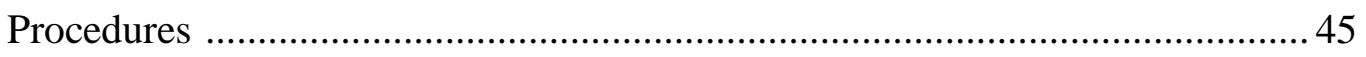

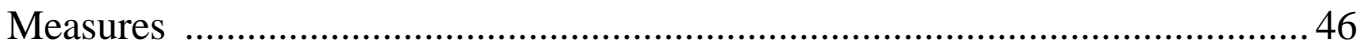

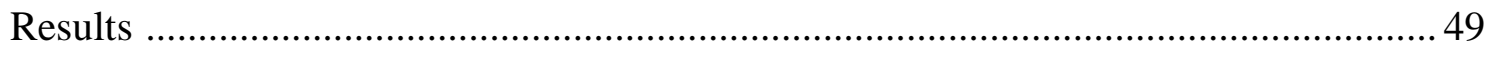

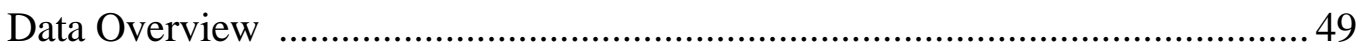

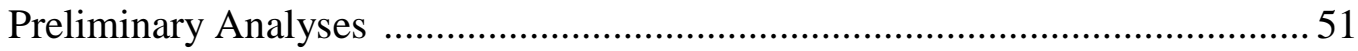

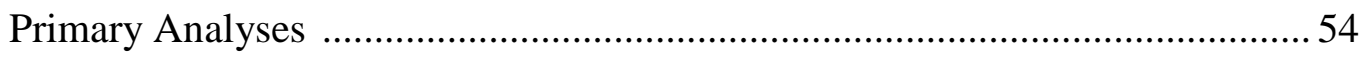

Supplementary Analyses ................................................................................ 63

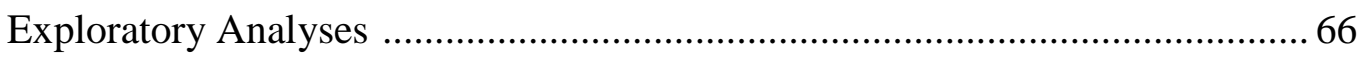

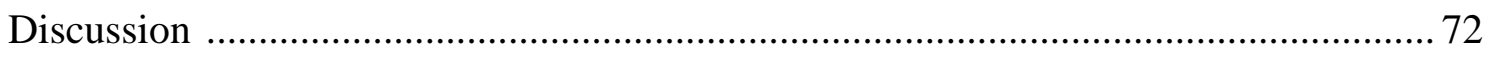


Ordering Effects and Internal Consistency ................................................... 72

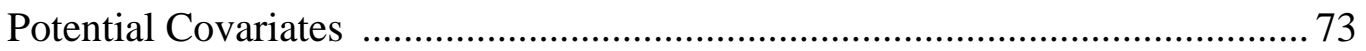

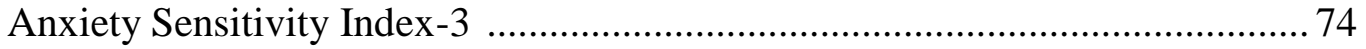

Self-Report Measures of Mindfulness and MI ............................................ 76

Construct Validity of MIST Focal Regions …............................................... 78

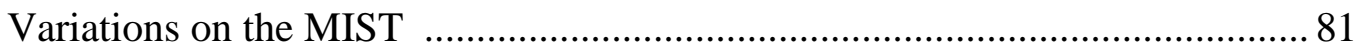

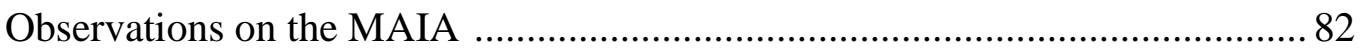

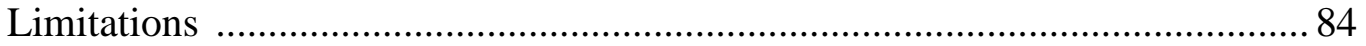

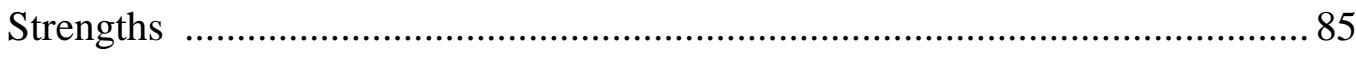

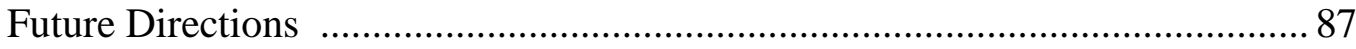

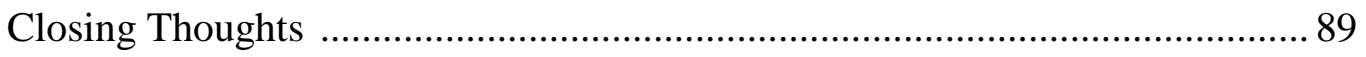

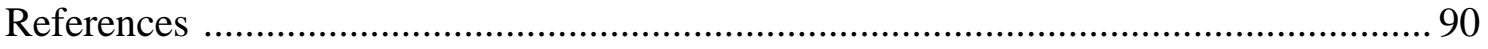

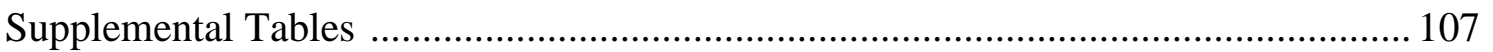

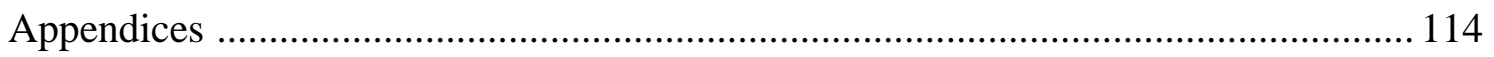

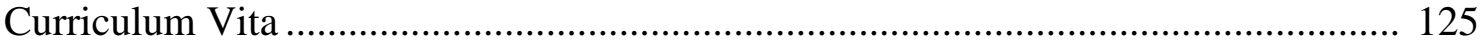




\section{LIST OF TABLES}

TABLE

PAGE

1. Facets of Mindfulness, as Identified in Definitions of Mindfulness ….........................107

2. Mechanisms of Mindfulness, as Identified in Theoretical Papers ................................108

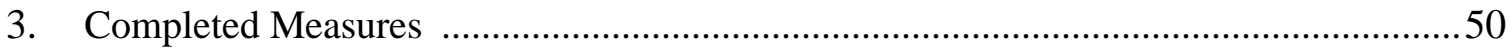

4. MIST Focal Regions, by Sequence in Script …………….....................................52

5. MIST Focal Regions, by Region of Body …………................................................53

6. Pearson Product-Moment Correlations for Interoceptive Tasks and Potential

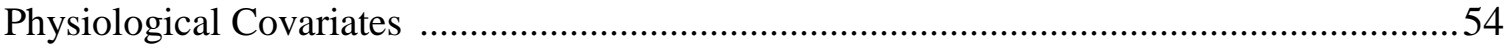

7. Pearson Product-Moment Correlations for Interoceptive Tasks and ASI-3 Subscales ..56

8. Semi-Partial Correlations for Interoceptive Tasks and ASI-3 Subscales ......................109

9. Pearson Product-Moment Correlations for Interoceptive Tasks and Selected MAIA

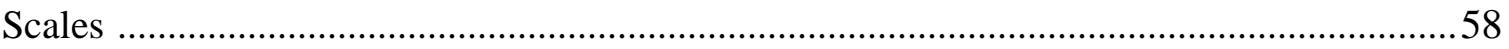

10. Semi-Partial Correlations for Interoceptive Tasks and Selected MAIA Scales ...........109

11. Pearson Product-Moment Correlations for PHLMS Awareness Scale and FFMQ Act with Awareness Scale with Selected MAIA Scales ...........................................................61

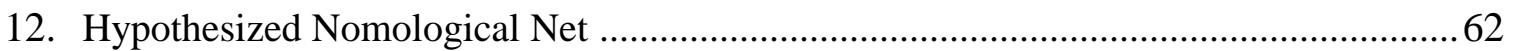

13. Observed Pattern of Pearson Product-Moment Correlations ..........................................63

14. Independent Samples T-tests Comparing Mean Scores on MIST Focal Regions ..........64 
15. Pearson Product-Moment Correlations for MIST Focal Regions and Potential Physiological Covariates .65

16. Pearson Product-Moment Correlations for MIST Focal Regions, MIST-total, and Hypothetically-Related Variables 66

17. Pearson Product-Moment Correlations and Semi-Partial Correlations for MIST Back, MIST-total, and Hypothetically-Related Variables ........................................................ 110 18. Independent Samples T-tests Examining Differences in MIST-ACN \& MIST-AC Mean Scores Between Genders 68

19. Pearson Product-Moment Correlations for MIST-ACN, MIST-AC, and Potential Physiological Covariates .68

20. Pearson Product-Moment Correlations for New Versions of MIST, MIST-total, and Hypothetically-Related Variables .70

21. Semi-Partial Correlations for New Versions of MIST, MIST-total, and HypotheticallyRelated Variables 111

22. Pearson Product-Moment Correlations Between Variables of the Proposed Nomological Net 


\section{CHAPTER 1 \\ INTRODUCTION}

In both historical and contemporary mindfulness practice, interoception has been widely theorized to be a centrally important mechanism of clinical change. However, studies exploring the relationship between mindfulness and interoception have repeatedly obtained null results (Khalsa et al., 2008; Nielsen \& Kaszniak, 2006; Parkin et al., 2013).

One possible explanation for these results is that researchers have mistakenly conflated distinct variants of interoception. In this chapter, I will review operational definitions, theories, and research on both mindfulness and interoception. I will then propose a new construct, mindful interoception (MI), which is based on the specific variant of interoception taught in clinical practice. I will then review the existing measures of mindfulness and interoception, and explore why these measures, in particular the traditional measures of interoception, likely do not measure MI. Finally, I will propose a new behavioral measure of MI, the Mindful Interoception Sampling Task (MIST), identify the needs for such a measure, and explore strategies for its development and validation.

\section{Mindfulness}

Mindfulness, a form of awareness originating in Buddhist psychology, has been increasingly widely incorporated into Western clinical practice. Clinicians now regularly train clients in mindfulness practices such as mindfulness meditation and mindful yoga to 
benefit the clients' mental and physical health. Popularized by clinical interventions such as Mindfulness-Based Stress Reduction (Kabat-Zinn, 1990), Acceptance and Commitment Therapy (Hayes et al., 2006), Mindfulness-Based Cognitive Therapy (Teasdale et al., 2000), and Dialectical Behavior Therapy (Linehan, Heard, \& Armstrong, 1993), mindfulness-based interventions have now been developed for a breadth of clinical issues, including generalized anxiety (Roemer, Orsillo, \& Salters-Pedneault, 2008), depression relapse (Teasdale et al., 2000), chronic pain (Kabat-Zinn, 1982; KabatZinn, Lipworth, \& Burney, 1985), borderline personality disorder (Linehan, Heard, \& Armstrong, 1993), alcohol and substance use disorders (Witkiewitz, Marlatt, \& Walker, 2005), eating disorders (Kristeller, Baer, \& Quillian-Wolever, 2006), relationship counseling (Carson et al., 2004), and pre-military deployment training (Jha, Stanley, Kiyonaga, Wong, \& Gelfand, 2010).

Drawing upon Lazarus and Folkman's (1984) transactional model of stress and coping, Salmon, Sephton, and Dreeben (2010) have proposed a model in which mindfulness influences cognitive appraisals, coping, event outcomes, emotional outcomes, physiological outcomes, health behavior, and health outcomes. A metaanalysis of 39 studies of mindfulness-based therapies found a "moderately effective" effect size for improving anxiety and mood symptoms pre- to post-intervention, with larger effect sizes for participants with pre-existing anxiety and mood disorders (Hofmann et al., 2010). Studies have also found that mindfulness practice is associated with increased cortisol rhythmicity (Matousek, Dobkin, \& Pruessner, 2010), increased telomerase activity (Jacobs et al., 2010), improved immune functioning (Carlson et al., 2007), and decreased systolic blood pressure (Carlson et al., 2007). These findings 
suggest that mindfulness practice may contribute to mitigating the impact of processes such as aging and stress on physical health. Mindfulness practice additionally correlates with performance on attention tasks, including improved sustained attention to unexpected stimuli (Valentine \& Sweet, 1999), reduced attentional blink effect (Slagter et al., 2007), and improved orienting abilities (Jha, Krompinger, \& Baime, 2007).

Operational definitions. Despite the wellspring of research and support for mindfulness and mindfulness-based interventions in recent years, there remains considerable variability in how mindfulness is operationally defined. A widely cited definition of mindfulness comes from Jon Kabat-Zinn (2003), founder of the Mindfulness-Based Stress Reduction program, who defined mindfulness as "the awareness that emerges through paying attention on purpose, in the present moment, and nonjudgmentally to the unfolding of experience moment by moment” (p. 145). KabatZinn (2003) also states that all mindfulness practice shares a common outcome: the reduction of suffering.

Carmody's (2009) definition of mindfulness begins with the observation that Buddhist practices are historically based on cultivating a clear perception of the experiences that create a sense of personal self. Sati, a form of concentration, is a central part of these Buddhist practices and has been translated from Pali into English as "mindfulness." Carmody thus writes that mindfulness is a "state of sustained attention to these ongoing mental contents and processes without thinking about, comparing, or in other ways evaluating them" (p. 271). Carmody further notes that there exist differences in how various Buddhist traditions define Sati, just as there are differences between how Western practitioners define mindfulness. 
The most far-reaching attempt to operationalize mindfulness has come from a consortium of researchers who collaboratively proposed a "two-component model" of mindfulness (Bishop et al., 2004). The two components are: 1) self-regulated attention on "immediate experience", allowing for increased awareness of "mental events" and 2) bringing "curiosity, openness, and acceptance" to present-moment experiences. Echoing Kabat-Zinn's (2003) assertion that mindfulness reduces suffering, Bishop et al. note that mindfulness is used to improve awareness of mental processes that contribute to distress with the intention to end suffering.

Also building on Kabat-Zinn's (2003) definition, Shapiro et al. (2006) posit three components of mindfulness: intention (“on purpose"), attention ("paying attention"), and attitude ("in a particular way"). The authors note that the Japanese word for mindfulness includes the characters for mind and heart, suggesting that one translation of mindfulness could be "heart-mindfulness". In this way, attitude and attention can be described as having an accepting, open, and kind quality in mindfulness.

Table 1 provides a summary of the facets of mindfulness discussed in these operational definitions. Sustained attention, acceptance/non-evaluation, and present moment attention to immediate experience are commonly cited across definitions.

Mechanisms of change. Researchers have also sought to understand mindfulness in terms of mechanisms of clinical change. There is even less agreement about mechanisms of mindfulness than the aforementioned operational definitions of mindfulness; however, certain mechanisms are commonly cited across theories. As Table 2 illustrates, frequently cited mechanisms of clinical change include reperceiving, selfregulation, acceptance/non-attachment, and exposure. 
The first of these mechanisms, reperceiving (Shapiro et al., 2006) is described using different terminology in every paper: cognitive change (Baer, 2003), insight (Brown, Ryan, \& Creswell, 2007), change in perspective on self (Holzel et al., 2011b), and defusion and the observer self (Fletcher, Schoendorff, \& Hayes, 2010). While the descriptions of these mechanisms vary slightly, they all refer to an objective observation of one's own thoughts and feelings as "just thoughts" and "just feelings," thereby reducing evaluations and cyclical reactivity to experience. Self-regulation (Baer, 2003; Holzel et al., 2011b; Shapiro et al., 2006) describes the process of observing one's own thoughts, emotions, and behaviors, and subsequently choosing informed, intentional ways of thinking, feeling, and behaving. Acceptance/non-attachment (Baer, 2003; Brown, et al., 2007; Fletcher, et al., 2010) describes a non-evaluative, non-reactive perspective on experience that allows the experience to be as it is rather than changing it. Exposure (Baer, 2003; Brown, et al., 2007; Shapiro et al., 2006) refers to sustaining attention on a distressing stimulus, eventually resulting in fear reduction. In describing exposure in mindfulness practice, Shapiro et al. (2006) write: "Through this direct exposure, one learns that his or her emotions, thoughts, or body sensations are not so overwhelming or frightening. Through mindfully attending to negative emotional states, one learns experientially and phenomenologically that such emotions need not be feared or avoided and that they eventually pass away" (p. 381).

Mindfulness defined. Based on the definitions of mindfulness provided above, I will define mindfulness as sustained, non-evaluative present moment attention. There are certainly drawbacks to this definition, namely that it excludes various nuances articulated in the aforementioned definitions. More broadly, there is also some concern in the field that mindfulness may never be satisfactorily defined in all its complexity. Grossman 
$(2008,2011)$ notes that the term "mindfulness" has been taken out of its cultural context, and has therefore lost much of its meaning. He also suggests that a definition cannot accurately convey the experiential element of mindfulness. Grossman finally observes that the present discrepancies that exist between definitions and measures of mindfulness are reason enough to be reluctant to use the term.

As such, Grossman $(2008,2011)$ would likely discourage the use of the term "mindfulness," especially if the definition is derived from analysis of Western definitions of the word. While I am sympathetic to his perspective, I also contend that Western clinical science lacks a useful word to describe sustained, non-evaluative present moment attention. It may not perfectly align with the meaning of Sati in the original Pali, but even then, there is much disagreement among Buddhists across the world as to what Sati means (Carmody, 2009). That the term "mindfulness" has provided clinicians and researchers a pragmatic means to both think about and incorporate sustained nonevaluative present moment attention into clinical practice gives it enough utility to merit continuing its use. Accordingly, I will use "mindfulness" as a concise form of "sustained, non-evaluative present moment attention."

\section{Interoception}

Operational definitions. Interoception is a construct that refers broadly to the perception of internal sensation or "perceiving within" (Siegel, 2010). However, like mindfulness, there is some disagreement as to how interoception should be defined. Historically, interoception has largely been measured as perception of viscera or internal organs (e.g. heart, intestines, lungs). It can be difficult, however, to differentiate sensations that occur entirely internally from sensations that occur concurrently on the surface of the body. For instance, heartbeats could be perceived as pressure against the 
rib cage and skin, or as muscular contractions of the heart. In a case study, Khalsa et al. (2009) examined a man with complete bilateral insula and anterior cingulate cortex (ACC) damage, but an intact primary somatosensory cortex. As such, he was unable to perceive internal sensations, but could still perceive the sensation of touch. The researchers gave the participant increasing doses of isoproterenol to increase his heart rate and had him rate the intensity of his heart rate. In this condition, he demonstrated delayed but accurate reporting of heart rate intensity. The researchers next anaesthetized the skin around his chest and repeated the task. In this instance, he was unable to report an increase in heart rate. This suggests that traditional interoception measurements such as heartbeat detection still include elements of pressure and touch, even when the intention is solely to measure internal visceral sensation.

Craig (2002) argues that based on these findings and others in functional neuroanatomy, interoception should be defined as "the sense of the physiological condition of the entire body, not just the viscera" (p. 655). Using a similarly broad definition, Pollatos et al. (2007) write that interoception is simply "the ability to perceive bodily changes" (p. 179). In a review of body awareness questionnaires, Mehling et al. (2009) define interoception as "the processing of sensory input from inside the body in contrast to exteroception, the processing of input from outside the body (vision, hearing, smell, taste, and touch, with taste and touch having components of both)" [emphasis added] (p. 2). Cameron (2001) also defines interoception as "afferent information that arises from anywhere and everywhere within the body - the skin and all that is underneath the skin, e.g. labyrinthine and proprioceptive functions - not just the visceral organs" (p. 697). Lastly, Domschke et al. (2010) define interoception as "the 
physiological condition of the body, i.e. conscious awareness, emotional processes and behavior related to afferent physiological information arising from the body" (p. 2).

Taking into consideration the broad definitions of interoception commonly used today, interoception, interoceptive awareness, and interoceptive attention will be used interchangeably in this paper to covey awareness of endogenous physical sensations. Awareness of physical sensations will be defined to include sensations that occur internally or at the surface of the body. Although proprioception, the perception of the body in space, is necessary for identifying certain physical sensations, I will consider it a separate but complimentary form of perception.

Interoception and emotion. The idea that physical sensations are central to the experience of emotion has a long history in Western psychology. In 1884, William James wrote that "bodily changes follow directly the PERCEPTION of the exciting fact, and that our feeling of the same changes as they occur IS the emotion” (p. 190). In 1885, Carl Lange theorized that emotions were purely a cardiovascular event (Lang, 1994). In 1894, James shared credit for his theory of emotion with Lange in his essay "The Physical Basis of Emotion." The theory is now known as the James-Lange theory of emotion (Lang, 1994).

To date, the James-Lange theory is still prominently debated in theory of emotion. Among the most prominent early critics of the James-Lange theory was Walter Cannon (1927), who argued that arousal is not sufficient to create emotions and that people without interoceptive abilities still experienced emotions. Peter Lang (1994) notes that Cannon's critique was more pointedly aimed at Carl Lange's theory of emotions, which unlike James' theory did not allow for cognitive awareness of internal cues as a mediating factor. 
In 1962, Schachter and Singer proposed a two-factor theory of emotion that prominently featured physical sensations as central to emotional experience. Schachter and Singer wrote: "Given the same cognitive circumstances, the individual will react emotionally or describe his feelings as emotions only to the extent that he experiences a state of physiological arousal" (p. 382). They also contend "the same state of physiological arousal could be labeled 'joy' or 'fury' or 'jealousy' or any of a great diversity of emotional labels depending on the cognitive aspects of the situation" (pp. 381-382).

Schachter and Singer (1962) found support for this theory by administering epinephrine to participants, and then manipulating whether the participants expected the subsequent physiological arousal, and whether a confederate interacted with them in a euphoric or angry manner. In conditions where the participants did not expect the physiological arousal, they were more likely to describe their emotional state as euphoric or angry depending on the presentation of the confederate. In conditions where the participants did expect the arousal, they were more likely to attribute the physiological response to the epinephrine.

To better ascertain the relative importance of interoception in emotional experience, researchers have studied the emotional experience of individuals with interoceptive deficiencies, such as persons with spinal transections or pure autonomic failure (Wiens, 2005). While some researchers have pointed to examples of emotional diminution in quadriplegics (Damasio, 1994) and persons with pure autonomic failure (Critchley, Mathias, \& Dolan, 2002), other studies have found little evidence of diminished emotional functioning (Crichtley, Mathias, \& Dolan, 2001; Heims et al., 2004). 
Today most theories of emotion agree that emotional states can be generated and maintained by appraisals of both cognitive and physiological phenomena (Beck, Emery, \& Greenberg, 1985; Lang, 1994; Lazarus, 1982), which would explain why individuals with interoceptive deficiencies in some instances still report experiences of emotions. Physical sensations remain, however, a relevant object of evaluation within the phenomenal field and may be implicated in the majority of emotional states.

Interoception, emotion, and the brain. In the last 20 years, neuroimaging studies have provided compelling evidence for the centrality of interoception to the experience of emotion.

The insular cortex, particularly the anterior insular cortex, has been identified as the neural structure most closely related to awareness of internal visceral sensations (Cameron, 2001; Craig, 2002). Craig (2002) writes that that the anterior insular cortex is the location of the "subjective evaluation" of how you emotionally feel. Craig (2002) also notes that the anterior insula and anterior cingulate cortices (ACC) (in addition to subcortical regions such as the amygdala and ventral striatum) are activated together in "virtually all imaging studies of emotion" (p. 663).

Studies suggest that the ACC is central to motivation (Craig, 2002; Paulus and Stein, 2006); for instance, Bechara and Naqvi (2004) note that lesions to the ACC result in apathy. Lesions of the anterior insular cortex also produce anergia (Craig, 2009). Paulus and Stein (2006) have theorized that the bidirectional connections between the ACC and the insula link interoception with cognitive and affective processes.

A study of individuals with either amygdala or insula lesions provides further support for the centrality of the insula in affect (Berntson et al., 2011). In response to pictures from the International Affective Picture System (IAPS), individuals with 
amygdala lesions only demonstrated reduced arousal for negatively valenced pictures and no deficit in ratings of arousal for negative or positive pictures compared to a control group. Individuals with insula lesions, however, demonstrated reduced arousal for positive and negative emotions, as well as reduced arousal ratings compared to the control group.

The anterior insular cortex has also been implicated in the broader feeling "I am," the basis of human awareness (Craig, 2009). Damasio (2003) observes that the body is the brain's only continually processed foci of attention and therefore perception of the body can be hypothesized as the basis for a continued sense of self over time.

Damasio's (1996) Somatic Marker Hypothesis also states that the interoceptive facet of emotional states is critical to decision making. In Descartes' Error (1994), he observes that anosognosic patients with damage to the insula and areas of the parietal lobe demonstrate absence of emotional responding, inability to acknowledge physical maladies, and deficits in decision-making (pp. 63-70). Damasio hypothesizes that without monitoring of bodily states, people are unable to gauge the extent to which a situation poses potential for risk or reward. The insula has been now confirmed in subsequent studies of preference judgments to be implicated in these processes (Clark et al., 2008; Kirk, Downar, \& Read Montague, 2011; Paulus \& Frank, 2003). Interoception is thus theorized to play a central role in emotions, and higher-order emotion-based processes, such as decision-making and sense of self.

\section{Mindful Interoception}

Operational definition. Having defined mindfulness as "sustained, nonevaluative present moment attention" and interoception as "awareness of endogenous physical sensations occurring internally or at the surface of the body," I propose that MI 
be defined as "sustained, non-evaluative present moment attention to endogenous physical sensations occurring internally or at the surface of the body."

Mindful interoception and historical Buddhism. MI, as such defined, has a long history in mindfulness practices, as well as Western clinical practices. Historically, Buddhism's Satipatthanna Sutta defines mindfulness of the body as the gateway to mindfulness practice (Holzel et al., 2011b; Olendzki, 2010). Mindfulness of body is the first of four foundations of mindfulness; the others are mindfulness of feelings, mindfulness of consciousness, and mindfulness of mental objects (Kuan, 2008; Olendzki, 2010).

According to Buddhist scholar Andrew Olendzki (2010), the first foundation of mindfulness can be described as "systematic training in attending to the senses" (p. 89). Mindfulness of the body is summarized in the Satipațthanna Sutta as follows: "If a monk or a nun thus contemplates the body as a body little by little, this is called 'the establishment of mindfulness that is contemplating the body as a body" (Kuan, 2008, p. 151). Olendzki (2010) writes that:

"The reason this is effective is that the mind can be aware of only one thing at a time... At first, there may be far more mind-moments of mental cognition than of sense cognition in the stream of consciousness, but over time, as the practice of mindfulness of the body develops, one can actually have multiple consecutive moments of sense awareness uninterrupted by 'thinking about' what one is sensing. To those who habitually think too much, this is experienced as blissful relief' (p. 89)

In Buddhist psychology, bodily sensations are more central to the experience of emotions than cognitions (Drummond, 2006) and are considered the conduit for attachment, aversion, and ignorance (Holzel et al., 2011b, Olendzki, 2010). From a Buddhist perspective, then, mindfulness of body frees the mind from becoming attached 
to or averse to emotions, thereby stopping the perpetual cycle of emotional reactivity and suffering.

MI in modern clinical practice. No Western mindfulness-based intervention so clearly incorporates MI into the curriculum as Mindfulness-Based Stress Reduction (MBSR) (Kabat-Zinn, 1990). Not surprisingly, Kabat-Zinn (2003) has cited the Satipathana Sutta as a foundation for his understanding of mindfulness practice.

The first practice in the MBSR program, the body scan, is a 45-minute guided attention task directing non-evaluative attention sequentially through regions of the body without moving the body (Dreeben, Mamberg, \& Salmon, 2013). The second practice, MBSR Hatha Yoga, directs non-evaluative attention to guided physical movements (Salmon et al, 2009). The third practice, mindfulness meditation, directs attention to the sensations of the breath. This form of meditation is also commonly practiced in many non-clinical settings.

Other mindfulness-based interventions, such as Mindfulness-Based Cognitive Therapy, have incorporated mindfulness meditation, the body scan, and mindful movement into treatment approaches (Williams et al., 2006). Mindfulness-Based Relapse Preventions (MBRP) for addictive behaviors has similarly developed the concept of the “SOBER breathing space," which includes mindful attention to internal sensations (Bowen, Chawla, \& Marlatt, 2010). In the acronym SOBER from MBRP, "S" stands for "Stop"; "O" stands for "Observe the sensations that are happening in your body"; "B" stands for "Breath"; "E" stands for "Expand your awareness to include the rest of your body, your experience, and to the situation"; and "R" stands for "Respond mindfully" (Bowen, Chawla, \& Marlatt, 2010, p. 90). 
In Dialectical Behavior Therapy (Linehan, 1993), clients are taught seven "core" skills: wise mind, observe, describe, participate, nonjudgmentally, one-mindfully, and effectively (Rizvi, Welch, \& Dimidjian, 2009). Although each core skill has potential relevance to MI-based practice, "observe" is the most closely related. This core skill encourages clients to observe their sensory experiences without judgmental evaluation (Rizvi et al., 2009). Although this can also include sensory experiences such as sight and smell, the act of observing physical sensations non-judgmentally is included within the training. This skill is taught as a means of discovering that "emotion itself is not threatening" (Rizvi et al., 2009, p. 249).

Acceptance and Commitment Therapy primarily uses metaphors, setting values, and language deconstruction as clinical tools; however, it also can include mindful attention to physical sensations such as breathing, muscle tension, pain, and craving (Orsillo et al., 2004; Robinson, Wicksell, \& Olsson, 2004; Wilson \& Byrd, 2004). Focusing-Oriented Psychotherapy (Gendlin, 1996), although not explicitly a mindfulnessbased therapy, incorporates a variant of MI as the core feature of the therapy. Gendlin developed the practice of "Focusing" to bring client's sustained attention to distressing somatic sensations. Referring to the "felt sense" of an emotion, he would instruct clients to give a "handle" to an emotion by labeling it (Gendlin, 1996). Clients were then instructed to continue exploring the "felt sense" and to identify new "handles" as new facets of the experience came to light. Therapeutically, Focusing-Oriented Psychotherapy provided a means for altering reactivity and avoidance to the somatic element of emotional experience. Gestalt Therapy also holds avoidance of painful feelings as a central maintaining factor in emotional distress (Perls, 1973). As Fritz Perls (1973) writes: 
"...the Gestalt technique demands... that [the patient] experience himself as fully as he can in the here and now. We ask the patient to become aware of his gestures, of his breathing, of his emotions, of his voice, and of his facial expressions as much as of his pressing thoughts... As he experiences the ways in which he prevents himself from "being" now... he will also begin to experience the self he has interrupted" (pp. 63-64).

In cognitive behavioral therapy, avoidance of affect (i.e. sensations, feelings, and thoughts) has been theorized as a maintaining factor for anxiety (Butler, Fennell, \& Hackman, 2008). According to Butler et al., avoidance of affect occurs across all anxiety disorders. As such, a number of cognitive behavioral treatments for anxiety disorders involve non-evaluative attention to physical sensations as part of the protocol. For instance, panic disorder is conceptualized as being maintained by misevaluations of internal sensations (Craske \& Barlow, 2008). As such, interoceptive exposure for individuals with panic disorder involves attending to intentionally elicited distressing interoceptive cues in an otherwise safe environment to extinguish fear responses (Craske \& Barlow, 2008). Butler et al. (2008) note that hypochondriasis is also maintained by catastrophic evaluations of internal sensations, only the distress is about what will happen in the future rather than in the present. Phobias have also been conceptualized as attention to both the phobic stimuli and the physical sensations of anxiety, creating a "fear of fear" (Butler et al., 2008, p. 15). Although cognitive behavioral therapists hold that cognitions can also be objects of appraisal, evaluation of sensations remains a central maintaining factor of distress. In a therapy case example, Beck, Emery, and Greenberg (1985) have the sample therapist speak the following to an anxious client:

"There is literally nothing else that you can be aware of but feelings and sensations. Anything that you experience in life is composed of feelings and sensations. If you're afraid of making a fool of yourself when giving a speech, what you're really afraid of are your sensations of anxiety, self-consciousness, and shame... By accepting these feelings, you can lessen them" (p. 233). 
Across many theoretical orientations and therapeutic modalities, MI is a widely used mechanism of change for anxiety and other psychological disorders.

Potential mechanisms of change. The aforementioned treatments share the common precept that attending to physical sensations with an attitude of non-judgment can mitigate reactivity to negative emotional states. Kabat-Zinn (1982) has hypothesized that non-judgmental exposure to physical sensations might reduce experiences of anxiety and chronic pain. Similarly, Linehan has described individuals with borderline personality disorder as emotion phobic (Baer, 2003; Linehan, 1993), and hypothesized that exposure to thoughts and feelings via non-judgmental attention might promote habituation and reduced emotional reactivity (Linehan, 1993). Hayes and colleagues theorized that avoidance of physical sensations, thoughts, and situations is a transdiagnostic maintaining factor of all psychopathology (Hayes et al., 1996). Hayes therefore proposes acceptance as a means of exposing people to their experiences in a safe way. Fletcher et al. (2010) also discuss the possibility that for anxious people, mindfulness practice could equate to a type of gradual exposure to anxiety-triggering somatic sensations, thereby increasing habituation and reducing avoidance.

Avoidance and sustained attention have been theorized as a maintaining factor and mechanisms of clinical change, respectively, across a variety of theoretical orientations. In a meta-analysis of 43 studies, Suls and Fletcher (1985) examined the comparative efficacy of avoidance strategies and attention strategies in terms of pain, stress, and anxiety reduction. They found that attention to "sensory schemata" resulted in better outcomes than avoidance. However, if the attention involved interpretation (what mindfulness practitioners might call evaluation or judgment), then the reverse was true. 
Overall, attention of any sort resulted in better long-term outcomes, while avoidance resulted in less distress in the short-term.

Borkovec and colleagues have identified anxious worry as a means of diverting attention from internal sensations and reducing distress in the short-term (Borkovec, Shadick, \& Hopkins, 1991). Borkovec (1994) writes: "Perhaps the most exciting and important discovery about worry is that it is negatively reinforced by its suppressing effects on autonomic activity and by this function results in a prevention of emotional processing" (p. 18). Borkovec, Ray, and Stober (1998) also note: "If worry as an avoidance response does immediately suppress somatic/affective aspects of anxious experience, it may thereby be negatively reinforced" (p. 564). Studies supporting these assertions include a study in which worrisome thinking prior to a public speech reduced cardiovascular reactivity compared to relaxation or neutral thought conditions (Borkovec \& $\mathrm{Hu}, 1990)$; however, the worrisome thinking condition showed no signs of fear extinction. Another study demonstrated that people spontaneously use verbalization as a means of avoiding emotional events, thereby decreasing sympathetic arousal (Tucker \& Newman, 1981). These converging studies provide support for the premise that distraction and worry are commonly used to avoid distressing internal sensations in the short term, while reducing extinction of fear responses in the long term.

Foa and Kozak (1986) note that fear extinction is unlikely to occur unless the sensations of fear are felt during the confrontation. They further report that experiencing reduced arousal after prolonged exposure to a feared stimulus reduces the extent to which the stimulus is evaluated as threatening. Paradoxically then, interoceptive attention is both a symptom of anxiety and a treatment for anxiety in Western practice. More specifically hypervigilant interoception alternating with mental distraction is 
symptomatic of anxiety while mindful interoception is the shared mechanism that treatments such as mindfulness-based interventions, exposure therapy, Focusing-Oriented psychotherapy, and Gestalt Therapy use to reduce emotional reactivity.

\section{Measuring Mindful Interoception}

Measures of both mindfulness and interoception have been developed over the years, but to date there remain no measures of MI. In this section I will review measures of both mindfulness and interoception.

Self-report mindfulness measures. A number of self-report measures have been developed to assess trait and state mindfulness. A list of the most commonly used mindfulness questionnaires would include the Mindful Attention Awareness Scale (MAAS) (Brown et al., 2007), the Five Factor Mindfulness Questionnaire (FFMQ) (Baer et al., 2006), and the Toronto Mindfulness Scale (TMS) (Lau et al., 2006). The MAAS is a 15-item self-report questionnaire that assesses the degree to which people attend to everyday tasks. The TMS is a 13-item self-report measure with two subscales, "curiosity" and "decentering," assessing "what you just experienced, just now." The FFMQ is a 39item five-factor scale developed from a factor analysis of five earlier mindfulness scales. The five subscales of the FFMQ are observing, describing, acting with awareness, nonjudging of inner experience, and non-reactivity to inner experience.

The Philadelphia Mindfulness Scale (PHLMS) (Cardaciotto et al., 2008) has been less widely used, but contains questions that directly assess MI. The PHLMS is a 20-item self-report questionnaire with two subscales, "acceptance" and "awareness."

Although MI is a central feature of both historical Buddhism and modern-day mindfulness-based practices, the aforementioned scales largely fail to assess it. Of these scales, only the FFMQ and PHLMS have prompts that directly relate to interoception; 
however, neither measure has a distinct subscale for MI. The subscales that most closely relate to interoception are the awareness subscale of the PHLMS and the observing subscale of the FFMQ.

Examining the ten prompts on the "awareness" subscale of the PHLMS, two or three clearly relate to interoception (e.g. "When I am startled, I notice what is going on inside my body"), three or four more are indirectly related ("When talking with other people, I am aware of the emotions I am experiencing"), and two or three are not related (e.g. "I am aware of what thoughts are passing through my mind."). The observing scale of the FFMQ more specifically assesses awareness of sensations, with a few questions partially assessing interoception (e.g. "I notice how foods and drinks affect my thoughts, bodily sensations, and emotions") and other questions assessing non-interoceptive sensations (e.g. "I pay attention to sounds, such as clocks ticking, birds chirping, or cars passing").

Both the awareness subscale of the PHLMS and the observing subscale of the FFMQ phrase certain questions in a way that both a mindful person and an anxious person might endorse. For instance, "I notice how foods and drinks affect my thoughts, bodily sensations, and emotions" could be endorsed both by a hypervigilant, hypochondriacal person and a person trained in mindfulness practice, although the interpretations would vary. In support of this hypothesis, the observing subscale of the FFMQ has the poorest correlation with the other four subscales (and a non-significant correlation with the nonjudging of inner experience scale) except when limited to participants with meditation experience, in which case it is significantly correlated with all four scales (Baer et al., 2006). As such, it seems likely that participants without 
experience in mindfulness practice are interpreting observing prompts differently than participants with experience in mindfulness practice.

Carmody and Baer (2008) have also examined FFMQ subscales in relationship to MBSR practice, including MI-based practices. They found that the observing subscale does increase significantly from pre-MBSR to post-MBSR. They also found that the observing subscale was significantly correlated with body scan practice time, yoga practice time, and total formal practice time, but not sitting meditation or total informal practice time. This is consistent with the aforementioned results suggesting that the observing scale successfully measures mindfulness of sensations in the specific context of mindfulness interventions or mindfulness practice.

In addition to debating whether "mindfulness" can be operationally defined, Grossman $(2008,2011)$ has also extensively questioned the use of self-report measures in mindfulness research. Grossman observes that there are differences in how people interpret questions on measures and that mindfulness practitioners likely overrate their own mindfulness. For instance, he describes the strong social desirability effect and cognitive dissonance present when mindfulness practitioners rate their own levels of mindfulness. Grossman also questions whether people can accurately report their own attentional abilities. Finally, Grossman claims that mindfulness questionnaires lack external criteria to validate the measures, as there is no consensus as to the definition of mindfulness or what mindful behavior is.

As such mindfulness measures may currently lack content validity on a general level, while also failing to assess MI more specifically. Next I will discuss self-report measures of body awareness that may also be relevant to measuring MI. 
Self-report body awareness measures. There are a number of self-report measures that have been developed to assess aspects of somatic attention. In a review of body awareness questionnaires, Mehling et al. (2009) identified 12 measures that specifically measure body awareness. These self-report measures included the Body Intelligence Scale, a scale that is informed by transpersonal psychology and focuses on "energy" in the body (Anderson, 2006); the Body Responsiveness Questionnaire, a scale developed for yoga practitioners (Daubenmeier, 2005); the Timer Questionnaire, a scale to assess gender differences in body awareness (Franzoi, 1989); the Scale of Body Awareness, a scale to assess body awareness and medical care use by older adults (Hansell, Sherman, \& Mechanic, 1991); the Body Vigilance Scale, a scale to assess body awareness in panic disorder, (Schmidt, Lerew, \& Trakowski, 1997); and the Health Consciousness Subscale of the Multidimensional Health Questionnaire, a scale for measuring the extent to which people think about their health,(Snell \& Johnson, 1996).

In the scales reviewed, only the Private Body Consciousness Subscale (PBCS) of the Body Consciousness Questionnaire (Miller, Murphy, \& Buss 1981) and the Body Awareness Questionnaire (BAQ) (Shields, Mallory, \& Simon, 1989) had more than four published studies in which the measure was used. Additionally, only the PBCS and BAQ demonstrated a high standard for reliability, as assessed by the authors. Four scales--the BAQ, the PBCS, the Body Vigilance Scale (BVS), and the Scale of Body Connection (SBC) (Price \& Thompson, 2007)--met a high standard for validity as assessed by the authors.

Examining these measures more closely, eight of the eighteen items on the BAQ assess the ability to predict future bodily states, in direct contrast to the construct of MI in which attention is oriented to the present moment. Interestingly, the BAQ also does not 
assess awareness of sensations in the context of emotional states. The PBCS subscale of the BCQ consists of only 5 questions, each of which assesses awareness of negative physical sensations. The BVS similarly focuses on awareness of negative physical sensations, eliciting ratings for 15 forms of physical discomfort. The language of these measures consistently includes evaluations of sensations, and is thus incompatible with MI. Not surprisingly, the BAQ and BVS are both positively correlated with hypochondriac tendency (Ginzburg et al., 2013). Studies have consistently shown that individuals who tend to experience sensations as strong and negatively valenced also have the least ability to accurately discern subtle sensations (Bogaerts et al., 2008; Mailloux \& Brener, 2002; Steptoe \& Noll, 1997), suggesting that high scorers on the aforementioned self-report measures may have difficulty with in vivo interoception. However, there remains no research to date on the relationship or lack thereof between these self-report measures of body awareness, and other measures of interoception (e.g. heartbeat detection, fMRI studies).

At least one study (Sze et al., 2010) has examined the BAQ and PBCS in the context of mindfulness meditators. The scales, however, were combined into one scale of "visceral awareness," and the only reported outcome was that mindfulness meditators reported significantly higher "visceral awareness" than experienced dancers or controls. As such, there is still no clear association between trait mindfulness or mindfulness practice with these body awareness self-report measures.

Although it has been used sparingly in research to date, the Scale of Body Connection (SBC) is the one scale reviewed by Mehling et al. (2009) that most closely approximates MI. Items include awareness of both positive and negative physical experiences, and the measure differentiates between avoidant "Body Dissociation" and 
more mindful "Body Awareness" in its two subscales. However, it is unclear whether the self-report format provides accurate retrospective accounts of mindful interoception. Additionally, the prompts do not explicitly assess non-evaluative attention to physical sensations. For instance, a mindful person and a hypochondriacal person would likely interpret the prompt "Notice where tension is in my body" quite differently. The emphasis on global/static traits is also inconsistent with mindful attention to present moment, dimensional, active experience.

To date, the SBC has been used in a study of Mindful Awareness Body-Oriented Therapy for women with a substance abuse disorder (Price et al., 2011), for bodyoriented therapy for adult victims of childhood sexual abuse (Price, 2005), and for bodyoriented group psychotherapy for treating trauma (Langmuir, Kirsh, \& Classen, 2012). The latter two studies found improvements across time in both the body awareness and body dissociation subscales, while the substance abuse study found improvements only in the bodily dissociation subscale.

Mehling et al. (2009) raised concerns about the instruments reviewed, for example that they often overlook the "quality or mode" of attention. Concerning the quality of mindfulness they write, "Currently, validated measures for body awareness are not able to discern between (a) anxiety-related hypervigilance toward pain and other physical sensations with catastrophizing interpretation bias and (b) a non-judgmental, meditative, 'mindful' awareness of these sensations" (p. 12). They also note that most authors treat "body awareness" as a unitary construct yet the measures reviewed clearly assess varying constructs.

In response to these perceived gaps in the literature, Mehling, Price (developer of the SBC), and colleagues have collaboratively developed the Multidimensional 
Assessment of Interoceptive Awareness (MAIA), a self-report scale of various

dimensions of interoceptive attention (Mehling et al., 2012). The MAIA is a 32-item selfreport measure assessing eight scales of interoceptive awareness: Noticing, Distracting, Not-Worrying, Attention Regulation, Emotional Awareness, Self-Regulation, Body Listening, and Trusting. The MAIA assesses awareness of negative, positive, and neutral sensations; awareness of the entire body; and avoidance and acceptance of sensations in the context of emotional states. Although each scale is conceptually related to MI, the 7item Attention Regulation scale, the 3-item Body Listening scale, and the 3-item NotWorrying scale appear most closely related. The Attention Regulation scale includes items such as "I can maintain awareness of my inner bodily sensations even when there is a lot going on around me" and "I can refocus my attention from thinking to sensing my body." The Body Listening scale includes the following prompt: "I listen for information from my body about my emotional state." The Not-Worrying scale includes the following prompt: "I can notice an unpleasant body sensation without worrying about it."

When asked why the word "mindfulness" was not used to describe the MAIA or the scales of the MAIA, Mehling answered that his understanding of mindfulness is that it is "awareness of anything, rather than of the body" (personal communication, March $\left.16^{\text {th }}, 2012\right)$. Using the definition "sustained non-evaluative present moment attention to physical sensations," the MAIA would likely be considered a measure of MI. This point underscores the importance of operationally defining "mindfulness" such that some consensus on the definition can be reached among clinicians and researchers.

\section{Detection tasks.}

Overview of detection tasks. Although interoception has been defined to include awareness of many different sensations including itch, tickle, sensual touch, ache, 
vasomotor flush, hunger, thirst, and air hunger (Craig, 2008; Paulus \& Stein, 2006), historically interoception has been measured using tasks that assess the accuracy of heartbeat detection. In this section, I will review the history of heartbeat detection tasks and their applicability for measuring MI.

The two most commonly used heartbeat detection tasks are tone-based discrimination tasks and the Schandry heartbeat detection task (Domschke et al., 2010; Schandry, 1981). In tone-based heartbeat detection tasks, the participant is asked to determine whether several series of auditory beeps correspond with the participant's actual heart rate. For each trial, the tones are either matched to the person's heartbeat or on a delay. Participants are then measured on the accuracy with which they correctly identify matched tones and unmatched tones.

In the Schandry heartbeat detection task, participants are asked to count their heartbeats over a few brief periods of time, each lasting under a minute, and are then assessed for accuracy (Schandry, 1981). Accuracy is then calculated as a percentage error.

Critics of the Schandry heartbeat detection task have argued that it is more a measure of time estimation; however, Ehlers and Breuer (1992) found that participants performed worse on measures of time estimation than they did on the Schandry heartbeat detection task. Domschke et al. (2010) add that heartbeats are typically underreported, suggesting that participants are missing heartbeats rather than simply guessing.

Critics of the tone-based discrimination tasks note that accuracy rates are consistently near chance (Domschke et al., 2010; Khalsa et al., 2008; Parkin et al., 2013). There is also some concern that the competition of cues between tones and heartbeats confounds measurement of interoception (Pennebaker, 1982). It is possible that the act of 
counting during the Schandry heartbeat detection task also distracts attention from interoception.

Across types of detection tasks, heartbeat perception has been found to be influenced by a number of variables including gender, blood pressure, body fat and fitness, resting heart rate heart rate, and stress (Domschke et al., 2010). Additionally, participants' self-reported performances frequently do not significantly correlate with actual performance and there are anecdotal reports of participants using guesswork during the tasks (Wiens, 2005). As such, it is still unclear exactly what heartbeat detection tasks measure, although there are consistent outcomes found within the research literature.

Although heartbeat perception is by far the most common measure of interoception, a few other in vivo measures do exist. For instance, researchers have examined participants' sensitivity to incrementally increased resistance to airflow via tubes or mesh pieces fitted over the mouth (Dahme, Richter, \& Mass, 1996). Dahme et al. have also measured sensitivity to bronchoconstriction as various levels of allergic agents were introduced. Khalsa et al. measured changes in perception of heartbeat as incremental doses of isoproterenol were administered (2009). "Balloon distension of the sigmoid colon by a calibrated rectosigmoid probe" has also been used as a stimulus to measure interoceptive sensitivity in the gastrointestinal tract (Holzl et al. 1996, p. 202).

Collectively, these alternative interoceptive measures are invasive, potentially dangerous, and complicated. Another major limitation is that they create artificial sensations, thus providing little information about interoception as it occurs naturally. As such, heartbeat detection tasks remain the gold standard for measuring interoception. 
Mindfulness and detection tasks. Although interoceptive awareness is theoretically and clinically central to mindfulness, there remain no studies to date in which performance on detection tasks is associated with mindfulness measures or practice. In this section, I will review the research to date on heartbeat detection tasks and mindfulness.

Nielsen and Kaszniak (2006) administered a tone-based heartbeat detection task to 11 long-term meditators (at least 10 years of meditation practice, practicing an average of 8.2 times per week) and 17 nonmeditating controls. They found no significant difference between meditators and non-meditators on the heartbeat detection task. Nielsen and Kaszniak also found that stronger heartbeat detection was positively associated with higher skin conductance responses to nonmasked unpleasant and neutral pictures in the International Affective Picture System, suggesting that negative emotional reactivity is related to heartbeat detection scores.

Khalsa et al. (2008) ran a similar study, assessing whether there were significant differences in tone-based heartbeat detection between 17 nonmeditators and 30 meditators (17 Kundalini, 13 Tibetan Buddhist, minimum of 15 years of formal practice). Although this study had greater power, included comparison subjects matched on age and body mass, and included a second, additional testing day, there were still no significant differences found between meditators and nonmeditators on the heartbeat detection task. They did, however, find that meditation experience was positively associated with increased confidence in heartbeat detection.

Khalsa et al. (2008) suggest that awareness of heartbeats is not specifically cultivated in meditation practice, which could explain this null result. They also suggest 
that the results may have been different had the participants detected heartbeats while moving.

Parkin et al. (2013) ran a series of four studies with sample sizes ranging from 19 participants to 165 participants. Across these studies, they found that performance on the Schandry heartbeat detection task was not associated with practicing a 15-minute body scan for one week, with participating in an 8-week MBSR or MBCT group, or with trait mindfulness as measured by the FFMQ. They did find, however, that confidence in heartbeat perception increased with participation in the 8-week groups and with higher trait mindfulness scores.

Reflecting on the consistent null results found across the literature and the seemingly misplaced confidence of mindfulness practitioners, Parkin et al. (2013) suggest that mindfulness practice may actually impair interoceptive ability. They hypothesize that mindfulness practice may create mental representations of the body that are not consistent with actual bodily states. They also posit that people may be initially drawn to mindfulness practice because they are seeking ways to improve body awareness.

In light of these findings and these many attempts to explain them, I will argue that there is a more parsimonious and likely explanation for why these researchers did not obtain their hypothesized results.

Potential covariates. The most cited finding in the study of heartbeat perception tasks is a positive association with measures of anxiety (Domschke et al., 2010). As such, interoception research has long focused on the positive correlation between attention to somatic sensations and constructs such as anxiety, panic, hypochondriasis, and somatization (Cameron, 2001; Domschke et al., 2010). The experience of anxiety includes future-directed, evaluative thinking about potential threats. By this definition, 
anxiety is in direct contrast to mindful, present-moment non-evaluative attention. Given that mindfulness and anxiety should not theoretically be positively associated, this suggests that heartbeat detection tasks may not be assessing MI.

Domschke et al. (2010) conducted a meta-analysis of 29 heartbeat detection and anxiety studies. Domshcke et al. defined anxiety sensitivity as "beliefs about dangerousness of anxiety symptoms and the resulting fear of these symptoms" (p. 5). In most studies they reviewed, Anxiety Sensitivity was measured using the Anxiety Sensitivity Index-3 (ASI-3). Domschke et al. (2010) defined trait anxiety as "a general stable tendency to respond with anxiety to perceived threats in the environment," (p. 6) while defining State Anxiety as "a transitory emotional state or condition of the human organism fluctuating over time and varying in intensity" (p. 6). For the studies reviewed, these constructs were most frequently measured by the State Trait Anxiety Inventory. Panic Disorder was also diagnostically assessed; studies that included people with panic attacks but did not diagnostically assess panic disorder were included in the category "People with Panic Attacks." Domschke et al. (2010) reported the following mean effect sizes between heartbeat perception and the aforementioned subtypes of anxiety: Anxiety Sensitivity $(\mathrm{N}=149) d=0.61$; Trait Anxiety $(\mathrm{N}=202) d=0.37$; Panic Disorder $(\mathrm{N}=$ 609) $d=0.52$; Panic Disorder with Schandry heartbeat detection task $(\mathrm{N}=460) d=0.64$; and People with Panic Attacks $(\mathrm{N}=186) d=0.37$.

It is worth nothing that Domschke et al. (2010) found that studies using heartbeat detection tasks other than the Schandry heartbeat detection task typically did not find differences between anxious participants and non-anxious participants. It is likely, however, that the consistently near chance performance of participants on tone-based 
tasks greatly decreased the possibility of finding between-group differences (Domschke et al., 2010; Khalsa et al., 2008).

In a meta-study of heartbeat detection tasks, Van der Does et al. (2000) analyzed data from seven studies with 709 participants across eight diagnostic categories. Although few participants demonstrated highly accurate heartbeat perception, persons with panic disorder and other anxiety disorders were more accurate than healthy controls, depressed patients, patients with heart palpitations, and patients with infrequent panic attacks. The most accurate perceivers had the highest anxiety sensitivity scores as well.

Do detection tasks measure MI? According to Smallwood and Schooler (2006), mind wandering is less likely to occur during a demanding task, a novel task, or a timelimited task. As such, avoidantly distracting attention from physical sensations may not be an option during a time-limited, high-pressure task such as heartbeat detection. It may be then that hypervigilant anxious people and mindful people are both capable of attending to internal sensations over short periods of time; avoidance and mental distraction may only occur given appropriate time and opportunity.

Another potential explanation is that counting serves as a type of distraction for avoidant/anxious people, limiting direct sustained attention to the valence of internal sensation. Also, focusing on one specific physical sensation to the exclusion of other sensations could be a form of avoidance as well. As such, it remains unclear how mindful people would perform on a task of MI since heartbeat detection tasks do not appear to assess the construct.

Brain imaging. Presently, neuroscience is the experimental area in which interoception and mindfulness have been most consistently linked. Fletcher et al. (2010) describe in particular how the insula and interoception have been important foci of 
attention in mindfulness research, noting that the insular cortex is implicated in fear perception, motivation, error detection, emotional perception, and allocation of attentional resources. In The Mindful Brain Daniel Siegel (2007) writes that, "The insula transmits data from the body to the brain... and may directly be involved in the experience of looking inward" (p. 103).

Two neuroimaging studies have found positive associations between mindfulness meditation experience and gray matter concentration and thickness in the insula (Holzel et al., 2008; Lazar et al., 2005). Other neuroimaging studies have demonstrated specific changes in the insula of mindfulness practitioners during experimental tasks. For instance, Farb et al. (2007) found that MBSR participants were more likely than a waitlist group to activate the insula when focusing on moment-by-moment experience. Both the MBSR and waitlist group also demonstrated reduced activity in cortical midline regions of the brain (associated with self-referential thinking and the default network) when focusing on present-moment as compared to narrative, judgmental thought patterns.

In another study, Farb et al. (2010) hypothesized that for people with mindfulness training, negative emotions may be perceived as "fluctuations in body state sensations" rather than mental states reflecting what is good or bad. Using fMRI imaging, they found that MBSR participants demonstrated higher insula activity, lower self-referential processing, and lower emotional reactivity to sad film clips, in addition to fewer overall depressive symptoms, compared to waitlist controls. Also right insula activity and Wernicke's area were negatively correlated. The researchers theorized that there may be a trade-off between language-laden regulatory processes and interoceptive regulatory processes, with the former correlating highly with depression. 
Farb et al. (2012) further found that MBSR participants demonstrated increased connectivity between regions of the insula, even during non-interoceptive attention tasks. Additionally, MBSR practice time was positively correlated with greater signal amplitude in regions of the insula.

Lutz et al. (2008a) used fMRI imaging to examine the brain activity of 16 experienced meditators (10,000 to 50,000 hours of meditation practice experience) and 16 novice meditators (approximately 7 hours of meditation practice experience) during a meditation on feelings of "lovingkindness" or compassion. During the lovingkindness meditation, participants were presented with 252 -second audio clips that possessed positive, negative, or neutral valences. When emotional sounds were presented, the insula and cingulate cortices were more active in the meditation state than the resting state across participants. For presentation of negatively valenced sounds during the meditation, experienced meditators demonstrated more significant activation of the insula. Insula activity was also positively associated with self-reported intensity of the lovingkindness meditation across participants. The insula and empathy have also been linked in studies of adolescents with conduct disorder and high-functioning individuals with autism (Craig, 2009). In these studies, lower empathy levels were associated with reduced anterior insula cortex gray matter and activation levels (Craig, 2009).

Grant, Courtemanche, and Rainville (2011) found that long-term meditators showed increased insula activity compared to non-meditators when experiencing pain. This was accompanied with a significant downshift in the amygdala, prefrontal cortex, and hippocampus, and less connectivity between the prefrontal cortex and the anterior cingulate cortex. These findings have been replicated to an extent by Gard et al. (2011), in which they found that mindfulness practitioners experienced less pain when receiving 
shocks. This pattern was accompanied by increased insula activity and decreased prefrontal cortex activation. They also discovered reduced anticipatory anxiety leading up to the shocks in the mindfulness meditators. Although Grant et al. (2011) and Gard et al.'s (2011) studies demonstrate meditators' insula activity in relationship to physical pain, they may also be relevant to meditators' experience of the interoceptive facet of emotional pain. Indeed, studies are now indicating that emotional pain and physical pain are experienced similarly in the brain (Eisenberger, 2012; Eisenberger, Lieberman, \& Williams, 2003).

Some studies, however, have found no evidence of increased insula activity or volume in meditators and/or mindful people (Holzel et al., 2011a; Ives-Deliperi et al., 2010; Luders et al., 2009). Ives-Deliperi et al. (2010) even found a significant decrease in insula activity during mindfulness meditation. Further, at least one study demonstrated higher ACC activity for mindfulness meditators compared to non-meditators (Holzel et al., 2007), while another study found higher ACC activity for non-meditators compared to meditators (Brefczynski-Lewis et al., 2007). Are these studies anomalies or is there another possible explanation?

Fletcher et al. (2010) warn that if we do not agree what mindfulness is, it is difficult to know what to look for in neuroimaging. For instance, is mindfulness what is measured by a questionnaire, how long someone has practiced mindfulness meditation, or something else altogether? The danger is to draw conclusions from neuroimaging that are predicated on poorly understood and defined constructs. Fletcher et al. propose rigorous observation of well-defined behaviors as a means of clarifying what we are studying when we examine neuroimaging studies. 
While operational definitions of mindfulness may be partially to blame for contradictory results, it is also possible that the role of the insula, the ACC, and other regions of the brain in mindful interoception are not yet fully understood. A number of studies have also identified a strong relationship between insula activity, anterior cingulate cortex activity, and anxiety (Craig, 2002; Crichtley et al., 2004; Wiens, 2005). Right anterior insula activity is also implicated in recall-generated sadness, anger, anticipatory pain, panic, and disgust (Craig, 2002).

In a 2004 study, Critchley et al. found that right anterior insula activity was predictive of anxiety (as measured by the Hamilton Anxiety Scale). Additionally, anxiety was significantly positively correlated with scores on a tone-based heartbeat detection task. Using fMRI and voxel-based morphometry, 17 subjects were scanned while performing an interoceptive task (tone-based heartbeat detection task) and an exteroceptive task (tone detection task). No differences were found between subjective difficulty or performance accuracy for the two tasks. Relative interoceptive activity correlated non-significantly with depressive symptoms and trait ratings of negative affective experience; however, for these results to have been non-significant while demonstrating strong correlations, it suggests that the study was under-powered. The right anterior insula was also the region most strongly correlated with accuracy on the interoception task.

Paulus and Stein (2006) theorize that anxiety occurs when an interoceptive signal from the insula travels to the ACC, and the ACC then registers an exaggerated error signal for the difference between the observed body state and the expected body state. They postulate that "anxiety sensitivity" is thus simply an individual's proneness to miscalculate the threat of an interoceptive signal. Paulus and Stein further argue that this 
system of error signaling involving the insula and ACC is more central to the neuroanatomy of anxiety than the amygdala. In support of this hypothesis, they note that in individuals with obsessive-compulsive disorder, post-traumatic stress disorder, and simple phobias, symptom provocation is associated with increased blood flow to the insular cortex. They additionally point to increased insula activity in generalized anxiety disorder, social phobia, and panic disorder.

The insula has also been implicated in the experience of "craving" (Gray \& Crichtley, 2007). Naqvi et al. (2007) found that lesions in the insula eliminated craving for people addicted to smoking. Similarly, Kilts et al. (2001) found that crack cocaine addicts showed increased insula activity during the experience of craving the drug. These results cloud the interpretation of increased insula size and activation in mindfulness practitioners, given that one consequence of mindfulness practice is the reduction of craving (Olendzki, 2010).

Given that regions of the brain associated with interoception are also associated with anxiety and craving, it is likely premature to draw conclusions from neuroimaging studies demonstrating that mindfulness practice increases activity and structural thickness in these areas.

\section{The Mindful Interoception Sampling Task}

Developing a measure of mindful interoception. Clearly, there are many obstacles to measuring MI. Retrospective self-report questionnaires possess questionable validity and may be interpreted differently by different people. Ironically, the ability to carefully attend is necessary for accurate, retrospective reports of attention ability, which may result in invalid responses for many people. Further, self-presentation biases, 
particularly for people who have received mindfulness training, could easily skew the results. Accordingly, MI makes a poor object of self-report.

Neuroimaging and traditional interoceptive tasks struggle to differentiate anxious people and mindful people. Anxious people should be expected to be skilled at interoception in a time-limited, high-pressure situation, given that they evaluate internal cues as threatening and thus attention-worthy. However, models of anxiety described by theorists such as Borkovec, Foa, and Hayes, would also predict distraction or avoidance of internal cues if the opportunity were present. Specifically, these models of anxiety would predict that anxious people would avoid internal cues via distraction such as mind wandering given ample time, low novelty, and low cognitive demands (Schooler \& Smallwood, 2006).

Another obstacle to developing a measure of MI is control of interoceptive cues. Traditionally, attention tasks in psychology have measured the accuracy of attention by calculating number of items identified correctly/incorrectly, and/or by calculating speed of identification. However, endogenous interoceptive cues are not so easily controlled or measurable. One solution is to calculate the accuracy of identifying a measurable endogenous internal process, such as heartbeats. Yet even if heartbeat detection tasks were extended over longer periods of time, allowing for mind wandering, they still would not be measuring mindful interoception, given that they focus on one specific physical sensation to the exclusion of all other sensations. This form of rigid, hypervigilant attention is best representative of anxiety disorders such as panic disorder and hypochondriasis. Not surprisingly, panic disorder patients consistently obtain high scores on heartbeat detection tasks (Van der Does et al., 2000) 
Lutz et al. (2008b) explored a related distinction in their review of neuroimaging studies on focused attention (FA) meditation and open monitoring (OM) attention. They describe FA meditation as "voluntary focusing attention on a chosen object in a sustained fashion" and OM meditation as "non-reactively monitoring the content of experience from moment to moment, primarily as a means to recognize the nature of emotional and cognitive patterns" (p. 164). Lutz et al. consistently use open monitoring meditation as a synonym for mindfulness meditation, but they note that they prefer the term "open monitoring" because of the multiple definitions mindfulness has.

Lutz et al. (2008b) theorize that OM meditation should improve monitoring, vigilance and disengaging attention from stimuli that distract attention from the ongoing stream of experience, and demonstrate stronger monitoring of bodily states. This reflects the idea that mindful awareness of emotional states as they are experienced in the body involves attention to whatever is being experienced rather than attention to a rigid, predefined sensation. To this end, Lutz et al. (2008b) note a study in which open monitoring meditators demonstrated better performance than focused attention meditators on Wilkins' counting test, a sustained attention task, in which the stimuli was unexpected (Valentine \& Sweet, 1999, as cited by Lutz et al., 2008b).

An MI measure would thus need to allow for any sensation within a broad parameter to be the focus of attention. Such a measure would acknowledge that interoception occurs across many different areas of the body, and that ability to sustain attention on one area does not necessarily predict ability to sustain attention on another area. It would additionally acknowledge that $\mathrm{MI}$ is not about quantifying sensations (which in itself can be a form of distraction), but rather experiencing the quality and 
valence of the sensations in the present moment. As such, this precludes the use of narrowly defined targets of interoceptive attention, such as heartbeats.

What is needed then, is a measure that A) assesses in vivo interoception, B) measures sustained attention, C) assesses attention throughout the body, D) allows for attention to a variety of qualitatively distinct sensations, and E) does not require quantification of the target stimulus.

Point "E" is particularly tricky, given the nature of most attention tasks. Fortunately, cognitive psychologists studying "mind wandering" have already developed thought sampling methods for assessing sustained attention to a non-measurable stimulus.

In probe-caught thought sampling tasks, participants are interrupted during a task and queried about off-task episodes (Smallwood \& Schooler, 2006). In one such task, participants are asked to read a long text and are then interrupted periodically to determine if they are focused on the text or mind wandering. A slight variation is a selfcaught thought sampling task, in which participants track their own off-task episodes. Both types of measures generally require a yes/no response. In self-caught thought sampling, results are confounded by participants' ability/inability to remember to track mind wandering. Probe-caught thought sampling thus provides a more accurate sampling of mind wandering activity.

Besides possessing methodological utility, mind wandering tasks also have direct relevance to the construct of MI. If mental distraction is the primary means by which people avoid the interoceptive element of emotion, then a probe-caught sampling task, assessing sustained attention to sensations within sequential, broadly defined areas of the body, could provide a measure of MI. 
Another consideration in measuring MI is how to assess for non-evaluation or nonjudgment. Fortunately, sustained interoception is implicitly non-evaluative. Carmody (2009) notes that judgment only occurs when the mind is distracted from the present moment. As previously mentioned, mindfulness of body is considered the gateway to mindfulness in Buddhist psychology because pure sensory awareness precludes evaluative thoughts that create aversions and attachments (Olendzki, 2010). Present moment attention is therefore synonymous with non-evaluative attention.

Supporting the premise that present-moment attention decreases mental suffering, Killingsworth and Gilbert (2010) have shown that mind wandering is negatively associated with happiness. In this study, the researchers developed an iPhone app that queried and recorded people's mental state at random times throughout the day. The prompts measured emotion (“How are you feeling right now?") and mind wandering (“Are you thinking about something other than what you are currently doing?"). People were less happy when mind wandering than when not and this was true for all activities. People were no happier when thinking about pleasant thoughts than they were when attending to the present moment, and were significantly less happy when thinking about neutral or negative thoughts than when attending to the present moment. Time-lag analyses revealed that mind wandering typically caused negative moods, instead of being the effect. Smallwood et al. (2007) have also found that mind wandering as measured by a thought sampling task is associated with dysphoria.

Killingsworth and Gilbert's (2010) study found that mind wandering occurred in $46.9 \%$ of queries. In a text comprehension study (Smallwood \& Schooler, 2006), 13\% of participants reported mind wandering during an attention task to a neutral stimulus. Given that it is likely more difficult to sustain attention to endogenous physical 
sensations than to a novel and distinct reading task, a probe-caught sampling task that directs attention to internal cues should catch participants' minds wandering a significant percentage of the time. With multiple probes per testing, there should also be a good range of response scores. To allow for the possibility of mind wandering, the task would need to allow for significant periods of non-directed silence during which the participants' attention would have the opportunity to wander. The task would also need to assess various interoceptive foci of the body to attain a comprehensive measure of MI ability.

It would additionally be necessary to demonstrate that an MI sampling task is specifically measuring sustained attention to internal sensations rather than sustained attention broadly defined. To address this concern, performance on an MI sampling task could be contrasted with a measure of mindful attention that is not specifically focused on interoceptive cues.

The validity of a MI sampling task would also be dependent upon whether people can accurately report attention to physical sensations. Traditional mind wandering sampling tasks use text as a focus of attention; as such, people are able to track their own mind wandering based on whether or not they have made progress through the text. With a non-linear focus of attention such as physical sensations, there is no progress marker that allows people to easily assess whether their minds have wandered. Accordingly, some people may struggle to identify instances of mind wandering. It is also conceivable that people who experience high levels of mind wandering will underreport instances of mind wandering if they are not attuned to when it occurs. As such, it will be particularly important to assess whether a MI sampling task consistently correlates with 
hypothetically related constructs. With sufficient convergent evidence, these potential critiques of a MI sampling task will be effectively addressed.

The Mindful Interoception Sampling Task (MIST). As noted previously, five criteria need to be met in order to develop a valid measure of mindful interoception. The measure must A) assess in vivo interoception, B) measure sustained attention, C) assess attention throughout the body, D) allow for attention to a variety of qualitatively distinct sensations, and E) not require quantification of the target stimulus. Following several prototypes, the current Mindful Interoception Sampling Task or the "MIST" was developed.

The MIST is a probe-caught sampling task that measures attention to endogenous interoceptive cues in four distinct regions of the body: the abdomen, the chest, the muscles of the back, and the neck and throat. These regions of the body were selected based on the observation that frequently cited physical concomitants of emotional experience are often experienced in these areas. Research on the regions of the body where people physically experience emotions confirms that these regions of the body are frequently cited as central to emotional experience (Nummenmaa, Glerean, Hari, \& Hietanen, 2014). On the MIST, participants listen to standardized audio directions at the onset, followed by one trial run, and four two minute periods of silence during which they are instructed to attend to interoceptive cues (see Appendix $A$ for full text). Each period of silence lasts two minutes and possesses three random audio probes to assess mind wandering. If the participant's mind has wandered, he/she is instructed to click a counter. If the participant's mind has not wandered, he/she is instructed to continue attending to the body. At the conclusion of the recording, the participant's number of 
clicks is recorded as his/her MIST total score. A high score on the MIST is thus reflective of fewer reported instances of MI.

Although neuroimaging, detection tasks, and self-report measures all fall short of validly assessing MI, these measures are still useful for developing a nomological net assessing the construct validity of the MIST. Measures that most closely measure MI (e.g., scales of the MAIA) would be expected to demonstrate the strongest associations (an approximation of convergent validity), followed by measures that assess mindfulness of sensations more broadly (e.g., the awareness subscale of the Philadelphia Mindfulness Questionnaire), followed by general non-interoceptive mindfulness measures (e.g. the act with awareness subscale of the FFMQ) and neuroimaging of general interoceptive ability (e.g. fMRI insula activity). Traditional measures of interoception (e.g. the Schandry heartbeat detection task) and measures of anxiety sensitivity (e.g. the ASI-3) would further be expected to be uncorrelated or to demonstrate discriminant validity.

For the purposes of this initial validation study, construct validity measures have been selected based on the population being studied and the resources available. To this end, neuroimaging was excluded as a measure based on feasibility. Compared to neuroimaging, some of the potential strengths of the MIST include its cost effectiveness, ease to administer, and short duration. However, the MIST protocol in conjunction with neuroimaging techniques could someday provide the first opportunity to determine in vivo relationships between $\mathrm{MI}$ and regions of the brain, such as the insula.

The primary importance of the MIST, however, is to provide a means to accurately and efficiently measure MI as a mediating variable in clinical interventions. Understanding the relative importance of improved MI in interventions will provide scientist-practitioners a reason to choose MI-based interventions for specific clinical 
purposes and to create new interventions incorporating this mechanism of change. 


\section{CHAPTER II}

\section{METHODS}

\section{Participants}

Participants in this study were male and female students recruited from undergraduate psychology courses at the University of Louisville. College student samples were similarly used in the original validation studies of the self-report measures used to determine convergent and discriminant validity in this study. Participants in the current study were compensated with course credit in their psychology course, as determined by their instructor. The inclusion criteria for the study were as follows: A) 18 years of age or older and B) English reading proficiency sufficient for following directions and responding to self-report measures.

An a priori power analysis was conducted using $\mathrm{G}^{*}$ Power 3.1.3 (Erdfelder, Faul, \& Buchner, 1996) software to determine the required sample size for the study. Of the analyses being run, the only relationship that had been previously researched was that between anxiety sensitivity and heartbeat detection tasks. In their 2010 meta-analysis, Domschke et al. reported that the relationship between anxiety sensitivity and heartbeat detection tasks had a Cohen's $d$ of $0.61(N=149)$.

Given the unknown effect sizes of the relationships being examined in this study, a conservative approach was used to determine the a priori required sample size. Using a two-tailed correlation with power $=0.95$, and $\alpha=0.05, \mathrm{G}^{*}$ Power indicated that a sample 
size of 71 was required to detect a small to medium effect size $(d=0.4)$. To be conservative, we aimed to recruit at least 100 participants and recruited 108 participants in total.

\section{Procedures}

Participants met with study personnel in the Biobehavioral Research Laboratory at the University of Louisville. Study personnel first offered the participant a seat, then reviewed informed consent, provided informed consent forms, and offered to answer questions.

Once informed consent was obtained the following steps occurred. The participants filled out a brief demographic form with gender and date of birth to identify and exclude potential participants under the age of 18 . The researcher then collected a resting blood pressure reading using an electronic sphygmomanometer.

Using a random number generator to select the first task, the researcher then administered either the MIST (see Appendix $C$ for detailed protocol) or the Schandry heartbeat detection task (see Appendix $D$ for detailed protocol). If the Schandry heartbeat detection task was selected first, the researcher next attached a 3-lead EKG with the participant's permission (see Appendix $B$ for detailed protocol). Once an EKG signal was obtained, the researcher collected a resting heart rate reading. The researcher then administered the Schandry heartbeat detection task and subsequently removed the 3-lead EKG.

After the completion of both the MIST and the Schandry task, the participant was asked to complete the following battery of self-report measures: the ASI-3 (see Appendix E), the Act with Awareness subscale of the FFMQ (see Appendix F), the Awareness scale 
of the PHLMS (see Appendix $G$ ), and the following MAIA subscales, a) Not-worrying, b) Attention Regulation, and c) Body Listening (see Appendix $H$ ). The order of administering the battery of self-report measures was also determined by random number generator. Finally, the participant was asked for any feedback on the study and thanked for his/her participation in the study.

\section{Measures}

Control variables and demographic data. Gender, blood pressure, and resting heart rate data were collected as potential covariates. Gender has been demonstrated to correlate with performance on the Schandry heartbeat detection task (Ehlers et al., 2000). Blood pressure (O’Brien, Reid, \& Jones, 1998) and resting heart rate (Knapp-Kline \& Kline, 2005) have been demonstrated to correlate with performance on other heartbeat detection tasks.

\section{Self-report measures.}

Anxiety sensitivity index-3 (Appendix E). The ASI-3 (Taylor et al., 2007) is an 18-item self-report questionnaire assessing three domains of anxiety sensitivity determined by factor analysis: physical concerns, cognitive concerns, and social concerns. Taylor et al. define anxiety sensitivity as "fear of arousal-related sensations" (p. 177) and observe that anxiety sensitivity is a "diathesis for various types of anxiety disorders, including panic disorder, social anxiety disorder, specific phobia, and posttraumatic stress disorder" (p. 177). Sample items from the ASI-3 include "It scares me when I am unable to keep my mind on a task" and "It scares me when my heart beats rapidly." The ASI-3 was validated on a sample of young adults across Canada and the United States and demonstrates good construct validity and reliability. 


\section{Act with awareness subscale of the five-facet mindfulness questionnaire}

(Appendix F). The FFMQ (Baer, et al., 2006) is a five-factor scale developed from a factor analysis of five earlier mindfulness scales. The Act with Awareness subscale is an 8-item scale that measures mindful attention without explicitly assessing MI.

Accordingly, the Act with Awareness subscale should demonstrate weaker convergent validity with the MIST than a more explicit measure of MI. Sample items from the Act with Awareness subscale include "I am easily distracted" and "I find it difficult to stay focused on what's happening in the present." The FFMQ was originally validated on undergraduate students and possesses good internal consistency and construct validity.

\section{Awareness subscale of the Philadelphia mindfulness questionnaire (Appendix}

G). The PHLMS is a self-report questionnaire with two orthogonal 10-item subscales, "acceptance" and "awareness" (Cardaciotto, et al., 2008). Unlike most other mindfulness self-report scales, the Awareness subscale of PHLMS has prompts that assess interoception.

Representative prompts on the PHLMS awareness subscale include "When I am startled, I notice what is going on inside my body," "When talking with other people, I am aware of the emotions I am experiencing," and "I am aware of what thoughts are passing through my mind.” The PHLMS was originally validated on a non-clinical college student sample, and the awareness scale demonstrates good internal consistency and convergent and discriminant validity.

The Attention Regulation, Body Listening, and Not-Worrying Scales of the Multidimensional Assessment of Interoceptive Awareness (Appendix H). The MAIA is a self-report measure assessing eight scales of interoceptive awareness (Mehling et al., 2012). Of these scales, the 7-item Attention Regulation scale, the 3-item Body Listening 
scale, and the 3-item Not-Worrying scale were selected as the most face valid scales for assessing MI. These scales were additionally the most face valid scales for measuring MI of any self-report measures of body awareness reviewed. Representative prompts include "I can maintain awareness of my inner bodily sensations even when there is a lot going on around me," "I listen for information from my body about my emotional state," and "I can notice an unpleasant body sensation without worrying about it." These scales demonstrated good internal consistency and convergent and discriminant validity.

\section{Behavioral measures of interoception.}

The Mindful Interoception Sampling Task (MIST). The MIST is a probe-caught sampling task that measures attention to endogenous interoceptive cues in four distinct regions of the body.

The Schandry heartbeat detection task. The Schandry heartbeat detection task (Schandry, 1981) is one of the most commonly used measures of interoception. Participants are asked to count their heartbeats over three periods of time: 25 seconds, 35 seconds, and 45 seconds. Using an EKG, participants' heartbeat estimates are then assessed for accuracy by calculating the difference between reported and actual heartbeats and dividing that value by actual heartbeats. The researcher then takes the absolute value of each detection period error score and adds these three values together. Accordingly, a higher score on the Schandry heartbeat detection task indicates less accurate heartbeat detection. 


\section{CHAPTER III}

\section{RESULTS}

The following chapter reviews the findings of the study, including those of primary, supplementary, and exploratory analyses. Primary analyses directly assessed $a$ priori hypotheses of the study. Supplementary analyses assessed new questions that arose as a consequence of findings in the primary analyses. Exploratory analyses examined questions related to future directions in the development and validation of the MIST, and broader questions about assessment of MI.

Corrections for multiple comparisons were not applied as attempting to reduce Type I errors for null results would have increased the likelihood of Type II errors (Rothman, 1990). This risk of making Type II errors is particularly important to consider for this current study given how little is known about the newly proposed construct of MI or the MIST itself. Still, all results, and particularly the post-hoc secondary and exploratory analysis results, should be interpreted with the caveat that the number of correlations conducted increases the likelihood of Type I errors. Accordingly, results are to be interpreted as probabilities rather than as absolutes, and more importantly, as guides for further confirmatory research.

\section{Data overview}


A total of 108 individuals participated in this study. Overall there were 89 female and 19 male participants. Fifteen data points total were excluded due to procedural errors (e.g. incomplete questionnaires, equipment problems). Data points three standard deviations above or below the mean were additionally removed to normalize the data. Using this standard, only four variables had outliers removed. Below is the total $N$ for each variable tested, before and after removal of outliers (Table 3).

Table 3

Completed Measures

$\mathrm{N}$ before data
removed

MIST

108

108

Schandry Task Total

105

104

ASI-3 Physical Concerns

107

105

ASI-3 Cognitive Concerns

107

106

ASI-3 Social Concerns

107

107

ASI-3 Total

107

107

FFMQ Act with Awareness

106

106

PHLMS Awareness

108

108

MAIA Not-worrying

108

108

MAIA Attention Regulation

108

107 
MAIA Body Listening

Systolic Blood Pressure

Diastolic Blood Pressure

Resting Heart Rate
108

106

106

106
108

106

106

106

The data were then analyzed to ensure that assumptions of parametric statistics were met. No variables violated the assumption of homoscedasticity. Only the ASI-3 Physical Concerns subscale, the ASI-3 Cognitive Concerns subscale, and the ASI-3 Total score violated the assumption of normality. Square root transformations were used to create normal distributions for these variables. Subsequent analyses using ASI-3 Physical Concerns, ASI-3 Cognitive Concerns, and ASI-3 Total were conducted using square-root transformed data.

\section{Preliminary Analyses}

Ordering Effects. An independent samples $t$-test was run to determine whether the order in which the MIST and the Schandry Task were presented influenced scores on these respective tasks. There was no significant difference on MIST scores between participants who completed the MIST first $(M=6.04, S D=2.43)$ and participants who completed the Schandry Task first $(M=6.05, S D=2.71) ; t(106)=-.03, p=.98$. Additionally, there was no significant difference on Schandry Task scores between participants who completed the MIST first $(M=1.10, S D=0.47)$ and participants who completed the Schandry Task first $(M=1.03, S D=0.65) ; t(98.1)=.64, p=.53$. 
Participants were administered one of four versions of the MIST, each with a different ordering of the four focal regions of the body. A repeated measures ANOVA determined that MIST focal region scores were not statistically significantly different based on their sequence within the script $(F(3,321)=1.45, p=.23$ (Table 4$)$.

Table 4

MIST Focal Regions, by Sequence in Script

\begin{tabular}{lcc}
\hline Region & $M$ & $S D$ \\
\hline MIST Region 1 & 1.38 & 0.83 \\
MIST Region 2 & 1.58 & 1.01 \\
MIST Region 3 & 1.51 & 0.95 \\
MIST Region 4 & 1.57 & 1.01 \\
\hline
\end{tabular}

Internal Consistency. Participants focused on four sequential regions of the body in each administration of the MIST. A repeated measures ANOVA determined that MIST region scores were not statistically different based on specific region of the body $(F(3$, $321)=1.156, p=.33$ ) (Table 5). Mauchly's test of sphericity revealed the assumption of sphericity was not violated for this analysis: $\chi^{2}(5)=10.02, p=.08$. 
Table 5

MIST Focal Regions, by Region of Body

\begin{tabular}{lcc}
\hline Region & $M$ & $S D$ \\
\hline MIST Abdomen & 1.56 & 0.95 \\
MIST Chest & 1.39 & 0.96 \\
MIST Back & 1.57 & 0.95 \\
MIST Neck/Throat & 1.53 & 0.95 \\
\hline
\end{tabular}

Identifying Potential Covariates. As described earlier, gender, systolic blood pressure, diastolic blood pressure, and resting heart rate were identified as potential covariates for analyses involving interoceptive tasks. The following analyses were conducted to assess potential collinearity between the Schandry Task, the MIST, and the aforementioned variables.

An independent samples t-test found no significant difference on MIST scores between male participants $(M=5.79, S D=2.07)$ and female participants $(M=6.10, S D=$ $2.67) ; t(106)=-.48, p=.63$. A second independent samples t-test found no significant difference on Schandry Task scores between male participants $(M=1.08, S D=0.75)$ and female participants $(M=1.06, S D=0.53) ; t(20.69)=.085, p=.93$.

Pearson product-moment correlations were conducted to determine the relationships between the interoceptive tasks and physiological measurements. Significant correlations were found between the MIST and systolic blood pressure $(r=-$ $.28, p<.01)$ and between the Schandry Task and resting heart rate $(r=.28, p=.01)$. Specifically, higher systolic blood pressure was significantly correlated with low scores on the MIST (i.e. fewer instances of mind wandering). Additionally, higher resting heart 
rate was significantly correlated with high scores on the Schandry task (i.e. worse accuracy). Other relationships tested were non-significant. Table 6 summarizes these results.

Table 6

Pearson Product-Moment Correlations for Interoceptive Tasks and Potential Physiological Covariates

\begin{tabular}{llll}
\hline Measure & $\begin{array}{l}\text { Systolic Blood } \\
\text { Pressure }\end{array}$ & $\begin{array}{l}\text { Diastolic Blood } \\
\text { Pressure }\end{array}$ & Resting Heart Rate \\
\hline MIST & $\begin{array}{l}r=-.28^{* *} \\
p<.01\end{array}$ & $\begin{array}{l}r=-.13 \\
p=.20\end{array}$ & $\begin{array}{l}r=.04 \\
p=.72\end{array}$ \\
Schandry Task & $r=-.08$ & $r=.04$ & $r=.28^{* *}$ \\
& $p=.43$ & $p=.68$ & $p=.01$
\end{tabular}

Note. $*=p \leq .05, * *=p \leq .01$.

Based on the observed collinearity, semi-partial correlations were conducted with the MIST and Schandry Task, controlling for systolic blood pressure and resting heart rate, respectively. These analyses were conducted in addition to Pearson product-moment correlations. Visual comparisons of semi-partial correlations and Pearson productmoment correlations were used to assess the relative influences of the covariates on the results. The results of the semi-partial correlational analyses can be found in the Supplementary Tables section.

\section{Primary Analyses}


Hypothesis 1. The MIST was hypothesized to be either positively correlated or uncorrelated with all 3 subscales (physical, cognitive, and social concerns) of the Anxiety Sensitivity Index-3 (ASI-3).

Pearson product-moment correlations were conducted to determine the relationships between the MIST and the ASI-3 subscales. Semi-partial correlations, were also conducted to determine the amount of covariance accounted for by the MIST controlling for the effects of systolic blood pressure. No significant correlations were found in either analysis, confirming the hypotheses. Tables 7 and 8 summarize these results.

Hypothesis 2. The Schandry heartbeat detection task was hypothesized to be negatively correlated with all 3 subscales (physical, cognitive, and social concerns) of the Anxiety Sensitivity Index-3 (ASI-3).

Pearson product-moment correlations were conducted to determine the relationships between the Schandry Task and the ASI-3 subscales and total score. Semipartial correlations, were also conducted to determine the amount of covariance accounted for by the Schandry Task controlling for the effects of resting heart rate. No significant correlations were found in either analysis. The original hypothesis was not confirmed. Tables 7 and 8 summarize these results. 
Table 7

Pearson Product-Moment Correlations for Interoceptive Tasks and ASI-3 Subscales

\begin{tabular}{llll}
\hline Measure & ASI-3 Physical & ASI-3 Cognitive & ASI-3 Social \\
Concerns & Concerns & Concerns
\end{tabular}

\begin{tabular}{lcll}
\hline MIST & $r=.08$ & $r=-.09$ & \\
& $p=.41$ & $p=.34$ & $r=-.12$ \\
Schandry Task & $r=.00$ & $r=.03$ & \\
& $p=.97$ & $p=.78$ & $r=.07$ \\
& & $p=.50$
\end{tabular}

Hypothesis 3. The MIST was hypothesized to be negatively correlated with the act with awareness subscale of the FFMQ.

A Pearson product-moment correlation was conducted to determine the relationship between the MIST and the act with awareness subscale of the FFMQ. The results indicated there was a significant negative correlation between the two variables, $r$ $=-.30, p<.01$, confirming the hypothesis. A semi-partial correlation was also conducted to determine the amount of covariance accounted for by the MIST controlling for the effects of systolic blood pressure. The results indicated there was still a significant negative correlation between the MIST and the act with awareness subscale of the FFMQ, $r=-.27, p<.01$.

Hypothesis 4. The Schandry heartbeat detection task was hypothesized to be positively correlated or uncorrelated with the act with awareness subscale of the FFMQ.

A Pearson product-moment correlation was conducted to determine the relationship between the Schandry Task and the act with awareness subscale of the 
FFMQ. The results indicated there was not a significant correlation between the two variables, $r=.07, p=.47$, confirming the hypothesis. A semi-partial correlation was also conducted to determine the amount of covariance accounted for by the Schandry Task controlling for the effects of resting heart rate. The results indicated there was still not a significant correlation between the Schandry Task and act with awareness subscale of the FFMQ, $r=.08, p=.44$.

Hypothesis 5. The MIST was hypothesized to be negatively correlated with the following scales of the MAIA: not-worrying, attention regulation, and body listening. Pearson product-moment correlations were conducted to determine the relationships between the MIST and the not-worrying, attention regulation, and body listening scales of the MAIA. The results indicated there was a highly significant negative correlation between the MIST and the MAIA attention regulation scale $(r=-.44$, $\mathrm{p}<.01)$. Significant correlations with the other two MAIA scales were not found although the relationship with MAIA body listening approached significance $(r=-.17, p$ $=.07)$. Semi-partial correlations were also conducted to determine the amount of covariance accounted for by the MIST controlling for the effects of systolic blood pressure. The results again confirmed there was a highly significant negative correlation between the MIST and the MAIA attention regulation scale $(r=-.41, \mathrm{p}<.01)$ while no significant correlations with the other two MAIA scales were found. Tables 9 and 10 summarize these results.

Hypothesis 6. The Schandry heartbeat detection task was hypothesized to be positively correlated or uncorrelated with the following scales of the MAIA: notworrying, attention regulation, and body listening. 
Pearson product-moment correlations were conducted to determine the relationships between the Schandry Task and the not-worrying, attention regulation, and body listening scales of the MAIA. The results indicated there was a significant negative correlation between the Schandry Task and the MAIA body listening scale $(r=-.21, \mathrm{p}=$ .04), disconfirming the hypothesis. The other two MAIA scales had non-significant correlations, confirming the original hypothesis. Semi-partial correlations were also conducted to determine the amount of covariance accounted for by the Schandry Task controlling for the effects of resting heart rate. The results indicated there was again a significant negative correlation between the Schandry Task and the MAIA body listening scale $(r=-.21, \mathrm{p}=.04)$ while the other two MAIA scales still had non-significant correlations. Tables 9 and 10 summarize these results.

Table 9

Pearson Product-Moment Correlations for Interoceptive Tasks and Selected MAIA

Scales

\begin{tabular}{llll}
\hline Measure & $\begin{array}{l}\text { MAIA Not- } \\
\text { worrying }\end{array}$ & $\begin{array}{l}\text { MAIA Attention } \\
\text { Regulation }\end{array}$ & $\begin{array}{l}\text { MAIA Body } \\
\text { Listening }\end{array}$ \\
\hline MIST & $\begin{array}{l}r=.07 \\
p=.46\end{array}$ & $\begin{array}{l}r=-.44^{* *} \\
p<.01\end{array}$ & $\begin{array}{l}r=-.17 \\
p=.07\end{array}$ \\
Schandry Task & $\begin{array}{l}r=.05 \\
p=.61\end{array}$ & $\begin{array}{l}r=-.09 \\
p=.39\end{array}$ & $\begin{array}{l}r=-.21^{*} \\
p=.04\end{array}$ \\
& & & \\
Note. $*=p \leq .05, * *=p \leq .01$. & &
\end{tabular}

Hypothesis 7. The MIST was hypothesized to be negatively correlated with the awareness subscale of the PHLMS.

A Pearson product-moment correlation was conducted to determine the relationship between the MIST and the awareness subscale of the PHLMS. The results 
suggested there was not a significant correlation between the two variables, $r=-.10, p=$ .29 , indicating the hypothesis was not confirmed. A semi-partial correlation was also conducted to determine the amount of covariance accounted for by the MIST controlling for the effects of systolic blood pressure. The results suggested there was still not a significant correlation between the MIST and the awareness scale of the PHLMS, $r=-$ $.09, p=.36$.

Hypothesis 8. The Schandry heartbeat detection task was hypothesized to be positively correlated or uncorrelated with the awareness subscale of the Philadelphia Mindfulness Scale (PHLMS).

A Pearson product-moment correlation was conducted to determine the relationship between the Schandry Task and the awareness subscale of the PHLMS. The results suggested there was not a significant correlation between the two variables, $r=$ $.00, p=.99$, indicating the hypothesis was confirmed. A semi-partial correlation was also conducted to determine the amount of covariance accounted for by the Schandry Task controlling for the effects of resting heart rate. The results suggested there was still not a significant correlation between the Schandry Task and the awareness scale of the PHLMS, $r=-.03, p=.75$.

Hypothesis 9. The MIST was hypothesized to be uncorrelated with the Schandry heartbeat detection task.

A Pearson product-moment correlation was conducted to determine the relationship between the MIST and the Schandry Task. The results suggested there was not a significant correlation between the two variables, $r=-.03, p=.78$, indicating the hypothesis was confirmed. Semi-partial correlations were also conducted to determine 
the amount of covariance accounted for by the MIST and Schandry Task controlling for the effects of systolic blood pressure and resting heart rate, respectively. When controlling for the covariance between the MIST and systolic blood pressure, there was not a significant correlation between the MIST and Schandry Task, $r=-.01, p=.90$. When controlling for the covariance between the Schandry Task and resting heart rate, there was still not a significant correlation between the MIST and the Schandry Task, $r=$ $-.05, p=.64$.

Hypothesis 10. The awareness subscale of PHLMS was hypothesized to be positively correlated with the following scales of the MAIA: not-worrying, attention regulation, and body listening.

Pearson product-moment correlations were conducted to determine the relationships between the awareness subscale of the PHLMS and the not-worrying, attention regulation, and body listening scales of the MAIA. The results indicated there was a highly significant correlation in the hypothesized direction between the PHLMS awareness subscale and the MAIA attention regulation scale $(r=.40, p<.01)$. There was also a significant correlation in the hypothesized direction between the PHLMS awareness subscale and the MAIA body listening scale $(r=.19, p=.05)$. There was not a significant correlation between the PHLMS awareness subscale and the MAIA notworrying scale, disconfirming that hypothesis. Table 11 summarizes these results.

Hypothesis 11. The act with awareness subscale of the FFMQ was hypothesized to be positively correlated with the following scales of the MAIA: not-worrying, attention regulation, and body listening. 
Pearson product-moment correlations were conducted to determine the relationships between the act with awareness subscale of the FFMQ and the notworrying, attention regulation, and body listening scales of the MAIA. The results indicated there was a highly significant correlation in the hypothesized direction between the act with awareness subscale of the FFMQ and the MAIA attention regulation scale ( $r$ $=.33, p<.01)$. There was not a significant correlation between the FFMQ awareness subscale and the MAIA not-worrying or body listening scales, disconfirming those hypotheses. Table 11 summarizes these results.

Table 11

Pearson Product-Moment Correlations for PHLMS Awareness Scale and FFMQ Act with Awareness Scale with Selected MAIA Scales

\begin{tabular}{llll}
\hline Measure & $\begin{array}{l}\text { MAIA Not- } \\
\text { worrying }\end{array}$ & $\begin{array}{l}\text { MAIA Attention } \\
\text { Regulation }\end{array}$ & $\begin{array}{l}\text { MAIA Body } \\
\text { Listening }\end{array}$ \\
\hline PHLMS Awareness & $\begin{array}{l}r=.16 \\
p=.10\end{array}$ & $\begin{array}{l}r=.40^{* *} \\
p<.01\end{array}$ & $\begin{array}{l}r=.19 * \\
p=.05\end{array}$ \\
& $r=.07$ & $r=.33^{* *}$ & $r=.10$ \\
FFMQ Act with & $p=.46$ & $p<.01$ & $p=.33$ \\
Awareness & &
\end{tabular}

Hypothesis 12. To confirm construct validity, a specific pattern of relationships between the MIST and other tested variables was hypothesized in the form of a nomological net. Table 12 depicts the hypothesized pattern of relationships. 
Table 12

Hypothesized Nomological Net

\begin{tabular}{ll} 
Order Measures \\
\hline
\end{tabular}

Most significant negative correlation

MAIA Scales (not-worrying, attention regulation, \& body listening)

Less significant negative correlation

PHLMS awareness scale

Least significant negative correlation

FFMQ act with awareness scale

No correlation

Schandry Task

Uncorrelated or positive correlation

ASI-3 total and subscales (physical concerns, cognitive concerns, social concerns)

Table 13 depicts the actual pattern of relationships between the MIST and the variables of interest. 
Table 13

Observed Pattern of Pearson Product-Moment Correlations

\begin{tabular}{|c|c|}
\hline Measure & Correlation (r) \\
\hline MAIA attention regulation & $-.44 * *$ \\
\hline FFMQ act with awareness & $-.30 * *$ \\
\hline MAIA body listening & -.17 \\
\hline ASI-3 social concerns & -.12 \\
\hline PHLMS awareness & -.10 \\
\hline ASI-3 cognitive concerns & -.09 \\
\hline ASI-3 total & -.04 \\
\hline Schandry task & -.03 \\
\hline MAIA not-worrying & .07 \\
\hline ASI-3 physical concerns & .08 \\
\hline
\end{tabular}

\section{Supplementary Analyses}

To better understand the observed pattern of relationships between the MIST and the variables of the hypothesized nomological net, supplementary analyses were conducted to determine the relationship between component focal regions of the MIST and the variables of interest.

Independent samples t-tests were conducted to determine if there were differences between male and female participants for the focal regions of the MIST. No significant differences were observed. Table 14 depicts the results of those analyses. 
Table 14

Independent Samples T-tests Comparing Mean Scores on MIST Focal Regions

\begin{tabular}{|c|c|c|c|c|c|}
\hline & Male & Female & T-score & $\begin{array}{l}\text { Degrees of } \\
\text { Freedom }\end{array}$ & Sig. \\
\hline MIST Abdomen & $\begin{array}{l}1.58 \\
(0.90)\end{array}$ & $\begin{array}{l}1.55 \\
(0.97)\end{array}$ & .12 & 106 & .91 \\
\hline Chest & $\begin{array}{l}1.37 \\
(0.83)\end{array}$ & $\begin{array}{l}1.39 \\
(0.98)\end{array}$ & -.10 & 106 & .92 \\
\hline Back & $\begin{array}{l}1.26 \\
(0.87)\end{array}$ & $\begin{array}{l}1.64 \\
(0.96)\end{array}$ & -1.58 & 106 & .12 \\
\hline Neck/Throat & $\begin{array}{l}1.58 \\
(0.69) \\
\end{array}$ & $\begin{array}{l}1.52 \\
(1.00)\end{array}$ & .33 & $36.18^{\dagger}$ & .75 \\
\hline
\end{tabular}

Pearson product-moment correlations were then conducted to determine the relationships between the MIST focal regions and physiological measurements. Table 15 summarizes these results. 
Table 15

Pearson Product-Moment Correlations for MIST Focal Regions and Potential Physiological Covariates

\begin{tabular}{|c|c|c|c|}
\hline & $\begin{array}{c}\text { Systolic Blood } \\
\text { Pressure } \\
\end{array}$ & $\begin{array}{c}\text { Diastolic Blood } \\
\text { Pressure }\end{array}$ & $\begin{array}{c}\text { Resting Heart } \\
\text { Rate } \\
\end{array}$ \\
\hline MIST Abdomen & $\begin{array}{l}r=-.17 \\
p=.08\end{array}$ & $\begin{array}{l}r=-.06 \\
p=.54\end{array}$ & $\begin{array}{l}r=-.02 \\
p=.87\end{array}$ \\
\hline MIST Chest & $\begin{array}{l}r=-.17 \\
p=.08\end{array}$ & $\begin{array}{l}r=-.10 \\
p=.29\end{array}$ & $\begin{array}{l}r=.00 \\
p>.99\end{array}$ \\
\hline MIST Back & $\begin{array}{l}r=-.30 * * \\
p<.01\end{array}$ & $\begin{array}{l}r=-.18 \\
p=.07\end{array}$ & $\begin{array}{l}r=.03 \\
p=.78\end{array}$ \\
\hline MIST Neck/Throat & $\begin{array}{l}r=-.12 \\
p=.24\end{array}$ & $\begin{array}{l}r=.01 \\
p=.96\end{array}$ & $\begin{array}{l}r=.09 \\
p=.38\end{array}$ \\
\hline
\end{tabular}

Based on the observed collinearity between the back region and systolic blood pressure, semi-partial correlations were conducted with the back region, controlling for systolic blood pressure. These analyses were conducted in addition to Pearson productmoment correlations. Visual comparisons of semi-partial correlations and Pearson product-moment correlations were then used to assess the relative influences of systolic blood pressure on the results.

Table 16 depicts the pattern of relationships between the MIST focal regions and variables of interest, with a column of MIST-total correlations for comparison. Semipartial correlations were also conducted to determine the amount of covariance accounted for by the back region controlling for the effects of systolic blood pressure. Table 17 depicts this pattern of relationships. 
Table 16

Pearson Product-Moment Correlations for MIST Focal Regions, MIST-total, and Hypothetically-Related Variables

\begin{tabular}{|c|c|c|c|c|c|}
\hline Measure & $\begin{array}{l}\text { MIST- } \\
\text { total }\end{array}$ & $\begin{array}{l}\text { MIST } \\
\text { Abdomen }\end{array}$ & $\begin{array}{l}\text { MIST } \\
\text { Chest }\end{array}$ & $\begin{array}{l}\text { MIST } \\
\text { Back }\end{array}$ & $\begin{array}{l}\text { MIST } \\
\text { Neck/Throat }\end{array}$ \\
\hline $\begin{array}{l}\text { MAIA attention } \\
\text { regulation }\end{array}$ & $\begin{array}{l}r=-.44 * * \\
p<.01\end{array}$ & $\begin{array}{l}r=-.32 * * \\
p<.01\end{array}$ & $\begin{array}{l}r=-.32 * * \\
p<.01\end{array}$ & $\begin{array}{l}r=-.25^{* *} \\
p=.01\end{array}$ & $\begin{array}{l}r=-.27 * * \\
p=.01\end{array}$ \\
\hline $\begin{array}{l}\text { FFMQ act with } \\
\text { awareness }\end{array}$ & $\begin{array}{l}r=-.30 * * \\
p<.01\end{array}$ & $\begin{array}{l}r=-.22^{*} \\
p=.03\end{array}$ & $\begin{array}{l}r=-.26^{* *} \\
p=.01\end{array}$ & $\begin{array}{l}r=-.05 \\
p=.63\end{array}$ & $\begin{array}{l}r=-.29 * * \\
p<.01\end{array}$ \\
\hline $\begin{array}{l}\text { MAIA body } \\
\text { listening }\end{array}$ & $\begin{array}{l}r=-.17 \\
p=.07\end{array}$ & $\begin{array}{l}r=-.05 \\
p=.61\end{array}$ & $\begin{array}{l}r=-.23^{*} \\
p=.02\end{array}$ & $\begin{array}{l}r=-.12 \\
p=.20\end{array}$ & $\begin{array}{l}r=-.07 \\
p=.48\end{array}$ \\
\hline $\begin{array}{l}\text { ASI-3 social } \\
\text { concerns }\end{array}$ & $\begin{array}{l}r=-.12 \\
p=.20\end{array}$ & $\begin{array}{l}r=-.17 \\
p=.09\end{array}$ & $\begin{array}{l}r=.00 \\
p>.99\end{array}$ & $\begin{array}{l}r=-.07 \\
p=.47\end{array}$ & $\begin{array}{l}r=-.10 \\
p=.32\end{array}$ \\
\hline PHLMS awareness & $\begin{array}{l}r=-.10 \\
p=.29\end{array}$ & $\begin{array}{l}r=-.16 \\
p=.10\end{array}$ & $\begin{array}{l}r=-.15 \\
p=.12\end{array}$ & $\begin{array}{l}r=.07 \\
p=.46\end{array}$ & $\begin{array}{l}r=-.04 \\
p=.70\end{array}$ \\
\hline $\begin{array}{l}\text { ASI-3 cognitive } \\
\text { concerns }\end{array}$ & $\begin{array}{l}r=-.09 \\
p=.34\end{array}$ & $\begin{array}{l}r=-.07 \\
p=.51\end{array}$ & $\begin{array}{l}r=-.08 \\
p=.40\end{array}$ & $\begin{array}{l}r=-.07 \\
p=.50\end{array}$ & $\begin{array}{l}r=-.04 \\
p=.71\end{array}$ \\
\hline ASI-3 total & $\begin{array}{l}r=-.04 \\
p=.66\end{array}$ & $\begin{array}{l}r=-.07 \\
p=.46\end{array}$ & $\begin{array}{l}r=-.02 \\
p=.82\end{array}$ & $\begin{array}{l}r=-.05 \\
p=.64\end{array}$ & $\begin{array}{l}r=.03 \\
p=.80\end{array}$ \\
\hline Schandry task & $\begin{array}{l}r=-.03 \\
p=.78\end{array}$ & $\begin{array}{l}r=-.13 \\
p=.20\end{array}$ & $\begin{array}{l}r=.03 \\
p=.78\end{array}$ & $\begin{array}{l}r=.08 \\
p=.40\end{array}$ & $\begin{array}{l}r=-.06 \\
p=.57\end{array}$ \\
\hline MAIA not-worrying & $\begin{array}{l}r=.07 \\
p=.46\end{array}$ & $\begin{array}{l}r=.10 \\
p=.31\end{array}$ & $\begin{array}{l}r=.09 \\
p=.38\end{array}$ & $\begin{array}{l}r=.02 \\
p=.86\end{array}$ & $\begin{array}{l}r=-.01 \\
p=.95\end{array}$ \\
\hline $\begin{array}{l}\text { ASI-3 physical } \\
\text { concerns }\end{array}$ & $\begin{array}{l}r=.08 \\
p=.41\end{array}$ & $\begin{array}{l}r=.08 \\
p=.42\end{array}$ & $\begin{array}{l}r=-.02 \\
p=.87\end{array}$ & $\begin{array}{l}r=.04 \\
p=.68\end{array}$ & $\begin{array}{l}r=.12 \\
p=.24\end{array}$ \\
\hline
\end{tabular}

Note. ${ }^{*}=p \leq .05, * *=p \leq .01$.

\section{Exploratory Analyses}

Based on the relationships between variables of the nomological net and the MIST focal regions, it appears the abdomen and chest region most closely approximate 
the nomological net with the neck/throat region being a somewhat poorer fit and the back region a considerably poorer fit. Accordingly, two new variables were created to assess potential variations of the MIST. MIST-ACN was created by adding the scores from the abdomen, chest, and neck/throat regions. MIST-AC was created by adding the scores from the abdomen and chest regions. Results of these analyses should be interpreted with the caveat that scores obtained on each region may have been indirectly influenced by the presence of other focal regions that were present in the administration of the measure but excluded in the calculation of these new variables.

Independent samples t-tests were conducted to determine if there were significant differences between male and female participants on the new versions of the MIST. No significant differences were observed. Table 18 depicts the results of those analyses. 
Table 18

Independent Samples T-tests Examining Differences in MIST-ACN \& MIST-AC Mean Scores Between Genders

\begin{tabular}{|c|c|c|c|c|c|}
\hline & Male & Female & $T$-score & $\begin{array}{l}\text { Degrees } \\
\text { of } \\
\text { Freedom }\end{array}$ & Significance \\
\hline MIST-ACN & $\begin{array}{l}4.52 \\
(1.74)\end{array}$ & $\begin{array}{l}4.46 \\
(2.13)\end{array}$ & .13 & 106 & .90 \\
\hline MIST-AC & $\begin{array}{l}2.95 \\
(1.35)\end{array}$ & $\begin{array}{l}2.94 \\
(1.62)\end{array}$ & .01 & 106 & .99 \\
\hline
\end{tabular}

Note. Standard deviations appear in parentheses below means.

Pearson product-moment correlations were then conducted to determine the relationships between the new versions of the MIST and physiological measurements.

Table 19 summarizes these results.

Table 19

Pearson Product-Moment Correlations for MIST-ACN, MIST-AC, and Potential Physiological Covariates

\begin{tabular}{|c|c|c|c|}
\hline Measures & $\begin{array}{l}\text { Systolic Blood } \\
\text { Pressure } \\
\end{array}$ & $\begin{array}{l}\text { Diastolic Blood } \\
\text { Pressure }\end{array}$ & Resting Heart Rate \\
\hline MIST-ACN & $\begin{array}{l}r=-.21 * \\
p=.03\end{array}$ & $\begin{array}{l}r=-.07 \\
p=.45\end{array}$ & $\begin{array}{l}r=.03 \\
p=.75\end{array}$ \\
\hline MIST-AC & $\begin{array}{l}r=-.21 * \\
p=.03\end{array}$ & $\begin{array}{l}r=-.10 \\
p=.31\end{array}$ & $\begin{array}{l}r=-.01 \\
p=.92\end{array}$ \\
\hline
\end{tabular}

Note. $*=p \leq .05, * *=p \leq .01$. 
Based on the observed collinearity between the new versions of the MIST and systolic blood pressure, semi-partial correlations were conducted with these versions of the MIST, controlling for systolic blood pressure. These analyses were conducted in addition to Pearson product-moment correlations. Visual comparisons of semi-partial correlations and Pearson product-moment correlations were then used to assess the relative influences of systolic blood pressure on the results.

Table 20 depicts the pattern of relationships between the new versions of the MIST and other variables of interest, with a column of MIST-total correlations for comparison. Semi-partial correlations were also conducted to determine the amount of covariance accounted for by the new versions of the MIST controlling for the effects of systolic blood pressure. Table 21 displays this pattern of relationships. 
Table 20

Pearson Product-Moment Correlations for New Versions of MIST, MIST-total, and Hypothetically-Related Variables

\begin{tabular}{|c|c|c|c|}
\hline Measure & MIST-total & $M I S T-A C$ & MIST-ACN \\
\hline $\begin{array}{l}\text { MAIA attention } \\
\text { regulation }\end{array}$ & $\begin{array}{l}r=-.44 * * \\
p<.01\end{array}$ & $\begin{array}{l}r=-.40 * * \\
p<.01\end{array}$ & $\begin{array}{l}r=-.43^{* *} \\
p<.01\end{array}$ \\
\hline $\begin{array}{l}\text { FFMQ act with } \\
\text { awareness }\end{array}$ & $\begin{array}{l}r=-.30 * * \\
p<.01\end{array}$ & $\begin{array}{l}r=-.29 * * \\
p<.01\end{array}$ & $\begin{array}{l}r=-.35^{* *} \\
p<.01\end{array}$ \\
\hline $\begin{array}{l}\text { MAIA body } \\
\text { listening }\end{array}$ & $\begin{array}{l}r=-.17 \\
p=.07\end{array}$ & $\begin{array}{l}r=-.17 \\
p=.08\end{array}$ & $\begin{array}{l}r=-.16 \\
p=.10\end{array}$ \\
\hline $\begin{array}{l}\text { ASI-3 social } \\
\text { concerns }\end{array}$ & $\begin{array}{l}r=-.12 \\
p=.20\end{array}$ & $\begin{array}{l}r=-.10 \\
p=.31\end{array}$ & $\begin{array}{l}r=-.12 \\
p=.22\end{array}$ \\
\hline $\begin{array}{l}\text { PHLMS } \\
\text { awareness }\end{array}$ & $\begin{array}{l}r=-.10 \\
p=.29\end{array}$ & $\begin{array}{l}r=-.19 * \\
p=.05\end{array}$ & $\begin{array}{l}r=-.16 \\
p=.10\end{array}$ \\
\hline $\begin{array}{l}\text { ASI-3 cognitive } \\
\text { concerns }\end{array}$ & $\begin{array}{l}r=-.09 \\
p=.34\end{array}$ & $\begin{array}{l}r=-.09 \\
p=.36\end{array}$ & $\begin{array}{l}r=-.09 \\
p=.39\end{array}$ \\
\hline ASI-3 total & $\begin{array}{l}r=-.04 \\
p=.66\end{array}$ & $\begin{array}{l}r=-.06 \\
p=.56\end{array}$ & $\begin{array}{l}r=-.03 \\
p=.74\end{array}$ \\
\hline Schandry task & $\begin{array}{l}r=-.03 \\
p=.78\end{array}$ & $\begin{array}{l}r=-.06 \\
p=.54\end{array}$ & $\begin{array}{l}r=-.07 \\
p=.47\end{array}$ \\
\hline $\begin{array}{l}\text { MAIA not } \\
\text { worrying }\end{array}$ & $\begin{array}{l}r=.07 \\
p=.46\end{array}$ & $\begin{array}{l}r=.11 \\
p=.25\end{array}$ & $\begin{array}{l}r=.08 \\
p=.40\end{array}$ \\
\hline $\begin{array}{l}\text { ASI-3 physical } \\
\text { concerns }\end{array}$ & $\begin{array}{l}r=.08 \\
p=.41\end{array}$ & $\begin{array}{l}r=.04 \\
p=.70\end{array}$ & $\begin{array}{l}r=.08 \\
p=.40\end{array}$ \\
\hline
\end{tabular}

Note. $*=p \leq .05, * *=p \leq .01$.

The hypothesized nomological net proposed that the measures theoretically most closely related to MI would have the strongest relationship with the MIST. For 
exploratory purposes, the degree to which these other measures related to the hypothesized nomological net was also explored. Table 22 demonstrates the correlations between measures and the hypothesized nomological net. The order of correlations has been reversed from the original nomological net given that high MIST scores reflect higher levels of mind wandering whereas high scores on mindfulness measures reflect greater mindful attention. 


\section{CHAPTER IV}

\section{DISCUSSION}

The present study aimed to develop a measure of MI, the MIST, hypothesizing that the variant of interoception described in Buddhist writings and taught in present-day mindfulness practice is qualitatively different from the variant of interoception assessed by traditional measures of interoception. In order to establish construct validity of the measure, the MIST was hypothesized to have a specific pattern of relationships with conceptually related variables. Furthermore, the MIST was hypothesized to match this pattern of relationships more closely than the Schandry heartbeat detection task, a traditional measure of interoception. Results of the study suggest the MIST is a promising, valid, behavioral measure of mindfulness; however, there remain some lingering questions as to whether the MIST specifically assesses MI. The MIST does, however, clearly demonstrate stronger construct validity with MI than the Schandry Task, which may help explain the null results obtained by other studies examining the relationship between mindfulness practice and interoception as assessed by more traditional measures (Khalsa et al., 2008; Nielsen \& Kaszniak, 2006; Parkin et al., 2013).

This chapter will discuss the findings of this initial validation study, discuss strengths and weaknesses of the study, and propose future research that could build on these results and further contribute to the understanding of the effects of MI in clinical practice.

\section{Ordering Effects and Internal Consistency}


Participants in the study were administered both the MIST and Schandry Task, with the ordering of the two tasks randomly selected. Analyses indicated that the order in which the measures were administered did not influence participants' scores. These results suggest that participants neither benefited from practice effects nor were hindered by attentional fatigue across tasks.

Each participant was also randomly administered one of four variations of the MIST, each with a different sequence of the four MIST focal regions. No significant differences were observed between regions based on their sequence in the script. The absence of practice effects within the test suggests that the MIST measures a construct with stability within each individual assessment period.

The MIST was also analyzed for differences between specific focal regions of the body, independent of their sequence within the task. No significant differences were found between these focal regions. This suggests good internal consistency between the components of the MIST. Further, it implies the MIST is measuring a global construct that is not based on specific regions of the body.

\section{Potential Covariates}

Previous studies on the measurement of interoception identified gender, blood pressure, and heart rate as potential covariates (Ehlers et al., 2000; Knapp-Kline \& Kline, 2005; O’Brien, Reid, \& Jones, 1998). In the present study, analyses revealed systolic blood pressure and resting heart rate to be significantly collinear with the MIST and Schandry Task, respectively.

More accurate heartbeat detection on the Schandry Task was associated with slower resting heart rate, which is consistent with previous findings (Knapp-Kline \& Kline, 2005). A slower heart rate likely provides more opportunity to detect each 
individual heartbeat, thereby increasing accuracy. A slower heart rate is also associated with greater volume of blood flow with each beat, which could potentially increase sensory information and heart rate detectability.

Lower levels of reported mind wandering on the MIST were significantly associated with higher systolic blood pressure. Although this relationship was not specifically hypothesized, one explanation is that increased blood pressure with each contraction of the heart creates a more salient sensation, facilitating the maintenance of attention to the body.

The high collinearity of systolic blood pressure with the MIST and of resting heart rate with the Schandry Task raises the possibility that systolic blood pressure and resting heart rate were responsible for significant shared variance between these interoceptive tasks and other variables of interest. Accordingly, additional analyses were conducted controlling for these covariates for the respective interoceptive tasks. However, controlling for these covariates revealed negligible differences between the magnitudes of correlations across analyses (see Supplemental Tables).

\section{Anxiety Sensitivity Index-3}

Previous studies found that anxiety sensitivity was significantly correlated with increased accuracy on the Schandry Task (Eley, Stirling, Ehlers, Gregory, \& Clark, 2004; Steward-Buffett-Jerrott, \& Kokaram, 2001; Sturges \& Goetch, 1996). These results, however, were not replicated in the current study. This finding is incongruent with the proposed explanation that the lack of an association between the Schandry Task and mindfulness practice in other studies was partially a consequence of the Schandry Task's high collinearity with anxiety sensitivity. However, specific characteristics of the current 
sample may have clouded the true relationship between the Schandry Task and anxiety sensitivity.

Participants' scores in the current study on the social concerns subscale of the ASI-3 were over a standard deviation above the North American sample mean obtained in the validation study for the ASI-3 (Taylor et al., 2007). Their social concerns mean score was more consistent with the generalized anxiety and obsessive-compulsive disorder samples' means obtained in the validation study.

Representative prompts on the social concerns subscale include: "It is important for me not to appear nervous," "I worry that other people will notice my anxiety," and "It scares me when I blush in front of people." These characteristics of the sample may have clouded the relationship between the Schandry Task and other anxiety sensitivity scales, as anxious participants' attention was directed externally to the investigator rather than to more internal processes such as anxiety about physical symptoms or anxiety about thought processes. These more internal variants of anxiety sensitivity would be expected to have a closer relationship to anxious interoception and the Schandry Task by extension. For instance, prompts from the somatic concerns and cognitive concerns ASI3 scales include "It scares me when I am unable to keep my mind on a task" and "It scares me when my heart beats rapidly." These more internally directed anxiety sensitivities may have been more dominant in other study samples, accounting for the greater collinearity between the Schandry Task and the ASI-3 in previous research.

The MIST also did not demonstrate a significant relationship with the ASI-3, in this case confirming the hypothesis that there would either be a positive correlation or no correlation at all. However, given the unusual elevation in social anxiety sensitivity in the sample, it is worth considering whether the MIST primed concerns about social 
judgment. This potential for self-report inaccuracies and presentation biases is a limitation of the MIST that is not present in the Schandry Task, which has a more objective standard with which to measure attention.

\section{Self-Report Measures of Mindfulness and MI}

The self-report measures of mindfulness and MI examined in this study were the FFMQ act with awareness scale, the PHLMS awareness scale, and the not-worrying, body listening, and attention regulation scales of the MAIA. Each scale was hypothesized to have a significant negative correlation with the MIST, and to be uncorrelated or to have a significant positive correlation with the Schandry Task. As hypothesized, none of these scales were significantly correlated with the Schandry Task, with the exception of the body listening scale of the MAIA. The MAIA attention regulation scale and the FFMQ act with awareness scale were significantly negatively correlated with the MIST. The relationship between the MIST and the MAIA body listening scale almost reached significance, while the correlation with the PHLMS awareness scale was clearly nonsignificant and the correlation with the MAIA not-worrying scale was non-significant in the opposite direction of the hypothesis.

The pattern of relationships between the mindfulness variables and interoceptive tasks provides useful qualitative information about the variants of interoception being measured. The Schandry Task, as hypothesized, did not have a relationship with selfreport measures of MI, besides MAIA body listening, offering evidence that it is not a measure of MI. This would further explain why the Schandry Task has demonstrated no association with mindfulness practice in other studies. As hypothesized, the Schandry Task also was uncorrelated with the MIST, suggesting they measure distinct constructs. 
While the MIST did demonstrate a clear relationship with multiple measures of mindfulness, it did not demonstrate a significant relationship with the PHLMS awareness scale. This is a potential concern, given that the PHLMS awareness scale was hypothesized to have a particularly strong relationship with the MIST. Only the MAIA scales were hypothesized to have a stronger relationship with the MIST.

One potential explanation for the PHLMS awareness scale's non-significant relationship with the MIST is that the PHLMS awareness scale was measuring something other than MI. The PHLMS was initially hypothesized to have a strong relationship with the MIST by virtue of being a validated mindfulness scale with several prompts directly assessing awareness of the body. However, a closer examination of the prompts reveals that none directly assess non-evaluative attention to the body. For instance, "When I am startled, I notice what is going on inside my body" or "I notice changes inside my body, like my heart beating faster or my muscles getting tense" might both be endorsed by a person high in MI and a person high in hypochondriasis. Still, although the PHLMS awareness scale may not directly assess MI, it does have significant relationships with the other mindfulness measures in this study, suggesting some degree of construct validity. Another possibility is that the MIST measures something other than MI. Indeed, the MIST has strong relationships with purer attentional scales, like the attention regulation scale of the MAIA and the FFMQ act with awareness scales, while having poorer relationships with the PHLMS awareness scale and MAIA body listening scale. The possibility that the MIST is just a measure of attention is somewhat unlikely, however, given that the relationships the MIST has with self-report mindfulness measures (PHLMS excluded) are of similar magnitude to the relationships those measures have with one another, suggesting the MIST is assessing a similar construct. 


\section{Construct Validity of MIST Focal Regions}

There is another possible explanation for the MIST's weaker relationship with the PHLMS awareness scale. It may be that particular focal regions of the MIST are poor indicators of MI. To examine this possibility, individual focal regions of the MIST were assessed for their fit with the proposed nomological net.

A review of these patterns of relationships reveals the MIST back region has particularly weak relationships with every variable of interest with the exception of the MAIA attention regulation scale. The MIST back region was also the only variable to have a significant relationship with a physiological covariate, systolic blood pressure.

The MIST neck/throat region demonstrated strong significant relationships with the MAIA attention regulation scale and the FFMQ act with awareness scale, while having no relationship with PHLMS awareness scale or MAIA body listening scale. This suggests that the MIST neck/throat region may significantly influence the MIST's weaker relationships with the latter measures.

The MIST abdomen region also has strong significant relationships with the MAIA attention regulation scale and the FFMQ act with awareness scale, with a stronger but still non-significant relationship with the PHLMS awareness scale. The abdomen region has no relationship with the MAIA body listening scale.

The MIST chest region has strong significant relationships with the MAIA attention regulation scale, the FFMQ act with awareness scale, and the MAIA body listening scale. It also has a stronger but still non-significant relationship with the PHLMS awareness scale than the MIST.

Examining these focal regions independently, it is apparent that the back region, in particular, and the neck/throat region to a lesser extent are contributing to the 
unexpected patterns of relationships between the MIST and variables of the nomological net. It is possible that individuals high in MI struggle to attend to these regions; however, a more likely explanation is that individuals who are low in MI are performing better on these two focal regions than would be expected.

The back region and the neck/throat region, to a lesser degree, are regions in which muscular tension is a dominant sensation. It may be that people with high muscle tension have an advantage in attending to a region in which muscle tension is a particularly salient sensation. As MI is taught as a means of reducing stress, including physiological stress, it may be that people high in MI are at a slight initial disadvantage due to the reduced saliency of their muscular tension. This initial disadvantage might then negate the advantage of greater MI abilities.

Further correlational analyses examining the focal regions of the MIST reveal that the back region is highly significantly correlated with systolic blood pressure, with the abdomen and chest regions possessing significant but considerably weaker relationships with systolic blood pressure, and the neck/throat region possessing an insignificant association.

The range of associations between MIST focal regions and systolic blood pressure is further evidence that participants focus on different types of sensations within each region. The limited sensory innervation of the back and the limited sensations of breathing associated with the back may make blood pressure and muscle tension the most accessible focal points. Systolic blood pressure could be experienced as an actual pressure or as the felt reverberation of heart contractions. The felt sensations of heartbeats, blood pressure, and muscle tension in the back region could also be made more salient by participants sitting with their back pressed against the chair. 
In contrast, the abdomen and chest regions do not press against an exterior surface during the administration of the MIST. They also have greater sensory innervation and include more immediate breathing sensations. Still, these regions were significantly correlated with systolic blood pressure, suggesting that for some participants the felt intensity of each heart contraction or blood pressure may have influenced participants' ability to remain focused. The neck/throat region may have been less correlated with systolic blood pressure as a result of the availability of more accessible sensations of breathing in the throat.

In effect, the MIST does not control for differences in intensity of physical sensations. A dramatic example of this limitation would be an individual with severe chronic back pain. Although that individual may feel the urge to distract him/herself from the sensations in the back, he/she would have the "advantage" of a highly salient sensation that demands attention. In a less extreme example, an individual with a mild sunburn would also have less difficulty directing attention to such a sensation that demands his/her attention.

One possible solution is to instruct individuals to focus on the breath to the exclusion of other sensations. As participants can control the sensory intensity and rate of individual breaths, there is not the inherent advantage or disadvantage there is with focusing on heartbeats or muscle tension (unless breathing is painful for the individual). However, the exclusion of body sensations other than the breath limits the degree to which the construct being measured is similar to mindful observation of bodily sensations as they occur in day-to-day living. There is also the risk that narrowly focused attention on the breath could result in a measurement more akin to a heartbeat detection task; however, this risk might be mitigated some by instructing the individual to attend to any 
sensations associated with the breath. Another consideration is the removal of the back region from the MIST, given the high collinearity between this region and systolic blood pressure, its lack of sensations apart from muscle tension, and its poor fit with the nomological net. The back region is also the only focal region for which the effects of gender approached significance. Future studies may have more equal gender representation and thus more power to detect effects of gender, in which case the possible effects of gender on the back region may be a concern.

\section{Variations on the MIST}

To confirm the observation that removing variables might improve the construct validity of the MIST, new variables were created, the MIST-ACN and the MIST-AC. The MIST-ACN consists of scores from the abdomen, chest, and neck/throat regions of the MIST while the MIST-AC consists of scores from the abdomen and chest regions of the MIST.

Both composite measures demonstrated greater fidelity to the nomological net than the total MIST. The MIST-ACN has very strong relationships with the MAIA attention regulation and FFMQ act with awareness scale and strong but non-significant relationships with the MAIA body listening and PHLMS awareness scales. The MIST$\mathrm{AC}$ also has very strong relationships with the MAIA attention regulation and FFMQ act with awareness scale, and a significant relationship with the PHLMS awareness scale and a strong but non-significant relationship with the MAIA body listening scale.

As mentioned earlier in the results section, it should be noted that each region's scores may have been influenced by the presence of other focal regions that were present in the administration of the measure but excluded in the calculation of the MIST-AC and MIST-ACN. Still, these exploratory analyses strongly suggest that the MIST might be a 
more valid measure of $\mathrm{MI}$ if the back region and possibly the neck/throat region were excluded. In addition to increased validity, these shortened forms of the MIST could increase usability.

\section{Observations on the MAIA}

Although no pure measure of MI existed when this study was proposed, the authors of a yet-to-be published multidimensional paper-and-pencil measure of MI, the MAIA, provided permission for its use in this study. The MAIA has since been published (Mehling et al., 2012), making the current study one of the first to utilize the measure and independently assess the validity of MAIA scales.

Three scales from the MAIA were selected for use in this study: the attention regulation scale, the body listening scale, and the not-worrying scale. The former two scales were selected based on their strong conceptual similarities to MI while the latter scale was selected based on the theory that MI ability would be greatest for individuals who can sustain attention to physical experiences without avoiding the experience via worry. Representative prompts from these scales include: "I can refocus my attention from thinking to sensing my body" (attention regulation scale); "When I am upset, I take time to explore how my body feels" (body listening scale); and "I can notice an unpleasant body sensation without worrying about it" (not-worrying scale).

Contrary to my hypotheses, the MAIA not-worrying scale was uncorrelated with the MIST or any other measure of mindfulness or MI in the current study. The MAIA not-worrying scale did, however, have a strong relationship with ASI-3 physical and cognitive concerns, suggesting high "not-worrying” about physical symptoms is correlated with low anxiety sensitivity to physical and cognitive concerns, as would be expected. 
In the Mehling et al. (2012) validation study for the MAIA, the not-worrying scale had a strongly significant relationship with the attention regulation scale and a slightly stronger relationship with the body listening scale than it does in the current study. That the relationship with the attention regulation scale in the current study is not only non-significant but is opposite the hypothesized direction was certainly not expected but consistent with the overall lack of relationship observed between MI and worry/anxiety-related scales. Another potential explanation for these findings is the presence of measurement error in any replication of previous studies (Stanley \& Spence, 2014).

The MAIA body listening scale demonstrated a significant relationship with the MAIA attention regulation and PHLMS awareness scale but not with the FFMQ act with awareness or MAIA not-worrying scales. This might be indicative of the more cognitive bent of the latter two measures. However, the body listening scale also had a surprising significant relationship with the Schandry Task while having an almost significant relationship with the MIST and a non-significant relationship with each focal region of the MIST except the chest region.

The body listening scale, like the PHLMS awareness scale, does not specifically assess the non-evaluative component of MI. The three prompts for the scale are: "I listen for information from my body about my emotional state," "When I am upset, I take time to explore how my body feels," and "I listen to my body to inform me about what to do." By not clearly distinguishing between types of interoception, the MAIA body listening scale may actually be measuring interoception more broadly, accounting for its similarly strong relationships with both the MIST and the Schandry Task. 
The MAIA attention regulation scale demonstrated very strong significant relationships with the MIST, the MAIA body listening scale, the PHLMS awareness scale, and the FFMQ act with awareness scale. The MAIA attention regulation scale also demonstrated an ordering of relationships with these scales that suggests a valid measure of MI: in order, the MIST, the PHLMS awareness scale, the FFMQ act with awareness scale, and close behind, the MAIA body listening scale. The strength and ordering of these relationships reveal that the MAIA attention regulation scale is a particularly strong and valid measure of MI from a construct validity perspective, aside from any theoretical limitations of paper-and-pencil measures.

\section{Limitations}

Although this study aimed to recruit a diversity of participants, the actual sample was unusual in several ways. There were 89 female participants to only 19 male participants, bringing into question the applicability of the results to a male population. Moreover, the participants were recruited exclusively from undergraduate psychology courses. As such, there was limited diversity of education, age, and academic interest. Examining the data, participants also reported levels of social anxiety sensitivity consistent with clinically anxious populations. This may have resulted in impression management and lack of awareness of internal processes across measures. All results should be interpreted in light of this possibility.

A limitation in validating the MIST is the inherent difficulty of assessing how accurately individuals are reporting. The convergent validity the MIST demonstrates with other measures of mindfulness and MI does however suggest the MIST is not more prone to presentation biases than other scales. That there is less interpretation involved in the MIST than retrospective paper-and-pencil questionnaires may even increase veracity of 
responses. Still, the MIST could be more prone to presentation biases than most other measures given the social pressure inadvertently created by collecting individual's selfreport on a performance task. Although data collection was designed to reduce social pressure by collecting responses through clickers via a computer that was not facing the participants, it is possible social pressures still played a role in participants' responding.

There are some concerns, too, about the ecological validity of the MIST. Being instructed in a research setting to sustain attention to endogenous sensations may be a qualitatively different experience than attending to emotionally-charged sensations as they occur in everyday life. The assumption of the study is that both experiences draw upon similar skills; however, the possibility that these skillsets are quite different should be considered when drawing conclusions about MI and its potential role as a clinical mechanism of change.

Lastly, the dearth of validated scales available with which to validate the MIST limited the conclusions drawn from the results. For instance, the PHLMS awareness scale and MAIA body listening scale both superficially appeared to be mindfulness scales that assessed interoception; however, the lack of questions specifically assessing nonevaluative attention in both scales may have clouded any results or lack thereof. Further research using a broad range of measurements will be needed to overcome this current limitation.

\section{Strengths}

In clinical research, there are many studies in which the results can be predicted with a high level of certainty before the study is ever conducted. In contrast, the present study asked a genuinely novel question for which there was a high probability the hypotheses could be disproven. Numerous research groups previously attempted to 
determine the relationship between mindfulness and interoception, with virtually no success. The current study, in turn, was the first to propose the existence of variants of interoception, and of MI specifically. Given the novelty of the construct being proposed, the MIST, a behavioral measure of MI, was then validated using an entirely different modality of measures, paper-and-pencil questionnaires. Using this standard, there was little to no guarantee that measuring mind wandering while a person attends to endogenous sensations in the body would A) demonstrate MI construct validity, and B) demonstrate better MI construct validity than a traditional interoceptive task.

That significant correlations in the hypothesized directions were observed for a study charting such novel terrain is both an encouraging and substantial achievement. It should be emphasized that the very existence of a behavioral measure of mindfulness with strong relationships to previously validated mindfulness measures is in itself a novel and exciting discovery. Scores of mindfulness researchers and practitioners have lamented the use of retrospective, self-report measures to assess mindfulness. Focusing on temporally distant and vaguely defined experiences and evaluating those experiences as mindful or not is difficult for participants, of questionable accuracy, and is antithetical to mindfulness practice and theory. The MIST, in contrast, is the first behavioral, presentmoment measure of mindfulness that has been developed. Although it does rely on a selfreported evaluation of mind wandering, it uses a value-free, present-moment, yes/no question to determine whether attention is focused or distracted.

This behavioral measure of mindfulness may or may not, however, specifically measure MI. The pattern of observed relationships between the MIST and variables of the nomological net did not clearly distinguish between mindfulness broadly defined and MI. This ambiguity could be reflective of the validity of the questionnaires used for validation 
or the MIST itself. Another possibility is that MI is so central to mindfulness that the two constructs are essentially indistinguishable. Given these various possibilities, further research, as outlined in the following section, is still needed to distinguish between measurement of mindfulness broadly defined and MI specifically. Still, whatever the case may be, the MIST has potential for wide use as the first validated behavioral measure of mindfulness.

\section{Future Directions}

This initial validation study of the MIST suggests numerous possibilities for future research on the MIST and MI more generally. First, the current results could be replicated, using the same battery of measures as this study. However, this subsequent study could also include an extended battery of measures that would further corroborate the validity of the MIST. This could include an additional anxiety measure and a depression scale to determine if general anxiety and mood have relationships with the MIST. Neuroimaging could ascertain whether hypothesized regions of the brain (e.g. insula, ACC) are active during reported MI on the MIST, potentially providing further support for the validity of the measure. Traditional mind wandering sampling tasks could also be included to further ascertain whether the MIST is measuring the construct of MI or sustained attention more broadly.

The Schandry Task would no longer be included in this study, as the results of the current study clearly demonstrate that the Schandry Task does not measure MI. This future study could also include a more intentionally diverse sample on factors such as age, ethnicity, gender, education, and SES. A sample of experienced mindfulness practitioners could also be collected to determine expected differences between persons experienced with MI and those who are not. 
Another possibility to consider is running a parallel study to the one described above in which abbreviated versions of the MIST were also tested and validated. These abbreviated versions of the MIST would considerably reduce administration time and might increase the validity of the measure, as evidenced by the exploratory analyses described above.

Following these initial studies, a study could determine the reliability of the MIST and the effects of repeat administrations by testing participants every three weeks for three or four testing periods. With no mindfulness practice between administrations, participants' scores would be hypothesized to remain effectively the same over time.

A subsequent study could then test the MIST as a mediating variable for an MIbased mindfulness intervention. Participants could be tested on the MIST before treatment, at regular intervals during treatment, and after treatment. Using outcome variables such as anxiety measures, depression measures, mindfulness measures, quality of life measures, and physiological measures (e.g. heart rate, skin conductance, heart rate variability, blood pressure) the MIST would be assessed as a potential mediating variable for clinical improvements. Measurements such as the Schandry Task, MAIA attention regulation scale, and MAIA body listening scale could be assessed at the same intervals and also analyzed for mediation effects. The results would indicate which variables best account for the effects of MI training and could provide evidence for MI as an active mechanism of clinical change. Changes in the MIST and the other interoception-based measurements over time could also be correlated with frequency and length of time practicing mindfulness and MI-based practices such as body scan or breath-focused meditation. 
Finally, the MIST could be used broadly as a measure in intervention studies in which MI or mindfulness is a potential active mechanism. For instance, a study on the effects of MBCT on depression might examine the MIST as a mediating variable on depression outcomes and might also examine the relationship between practice time on the body scan and changes on the MIST.

\section{Closing Thoughts}

Based on the results of this current study, the MIST already holds the distinction as the first and only behavioral measure of mindfulness, a long-awaited development in mindfulness research. By continuing the process of validating the MIST, it is possible that its relationship to MI specifically will become clearer and that the measure itself can and will be used across a multitude of settings to ascertain the clinical effects of MI. The MIST promises to help answer the question to what extent practicing open, non-

judgmental sustained attention to our somatic experiences promotes mental and physical health. With greater understanding of this phenomenon and the contexts in which it is most effective, mental health practitioners stand to refine and improve the efficacy of the clinical services we provide. 


\section{REFERENCES}

Baer, R. A. (2003). Mindfulness training as a clinical intervention: A conceptual and empirical review. Clinical Psychology: Science and Practice, 10, 125-143.

Baer, R. A., Smith, G. T., Hopkins, J., Krietemeyer, J., \& Toney, L. (2006). Using self-report assessment methods to explore facets of mindfulness. Assessment, 13, $27-45$.

Beck, A. T., Emery, G., \& Greenberg, R. L. (1985). Anxiety disorders and phobias. New York: Basic Books.

Berntson, G. G., Norman, G. J., Bechara, A., Bruss, J., Tranel, D., \& Cacioppo, J. T. (2011). The insula and evaluative processes. Psychological Science, 22, 80-86.

Bishop, S. R., Lau, M., Shapiro, S., Carlson, L., Anderson, N. D., Carmody, J., Segal, Z. V., Abbey, S., Speca, M., Velting, D., \& Devins, G. (2004). Mindfulness: A proposed operational definition. Clinical Psychology: Science and Practice, 11(3), 230-241.

Bogaerts K., Millen A., Li W., De Peuter S., Van Diest I., Vlemincx, E., Fannes, S., \& Van den Bergh, O. (2008) High symptom reporters are less interoceptively accurate in a symptom-related context. Journal of Psychosomatic Research, 65, $417-424$.

Borkovec T. D. (1994). The nature, functions, and origins of worry. In G. Davey \& F. Tallis (Eds.), Worrying: Perspectives on Theory, Assessment, and Treatment (pp. 5-34). New York: John Wiley \& Sons. 
Borkovec, T. D., \& Hu, S. (1990). The effect of worry on cardiovascular response to phobic imagery. Behaviour Research and Therapy, 28, 69-73.

Borkovec, T. D., Ray, W. J., \& Stober, J. (1998). Worry: A cognitive phenomenon intimately linked to affective, physiological, and interpersonal behavioral processes. Cognitive Therapy and Research, 22, 561-576.

Borkovec, T. D., Shadick, R. \& Hopkins, M. (1991). The nature of normal and pathological worry. In R. M. Rapee \& D. H. Barlow (Eds.), Chronic anxiety, generalized anxiety disorder, and mixed anxiety depression (pp. 29-51). New York: Guilford Press.

Bowen, S., Chawla, N., \& Marlatt, G. A. (2011). Mindfulness-based relapse prevention for addictive behaviors: A clinician's guide. New York, NY: The Guilford Press.

Brefczynski-Lewis, J. A., Lutz, A., Schaefer, H. S., Levinson, D. B., \& Davidson, R. J. (2007). Neural correlates of attentional expertise in long-term meditation practitioners. Proceedings of the National Academy of Sciences, 104, 1148311488.

Butler, G., Fennell, M., \& Hackman, A. (2008). Cognitive-Behavioural Therapy for Anxiety Disorders. London: The Guilford Press.

Brown, K. W., Ryan, R. M., \& Creswell, J. D. (2007). Mindfulness: Theoretical foundations and evidence for its salutary effects. Psychological Inquiry, 18 (4), $211-237$.

Cameron, O. G. (2001). Interoception: The inside story — a model for psychosomatic processes. Psychosomatic Medicine, 63, 697-710.

Cannon, W. B. (1927). The James-Lange theory of emotions: A critical 
examination and an alternative theory. American Journal of Psychology, 39, 106124.

Cardaciotto, L., Herbert, J. D., Forman, E. M., Moitra, E., \& Farrow, V. (2008).

The assessment of present-moment awareness and acceptance: The Philadelphia mindfulness scale. Assessment, 15, 204-223.

Carlson, L. E, Speca, M., Faris, P., \& Patel, K. (2007). One year pre-post intervention follow-up of psychological, immune, endocrine and blood pressure outcomes of mindfulness-based stress reduction (MBSR) in breast and prostate cancer patients. Brain, Behavior, and Immunity, 21, 1038-1049.

Carmody, J. (2009). Evolving conceptions of mindfulness in clinical settings. Journal of Cognitive Psychotherapy, 23(3), 270-280.

Carmody, J. \& Baer, R. A. (2008). Relationships between mindfulness practice and levels of mindfulness, medical and psychological symptoms and well-being in a mindfulness-based stress reduction program. Journal of Behavioral Medicine, 31(1), 23-33.

Carson, J. W., Carson, K. M., Gil, K. M., \& Baucom, D. H. (2004). Mindfulnessbased relationship enhancement. Behavior Therapy, 35, 471-494.

Clark, L., Bechara, A., Damasio, H., Aitken, M. R., Sahakian, B. J., \& Robbins, T. W. (2008) Differential effects of insular and ventromedial prefrontal cortex lesions on risky decision-making. Brain,131(5), 1311-1322.

Craig, A. D. (2002). How do you feel? Interoception: the sense of the physiological condition of the body. Nature Reviews Neuroscience, 3, 655-666.

Craig A. D. (2008) Interoception and emotion: a neuroanatomical perspective. In 
M. Lewis, J. Haviland-Jones, \& L. Barrett, (Eds.), Handbook of Emotions, Third Edition (pp. 272-288). New York: Guilford.

Craig, A. D. (2009). How do you feel-now? The anterior insula and human awareness. Nature Reviews Neuroscience, 10, 59-70.

Craske, M. G., \& Barlow, D. H. (2008). Panic Disorder and Agoraphobia. In D. H. Barlow (Ed.), Clinical Handbook of Psychological Disorders (pp.1-64). New York: Guilford.

Critchley, H. D., Mathias, C. J., \& Dolan, R. J. (2001). Neural activity in the human brain relating to uncertainty and arousal during anticipation. Neuron, 29, $537-45$.

Critchley, H. D., Mathias, C. J. \& Dolan, R. J. (2002) Fear conditioning in humans: the influence of awareness and autonomic arousal on functional neuroanatomy. Neuron 33, 653-663.

Critchley, H. G., Wiens, S., Rotshtein, P., Ohman, A., \& Dolan, R. J. (2004). Neural systems supporting interoceptive awareness. Nature Neuroscience, 7, 189195.

Dahme, B., Richter, R., \& Mass, R. (1996). Interoception of respiratory resistance in asthmatic patients. Biological Psychology, 42, 215-229.

Damasio, A. R. (1994). Descartes' error: Emotion, reason, and human brain. New York: Grosset/Putnam.

Damasio, A. R. (1996). The somatic marker hypothesis and the possible functions of the prefrontal cortex. Philosophical Transactions: Biological Sciences $351,1413-1420$.

Damasio, A. R. (2003). The Person Within. Nature, 423, 227. 
Daubenmier, J. (2005). The relationship of yoga, body awareness, and body responsiveness to self-objectification and disordered eating, Psychology of Women Quarterly, 29, 207-219.

Domschke, K., Stevens, S., Pfleiderer, B., \& Gerlach, A. L. (2010). Interoceptive sensitivity in anxiety and anxiety disorders: an overview and integration of neurobiological findings. Clinical Psychology Review, 30, 1-11.

Dreeben, S. J., Mamberg, M. H., \& Salmon, P. (2013). The MBSR Body Scan in Clinical Practice. Mindfulness, 4(4), 394-401.

Drummond, M. S. (2006). Conceptualizing the efficacy of mindfulness of body sensations in the mindfulness-based interventions. Constructivism in the Human Sciences, 11(1), 2-29.

Ehlers, A., \& Breuer, P. (1992). Increased cardiac awareness in panic disorder. Journal of Abnormal Psychology, 101, 371-382.

Ehlers, A., Mayou, R. A., Sprigings, D. C., \& Birkhead, J. (2000). Psychological and perceptual factors associated with arrhythmias and benign palpitations. Psychosomatic Medicine, 62, 693-702.

Eisenberger, N. I. (2012). The neural bases of social pain: evidence for shared representations with physical pain. Psychosomatic Medicine, 74(2), 126135.

Eisenberger, N. I., Lieberman, M. D., \& Williams, K. D. (2003). Does rejection hurt? An FMRI study of social exclusion. Science, 302, 290-292.

Erdfelder, E., Faul, F., \& Buchner, A. (1996). GPOWER: A general power analysis program. Behavior Research Methods, Instruments, \& Computers, 28, 111. 
Farb, N. A. S., Anderson, A. K., Mayberg, H., Bean, J., McKeon, D., \& Segal, Z. V. (2010). Minding one's emotions: Mindfulness training alters the neural expression of sadness. Emotion, 10, 25-33.

Farb, N. A. S., Segal, Z. V., \& Anderson, A. K. (2012). Mindfulness meditation training alters cortical representations of interoceptive attention. Social Cognitive and Affective Neuroscience, 6, 1-12.

Farb, N. A. S., Segal, Z. V., Mayberg, H., Bean, J., McKeon, D., Fatima, Z., \& Anderson, A. K. (2007). Attending to the present: meditation reveals distinct neural modes of self-reference. Social Cognitive and Affective Neuroscience, 2, $313-322$.

Foa, E. B., \& Kozak, M. J. (1986). Emotional processing of fear: Exposure to corrective information. Psychological Bulletin, 99, 20-35.

Fletcher, L. B., Schoendorff, B., \& Hayes, S. C. (2010). Searching for Mindfulness in the brain: A process-oriented approach to examining the neural correlates of mindfulness. Mindfulness, 1 (1), 41-63.

Franzoi, S. L., Kessenich, J. J., Sugrue, P. A. (1989) Gender differences in the experience of body awareness: An experiential sampling study. Sex Roles, 21, 499-515.

Gard, T., Holzel, B. K., Sack, A. T., Hempel, H., Lazar, S. W., Vaitl, D., \& Ott, U. (2011). Pain mitigation through mindfulness is associated with decreased cognitive control and increased sensory processing in the brain. Cerebral Cortex, Epub ahead of print, 1-11.

Gendlin, E. T. (1996). Focusing-oriented psychotherapy: A manual of the experiential method. New York: Guilford Press. 
Ginzburg, K., Tsur, N., Barak-Nahum, A., \& Defrin, R. (2013). Body awareness:

Differentiating between sensitivity to and monitoring of bodily signals. Journal of Behavioral Medicine, published online April 30, 2013, DOI: 10.1007/s10865013-9514-9.

Grant, J. A., Courtemanche, J., Rainville, P., 2011. A non-elaborative mental stance and decoupling of executive and pain-related cortices predicts low pain sensitivity in Zen meditators. Pain, 152 (1), 150-156.

Grossman, P. (2008). On measuring mindfulness in psychosomatic and psychological research. Journal of Psychosomatic Research, 64 (4), 405-408.

Grossman, P. (2011). Defining mindfulness by how poorly I think I pay attention during everyday awareness and other intractable problems for psychology's (re)invention of mindfulness: Comment on Brown et al. (2011). Psychological Assessment, 23, $1034-1040$.

Hansell, S., Sherman, G., \& Mechanic, D. (1991) Body awareness and medical care utilization among older adults in an HMO. Journal of Gerontology, 46(3), S151-159.

Hayes, S. C., Luoma, J. B., Bond, F. W., Masuda, A., \& Lillis, J. (2006). Acceptance and commitment therapy: Model, processes, and outcomes. Behaviour Research and Therapy, 44, 1-25.

Hayes, S. C., Wilson, K. G., Gifford, E. V., Follette, V. M., et al. (1996). Experiential avoidance and behavioral disorders: A functional dimensional approach to diagnosis and treatment. Journal of Consulting and Clinical Psychology, 64, 1152-1168.

Heims, H. C., Critchley, H. D., Dolan, R., Mathias, L., \& Cipolotti, L. (2004). 
Social and motivational functioning is not critically dependent on feedback of autonomic responses: neuropsychological evidence from patients with pure autonomic failure. Neuropsychologia, 42, 1979 - 1988.

Hofmann, S. G., Sawyer, A. T., Witt, A. A., \& Oh, D. (2010). The effect of mindfulness-based therapy on anxiety and depression: a meta-analytic review. Journal of Consulting and Clinical Psychology, 78, 169-183.

Holzel, B. K., Ott, U., Hempel, H., Hackl, A., Wolf, K., Stark, R., Vaitl, D., (2007). Differential engagement of anterior cingulate and adjacent medial frontal cortex in adept meditators and non-meditators. Neuroscience Letters, 421, 16-21.

Holzel, B. K., Ott, U., Gard, T., Hempel, H., Weygandt, M., Morgen, K., Vaitl, D. (2008). Investigation of mindfulness meditation practitioners with voxel-based morphometry. Social Cognitive and Affective Neuroscience 3, 55-61.

Holzel, B. K., Carmody, J., Vangel, M., Congleton, C., Yerramsetti, S. M., Gard, T., \& Lazar, S. W. (2011a). Mindfulness practice leads to increases in regional brain gray matter density. Psychiatry Research, 191, 36-43.

Holzel, B. K., Lazar, S. W., Gard, T., Schuman-Olivier, Z., Vago, D. R., \& Ott, U. (2011b). How does mindfulness meditation work? Proposing mechanisms of action from a conceptual and neural perspective. Perspectives on Psychological Science, 6, 537--559.

Holzl, R., Erasmus, L. P. \& Moltner, A. (1996). Detection, discrimination and sensation of visceral stimuli. Biological Psychology, 42, 199-214.

Ives-Deliperi, V. L, Solms, M., \& Meintjes, E. M. (2011). The neural substrates of mindfulness: An fMRI investigation. Social Neuroscience, 6(3), 231-242.

Jacobs, T. L., Epel, E. S., Lin, J., Blackburn, E. H., Wolkowitz, O. M., Bridwell, 
D. A., Zanesco, A. P., Aichele, S. R., Sahdra, B. K., MacLean, K. A., King, B. G., Shaver, P. R., Rosenberg, E. L., Ferrer, E., Wallace, B. A., and Saron, C. D. (2011). Intensive meditation training, immune cell telomerase activity, and psychological mediators. Psychoneuroendocrinology, 36, 664-681.

James, W. (1884). What is emotion? Mind, 19, 188-205.

James, W. (1894). The physical basis of emotion. Psychological Review, 1, 516529.

Jha, A. P., Krompinger, J., \& Baime, M. J. (2007). Mindfulness training modifies subsystems of attention. Cognitive, Affective, \& Behavioral Neuroscience, 7, 109119.

Jha, A. P., Stanley, E. A., Kiyonaga, A., Wong, L., \& Gelfand, L. (2010). Examining the protective effects of mindfulness training on working memory capacity and affective experience in a military cohort. Emotion, 10, 54-64.

Kabat-Zinn, J. (1982). An outpatient program in behavioral medicine for chronic pain patients based on the practice of mindfulness meditation: Theoretical considerations and preliminary results. General Hospital Psychiatry, 4, 33-47.

Kabat-Zinn, J. (1990). Full catastrophe living. Using the wisdom of your body and mind to face stress, pain and illness. New York: Bantam Doubleday Dell Publishing.

Kabat-Zinn, J. (2003). Mindfulness-based interventions in context: Past, present, and future. Clinical Psychology: Science and Practice, 10, 144-156.

Kabat-Zinn, J., Lipworth, L., \& Burney, R. (1985). The clinical use of mindfulness meditation for the self-regulation of chronic pain. Journal of Behavioral Medicine, 8(2), 163-190. 
Khalsa, S., Rudrauf, D., Damasio, A., Davidson, R., Lutz, A., \& Tranel, D. (2008). Interoceptive awareness in experienced meditators. Psychophysiology, 45 (4), 671-677.

Khalsa, S. S., Rudrauf, D., Feinstein, J. S., \& Tranel, D. (2009). The pathways of interoceptive awareness. Nature Neuroscience, 12, 1494-1496.

Killingsworth M. A., \& Gilbert, D. T. (2010). A wandering mind is an unhappy mind. Science, 330, 932.

Kilts, C. D., Schweitzer, J. B., Quinn C. K., Gross, R. E., Faber, T. L., Muhammad, F., Ely, T. D., Hoffman, J. M., \& Drexler, K. P. G. (2001) Neural activity related to drug craving in cocaine addiction. Archives of General Psychiatry, 58, 334-341.

Kirk, U., Downar, J., \& Read Montague, P. (2011). Interoception drives increased rational decision-making in meditators playing the ultimatum game. Frontiers of Neuroscience, 5, 49.

Knapp-Kline, K., \& Kline, J. P. (2005). Heart rate, heart rate variability, and heartbeat detection with the method of constant stimuli: slow and steady wins the race. Biological Psychology, 69, 387-396.

Kristeller, J. L., Baer, R. A, \& Quillian-Wolever, R. (2006). Mindfulness-based approaches to eating disorders. In R. A Baer (Ed.), Mindfulness-based treatment approaches: Clinician's guide to evidence base and applications (pp. 75-91). San Diego, CA: Elsevier Academic Press.

Kuan, T. (2008). Mindfulness in early Buddhism: new approaches through psychology and textual analysis of Pali, Chinese, and Sanskrit sources. London: Routledge. Lang, P. J. (1994). The varieties of emotional experience: A meditation on James-Lange 
theory. Psychological Review, 101, 211-221.

Lange, C. G. (1922) The emotions: A psychophysiological study (I. A. Haupt, Trans.) In K. Dunlap (Ed.). The emotions (pp. 33-90). Baltimore, MD: Williams \& Wilkins Company. (Original work published 1885).

Langmuir, J. I., Kirsh, S. G., \& Classen, C. (2012). A pilot study of body-oriented psychotherapy: Adapting sensorimotor psychotherapy for the group treatment of trauma. Psychological Trauma: Theory, Research, Practice, and Policy, 4(2), 214-220.

Lau, M. A., Bishop, S. R., Segal, Z. V., Buis, T., Anderson, N. D., Carlson, L., Shapiro, S., \& Carmody, J. (2006). The Toronto Mindfulness Scale: Development and validation. Journal of Clinical Psychology, 62, 1445-1467.

Lazar, S., Kerr, C., Wasserman, R., Gray, J., Greve, D., Treadway, M., McGarvey, M., Quinn, B., Dusek, J., Benson, H., Rauch, S., Moore, C., \& Fisch, B. (2005). Meditation experience is associated with increased cortical thickness. Ageing, 16 (17), 1893-1897.

Lazarus, R. S. (1982). Thoughts on the relations between emotion and cognition. American Psychologist, 37, 1019-1024.

Lazarus, R.S. \& Folkman, S. (1984). Stress, appraisal, and coping. New York: Springer Publishing Company.

Linehan, M. M., Heard, H. L., \& Armstrong, H. E. (1993). Naturalistic follow-up of a behavioral treatment for chronically parasuicidal borderline patients. Archives of General Psychiatry, 50, 157-158.

Luders, E., Toga, A. W., Lepore, N., \& Gaser, C. (2009). The underlying anatomical correlates of long-term meditation: larger hippocampal and frontal volumes of 
gray matter. Neuroimage, 45, 672-678.

Lutz, A., Brefczynski-Lewis, J. A., Johnstone, T., \& Davidson, R. J. (2008a). Voluntary regulation of the neural circuitry of emotion by compassion meditation: Effects of expertise. PLoS One, 3(3), e1897.

Lutz, A., Slagter, H. A., Dunne, J. D., \& Davidson, R. J. (2008b). Attention regulation and monitoring in meditation. Trends in Cognitive Sciences, 12, 163-169.

Mailloux, J., \& Brener, J. (2002) Somatosensory amplification and its relationship to heartbeat detection ability. Psychosomatic Medicine, 64, 353-357.

Matousek, R. H., Dobkin, P. L., \& Pruessner, J. (2010). Cortisol as a marker for improvement in Mindfulness-Based Stress Reduction. Complementary Therapies in Clinical Science, 16(1), 13-19.

Mehling, W. E., Gopisetty, V., Daubenmier, J., Price, C. J., Hecht, F. M., \& Stewart, A. (2009). Body awareness: Construct and self-report measures. PLoS One, 4(5). 118.

Mehling, W. E., Price, C., Daubenmier, J., Acree, M., Bartmess, E., \& Stewart, A. (2012). The multidimensional assessment of interoceptive awareness (MAIA). PLOS One, 7(11), 1-22.

Miller, L. C., Murphy, R., Buss, A. H. (1981) Consciousness of body: Private and public. Journal of Personality and Social Psychology, 41, 397-406.

Naqvi, N. H., Rudrauf, D., Damasio, H., \& Bechara, A. (2007) Damage to the insula disrupts addiction to cigarette smoking. Science, 315, 531-534.

Nielsen, L., \& Kaszniak, A. W. (2006) Awareness of subtle emotional feelings: a comparison of long-term meditators and nonmeditators. Emotion, 6, 392-405.

Nummenmaa, L., Glerean, E., Hari, R., \& Hietanen, J. K. (2014). Bodily maps of 
emotions. Proceedings of the National Academy of Sciences, 111(2), 646-651.

O'Brien, W. H., Reid, G. J., \& Jones, K. R. (1998). Differences in heartbeat awareness among males with higher and lower levels of blood pressure. International Journal of Psychophysiology, 29, 53-63.

Olendzki, A. (2010). Unlimiting mind: The radically experiential psychology of

Buddhism. Somerville, MA: Wisdom Publications.

Orsillo, S. M., Roemer, L., Block-Lerner, J., LeJeune, C., \& Herbert, J. D. (2005). ACT with anxiety disorders. In S. C. Hayes, \& K. D. Strosahl (Eds.), A practical guide to acceptance and commitment therapy (pp. 103-132). New York: Springer Science \& Business Media.

Parkin, L., Morgan, R., Rosselli, A., Howard, M., Sheppard, A., Evans, D., Hawkins, A., Martinelli, M., Golden, A., Dalgleish, T., \& Dunn, B. (2013). Exploring the relationship between mindfulness and cardiac perception. Mindfulness. Published online on February 5, 2013. DOI: 10.1007/s12671-012-0181-7.

Paulus, M. P., \& Frank, L. R. (2003). Ventromedial prefrontal cortex activation is critical for preference judgments. Neuroreport, 14, 1311-1315.

Paulus, M. P., \& Stein, M. B. (2006) An insular view of anxiety. Biological Psychiatry, $60,383-387$.

Perls, F. (1973). The gestalt approach and eye witness to therapy. New York: Bantam Books.

Pollatos, O., \& Schandry, R., Auer, D. P., \& Kaufmann, C. (2007). Brain structures mediating cardiovascular arousal and interoceptive awareness. Brain Research, $1141,178-187$.

Price, C. J. (2005) Body-oriented therapy in recovery from child sexual abuse: An 
efficacy study. Alternative Therapies in Health and Medicine, 11(5), 46-57.

Price, C. J., \& Thompson, E. A. (2007). Measuring dimensions of body connection: body awareness and bodily dissociation. Journal of Alternative and Complementary Medicine, 13, 945-954.

Price, C. J., Wells, E. A., Donovan, D. M., \& Rue, T. (2011). Mindful Awareness in Body-oriented therapy as an adjunct to women's substance use disorder treatment: A pilot feasibility study. Journal of Substance Abuse Treatment. Epub ahead of print.

Rizvi, S. L., Welch, S. S., \& Dimidjian, S. (2009) Mindfulness and Borderline Personality Disorder. In F. Didonna (Ed.) Clinical Handbook of Mindfulness (pp. 245-258), New York: Springer Science.

Robinson, P., Wicksell, R. K., Olsson, G. L. (2004). ACT with chronic pain patients. In S. C. Hayes \& K. D. Strosahl (Eds). A practical guide to acceptance and commitment therapy (pp. 315-345). New York: Springer.

Roemer, L., Orsillo, S. M., \& Salters-Pedneault, K. (2008). Efficacy of an acceptancebased behavior therapy for generalized anxiety disorder: Evaluation in a randomized control trial. Journal of Counseling and Clinical Psychology, 76, $1083-1089$.

Rothman, K. J. (1990). No adjustments are needed for multiple comparisons. Epidemiology, 1, 43-46.

Salmon, P., Lush, E., Jablonski, M., \& Sephton, S. E. (2009) Yoga and mindfulness: Clinical aspects of an ancient mind/body practice. Cognitive and Behavioral Practice. 16, 59-72.

Salmon, P. G., Sephton, S. E., \& Dreeben, S. J. (2010). Mindfulness-Based Stress 
Reduction. In J. D. Hebert \& E. Forman (Eds.), Acceptance and Mindfulness in Cognitive Behavior Therapy (pp. 132-163). Hoboken, New Jersey: Wiley.

Schachter, S., \& Singer, J. E. (1962). Cognitive, social, and physiological determinants of emotional state. Psychological Review, 69, 379-399.

Schandry, R (1981): Heart beat perception and emotional experience. Psychophysiology, $18,483-488$.

Schmidt, N. B., Lerew, D. R., \& Trakowski, J. H. (1997) Body vigilance in panic disorder: Evaluating attention to bodily perturbations. Journal of Consulting and Clinical Psychology, 65, 214-220.

Shapiro, S.L., Carlson, L.E., Astin, J.A., \& Freedman, B. (2006). Mechanisms of mindfulness. Journal of Clinical Psychology, 62, 373-386.

Shields, S. A., Mallory, M. A., Simon, A. (1989). The body awareness questionnaire: reliability and validity. Journal of Personality Assessment 53, 802-815.

Siegel, D. J. (2007). The mindful brain: Reflection and attunement in the cultivation of wellbeing. New York: W. W. Norton \& Company, Inc.

Siegel, D. J. (2010). Mindsight: The New Science of Personal Transformation. New York: Bantam.

Slagter, H. A., Lutz, A., Greischar, L. L., Francis, A. D., Nieuwenhuis, S., Davis, J. M., \& Davidson, R. J. (2007). Mental training affects distribution of limited brain resources. PLoS Biology, 5, 1228-1235.

Smallwood, J., \& Schooler, J. W. (2006). The restless mind. Psychological Bulletin, 132(6), 946-958.

Smallwood, J. O’Connor, R. C., Sudberry, M. V., \& Obonsawin, M. (2007). Mindwandering and dysphoria. Cognition and Emotion, 21, 816-842. 
Snell, W. J., \& Johnson, G. (1997). The multidimensional health questionnaire. American Journal of Health Behavior, 21, 33-42.

Stanley, D. J., \& Spence, J. R. (2014). Expectations for replications are yours realistic?. Perspectives on Psychological Science, 9(3), 305-318.

Steptoe, A., \& Noll, A. (1997) The perception of bodily sensations, with special reference to hypochondriasis. Behaviour Research and Therapy 35, 901-910.

Suls, J., \& Fletcher, B. (1985). The relative efficacy of avoidant and non-avoidant coping strategies: A meta-analysis. Health Psychology, 4, 249-288.

Sze, J. A., Gyurak, A., Yuan, J. W., \& Levenson, R. W. (2010). Coherence between emotional experience and physiology: Does body awareness training have an impact? Emotion, 10(6), 803-814.

Taylor S., Zvolensky, M. J., Cox, B. J., Deacon, B., Heimberg, R. G., Ledley, D. R., Abramowitz, J. S., ... Cardenas, S. J. (2007). Robust dimensions of anxiety sensitivity: Development and initial validation of the Anxiety Sensitivity Index -3 . Psychological Assessment, 19, 176-188.

Teasdale, J. D., Segal, Z. V., Williams, J. M. G., Ridgeway, V. A., Soulsby, J. M., Lau, M. A. (2000). Prevention of relapse/recurrence in major depression by mindfulness-based cognitive therapy. Journal of Consulting and Clinical Psychology, 68, 615-23.

Tucker, D. M., \& Newman, J. P. (1981). Verbal versus imaginal cognitive strategies in the inhibition of emotional arousal. Cognitive Therapy and Research, 5, 197-202. Valentine, E. R., \& Sweet, P. L. G. (1999). Meditation and attention: A comparison of the effects of concentrative and mindfulness meditation on sustained attention. Mental Health, Religion \& Culture, 2, 59-70. 
Van der Does, A. J. W., Antony, M. M., Ehlers, A., \& Barsky, A. J. (2000). Heartbeat perception in panic disorder: a reanalysis. Behaviour Research \& Therapy, 38 , $47-62$.

Wiens, S. (2005). Interoception in emotional experience. Current Opinion in Neurology, $18,442-447$.

Williams, J. M. G., Duggan, D. S., Crane, C., \& Fennell, M. J. V. (2006). Mindfulnessbased cognitive therapy for prevention of recurrence of suicidal behavior. Journal of Clinical Psychology, 62, 201-210.

Wilson, K. G., \& Byrd, M. R. (2004). Acceptance and Commitment Therapy for substance abuse and dependence. In S. C. Hayes \& K. Strosahl (Eds.), A practical guide to Acceptance and Commitment Therapy (pp. 153-184). New York: Springer.

Witkiewitz, K., Marlatt, G. A., Walker, D. D. (2005). Mindfulness-based relapse prevention for alcohol and substance use disorders. Journal of Cognitive Psychotherapy. 19, 221-228. 


\section{SUPPLEMENTAL TABLES}

Table 1

Facets of Mindfulness, as Identified in Definitions of Mindfulness

Facets of Mindfulness Cited By

Attention/Sustained Attention

$1,2,34$

Present-Moment

$1,2,3$

Non-judgment/Acceptance/

$1,2,3,4$

Non- Evaluative

On Purpose/Intention

1,4

Reduce Suffering

1,3

Focus on Immediate

$1,2,3$

Experience/Mental Events

Self-Regulation

Attitude/Curiosity/Openness/

3,4

Kindness

Note. 1 = Kabat-Zinn, 2003; 2 = Carmody, 2009; 3 = Bishop et al., 2004;

4 = Shapiro et al., 2006 
Table 2

Mechanisms of Mindfulness, as Identified in Theoretical Papers

Mechanisms of Mindfulness

Cited By

Self-Regulation/Self-Management

$1,2,4$

Acceptance/Non-Attachment

$2,3,5$

Reperceiving/Cognitive

$1,2,3,4,5$

Change/Observer

Self/Insight/Defusion

Flexibility

1

Values Clarification

1

Exposure

$1,2,3$

Relaxation

2

Body Awareness/Mind-Body

3, 4

Functioning

Integrated Functioning

3

Attention Regulation/Present

4,5

Moment Awareness

Note. 1 = Shapiro et al., 2006; 2 = Baer, 2003; 3 = Brown, Ryan, \& Creswell, 2007;

$4=$ Holzel et al., 2011b; 5 = Fletcher, Schoendorff, \& Hayes, 2010 
Table 8

Semi-Partial Correlations for Interoceptive Tasks and ASI-3 Subscales.

\begin{tabular}{llll}
\hline Measure & $\begin{array}{l}\text { ASI-3 Physical } \\
\text { Concerns }\end{array}$ & $\begin{array}{l}\text { ASI-3 Cognitive } \\
\text { Concerns }\end{array}$ & $\begin{array}{l}\text { ASI-3 Social } \\
\text { Concerns }\end{array}$ \\
\hline MIST (controlling for & $\begin{array}{l}r=.04 \\
p=.71\end{array}$ & $\begin{array}{l}r=-.12 \\
p=.21\end{array}$ & $\begin{array}{l}r=-.13 \\
p=.20\end{array}$ \\
systolic BP) & $r=-.02$ & $r=.03$ & $r=.07$ \\
Schandry Task & $p=.80$ & $p=.49$ \\
$\begin{array}{l}\text { (controlling for resting } \\
\text { heart rate) }\end{array}$ & $p=.84$ & & \\
\hline
\end{tabular}

Note. ${ }^{*}=p \leq .05, * *=p \leq .01$.

Table 10

Semi-Partial Correlations for Interoceptive Tasks and Selected MAIA Scales

\begin{tabular}{|c|c|c|c|}
\hline Measure & $\begin{array}{l}\text { MAIA Not- } \\
\text { worrying }\end{array}$ & $\begin{array}{l}\text { MAIA Attention } \\
\text { Regulation }\end{array}$ & $\begin{array}{l}\text { MAIA Body } \\
\text { Listening }\end{array}$ \\
\hline $\begin{array}{l}\text { MIST } \\
\text { (controlling for } \\
\text { systolic BP) }\end{array}$ & $\begin{array}{l}r=.13 \\
p=.19\end{array}$ & $\begin{array}{l}r=-.41 * * \\
p<.01\end{array}$ & $\begin{array}{l}r=-.17 \\
p=.08\end{array}$ \\
\hline $\begin{array}{l}\text { Schandry Task } \\
\text { (controlling for } \\
\text { resting HR) }\end{array}$ & $p=.94^{r=.01}$ & $p=.36^{r=-.09}$ & $\begin{array}{l}r=-.21 * \\
p=.04\end{array}$ \\
\hline
\end{tabular}


Table 17

Pearson Product-Moment Correlations and Semi-Partial Correlations for MIST Back, MIST-total, and Hypothetically-Related Variables

\begin{tabular}{|c|c|c|c|}
\hline Measures & MIST Back & $\begin{array}{l}\text { MIST Back } \\
\text { (controlling for } \\
\text { systolic BP) }\end{array}$ & MIST-total \\
\hline $\begin{array}{l}\text { MAIA attention } \\
\text { regulation }\end{array}$ & $\begin{array}{l}r=-.25^{* *} \\
p=.01\end{array}$ & $\begin{array}{l}r=-.22 * \\
p=.03\end{array}$ & $\begin{array}{l}r=-.44 * * \\
p<.01\end{array}$ \\
\hline MAIA body listening & $\begin{array}{l}r=-.12 \\
p=.20\end{array}$ & $\begin{array}{l}r=-.12 \\
p=.21\end{array}$ & $\begin{array}{l}r=-.17 \\
p=.07\end{array}$ \\
\hline ASI-3 social concerns & $\begin{array}{l}r=-.07 \\
p=.47\end{array}$ & $\begin{array}{l}r=-.07 \\
p=.47\end{array}$ & $\begin{array}{l}r=-.12 \\
p=.20\end{array}$ \\
\hline $\begin{array}{l}\text { ASI-3 cognitive } \\
\text { concerns }\end{array}$ & $\begin{array}{l}r=-.07 \\
p=.50\end{array}$ & $\begin{array}{l}r=-.10 \\
p=.34\end{array}$ & $\begin{array}{l}r=-.09 \\
p=.34\end{array}$ \\
\hline $\begin{array}{l}\text { FFMQ act with } \\
\text { awareness }\end{array}$ & $\begin{array}{l}r=-.05 \\
p=.63\end{array}$ & $\begin{array}{l}r=.00 \\
p=.97\end{array}$ & $\begin{array}{l}r=-.30 * * \\
p<.01\end{array}$ \\
\hline ASI-3 total & $\begin{array}{l}r=-.05 \\
p=.64\end{array}$ & $\begin{array}{l}r=-.08 \\
p=.39\end{array}$ & $\begin{array}{l}r=-.04 \\
p=.66\end{array}$ \\
\hline MAIA not-worrying & $\begin{array}{l}r=.02 \\
p=.86\end{array}$ & $\begin{array}{l}r=.07 \\
p=.46\end{array}$ & $\begin{array}{l}r=.07 \\
p=.46\end{array}$ \\
\hline $\begin{array}{l}\text { ASI-3 physical } \\
\text { concerns }\end{array}$ & $\begin{array}{l}r=.04 \\
p=.68\end{array}$ & $\begin{array}{l}r=-.01 \\
p=.95\end{array}$ & $\begin{array}{l}r=.08 \\
p=.41\end{array}$ \\
\hline PHLMS awareness & $\begin{array}{l}r=.07 \\
p=.46\end{array}$ & $\begin{array}{l}r=.09 \\
p=.35\end{array}$ & $\begin{array}{l}r=-.10 \\
p=.29\end{array}$ \\
\hline Schandry task & $\begin{array}{l}r=.08 \\
p=.40\end{array}$ & $\begin{array}{l}r=.10 \\
p=.31\end{array}$ & $\begin{array}{l}r=-.03 \\
p=.78\end{array}$ \\
\hline
\end{tabular}

Note. ${ }^{*}=p \leq .05, * *=p \leq .01$. 
Table 21

Semi-Partial Correlations for New Versions of MIST, MIST-total, and HypotheticallyRelated Variables.

\begin{tabular}{|c|c|c|c|}
\hline Measure & MIST-total & $\begin{array}{l}\text { MIST-AC } \\
\text { (controlling for } \\
\text { systolic blood } \\
\text { pressure) }\end{array}$ & $\begin{array}{l}\text { MIST-ACN } \\
\text { (controlling } \\
\text { for systolic } \\
\text { blood } \\
\text { pressure) }\end{array}$ \\
\hline $\begin{array}{l}\text { MAIA } \\
\text { attention } \\
\text { regulation }\end{array}$ & $\begin{array}{l}r=-.44 * * \\
p<.01\end{array}$ & $\begin{array}{l}r=-.38 * * \\
p<.01\end{array}$ & $\begin{array}{l}r=-.41 * * \\
p<.01\end{array}$ \\
\hline $\begin{array}{l}\text { FFMQ act } \\
\text { with } \\
\text { awareness }\end{array}$ & $\begin{array}{l}r=-.30 * * \\
p<.01\end{array}$ & $\begin{array}{l}r=-.27 * * \\
p=.01\end{array}$ & $\begin{array}{l}r=-.33 * * \\
p<.01\end{array}$ \\
\hline $\begin{array}{l}\text { MAIA body } \\
\text { listening }\end{array}$ & $\begin{array}{l}r=-.17 \\
p=.07\end{array}$ & $\begin{array}{l}r=-.16 \\
p=.09\end{array}$ & $\begin{array}{l}r=-.15 \\
p=.12\end{array}$ \\
\hline $\begin{array}{l}\text { ASI-3 social } \\
\text { concerns }\end{array}$ & $\begin{array}{l}r=-.12 \\
p=.20\end{array}$ & $\begin{array}{l}r=-.10 \\
p=.30\end{array}$ & $\begin{array}{l}r=-.12 \\
p=.21\end{array}$ \\
\hline $\begin{array}{l}\text { PHLMS } \\
\text { awareness }\end{array}$ & $\begin{array}{l}r=-.10 \\
p=.29\end{array}$ & $\begin{array}{l}r=-.18 \\
p=.07\end{array}$ & $\begin{array}{l}r=-.15 \\
p=.12\end{array}$ \\
\hline $\begin{array}{l}\text { ASI-3 } \\
\text { cognitive } \\
\text { concerns }\end{array}$ & $\begin{array}{l}r=-.09 \\
p=.34\end{array}$ & $\begin{array}{l}r=-.12 \\
p=.24\end{array}$ & $\begin{array}{l}r=-.11 \\
p=.27\end{array}$ \\
\hline ASI-3 total & $\begin{array}{l}r=-.04 \\
p=.66\end{array}$ & $\begin{array}{l}r=-.09 \\
p=.37\end{array}$ & $\begin{array}{l}r=-.06 \\
p=.53\end{array}$ \\
\hline $\begin{array}{l}\text { Schandry } \\
\text { task }\end{array}$ & $\begin{array}{l}r=-.03 \\
p=.78\end{array}$ & $\begin{array}{l}r=-.05 \\
p=.64\end{array}$ & $\begin{array}{l}r=-.06 \\
p=.55\end{array}$ \\
\hline $\begin{array}{l}\text { MAIA not- } \\
\text { worrying }\end{array}$ & $\begin{array}{l}r=.07 \\
p=.46\end{array}$ & $\begin{array}{l}r=.16 \\
p=.11\end{array}$ & $\begin{array}{l}r=.12 \\
p=.20\end{array}$ \\
\hline $\begin{array}{l}\text { ASI-3 } \\
\text { physical } \\
\text { concerns }\end{array}$ & $\begin{array}{l}r=.08 \\
p=.41\end{array}$ & $\begin{array}{l}r=.00 \\
p=.99\end{array}$ & $\begin{array}{l}r=.05 \\
p=.63\end{array}$ \\
\hline
\end{tabular}


Table 22

Pearson Product-Moment Correlations Between Variables of the Proposed Nomological $\mathrm{Net}$

\begin{tabular}{|c|c|c|c|c|c|c|}
\hline $\begin{array}{l}\text { Hyp. } \\
\text { Relations. }\end{array}$ & $\begin{array}{l}\text { Order of } \\
\text { Nom. Net }\end{array}$ & $\begin{array}{l}\text { MAIA } \\
\text { Attention } \\
\text { Regulatio } \\
n\end{array}$ & $\begin{array}{l}\text { MAIA } \\
\text { Body } \\
\text { Listening }\end{array}$ & $\begin{array}{l}\text { MAIA } \\
\text { Not- } \\
\text { worrying }\end{array}$ & $\begin{array}{l}\text { PHLMS } \\
\text { Awareness }\end{array}$ & $\begin{array}{l}F F M Q \\
\text { Act } \\
\text { with } \\
\text { Awaren } \\
\text { ess } \\
\end{array}$ \\
\hline $\begin{array}{l}\text { Most } \\
\text { significant } \\
\text { positive } \\
\text { correlation }\end{array}$ & $\begin{array}{l}\text { MAIA } \\
\text { Attention } \\
\text { Reg. }\end{array}$ & -- & -- & -- & -- & -- \\
\hline $\begin{array}{l}\text { Most } \\
\text { significant } \\
\text { positive } \\
\text { correlation }\end{array}$ & $\begin{array}{l}\text { MAIA } \\
\text { Body } \\
\text { Listening }\end{array}$ & $\begin{array}{l}r=.33^{* *} \\
p<.01\end{array}$ & -- & -- & -- & -- \\
\hline $\begin{array}{l}\text { Most } \\
\text { significant } \\
\text { positive } \\
\text { correlation }\end{array}$ & $\begin{array}{l}\text { MAIA } \\
\text { Not- } \\
\text { worrying }\end{array}$ & $\begin{array}{l}r=-.08 \\
p=.40\end{array}$ & $\begin{array}{l}r=-.14 \\
p=.14\end{array}$ & -- & -- & -- \\
\hline $\begin{array}{l}\text { Less } \\
\text { significant } \\
\text { positive } \\
\text { correlation }\end{array}$ & $\begin{array}{l}\text { PHLMS } \\
\text { awareness } \\
\text { scale }\end{array}$ & $\begin{array}{l}r=.40 * * \\
p<.01\end{array}$ & $\begin{array}{l}r=.19 * \\
p=.05\end{array}$ & $\begin{array}{l}r=.16 \\
p=.10\end{array}$ & -- & -- \\
\hline $\begin{array}{l}\text { Least } \\
\text { significant } \\
\text { positive } \\
\text { correlation }\end{array}$ & $\begin{array}{l}\text { FFMQ act } \\
\text { with } \\
\text { awareness } \\
\text { scale }\end{array}$ & $\begin{array}{l}r=.33^{* *} \\
p<.01\end{array}$ & $\begin{array}{l}r=.10 \\
p=.33\end{array}$ & $\begin{array}{l}r=.07 \\
p=.46\end{array}$ & $\begin{array}{l}r=.21 * \\
p=.03\end{array}$ & -- \\
\hline $\begin{array}{l}\text { No } \\
\text { correlation }\end{array}$ & $\begin{array}{l}\text { Schandry } \\
\text { Task }\end{array}$ & $\begin{array}{l}r=-.09 \\
p=.39\end{array}$ & $\begin{array}{l}r=-.21 * \\
p=.04\end{array}$ & $\begin{array}{l}r=.05 \\
p=.61\end{array}$ & $\begin{array}{l}r=.00 \\
p=.99\end{array}$ & $\begin{array}{l}r=.07 \\
p=.47\end{array}$ \\
\hline $\begin{array}{l}\text { Not } \\
\text { correlated } \\
\text { or } \\
\text { negative } \\
\text { correlation }\end{array}$ & $\begin{array}{l}\text { ASI-3 } \\
\text { total }\end{array}$ & $\begin{array}{l}r=.04 \\
p=.68\end{array}$ & $\begin{array}{l}r=.08 \\
p=.41\end{array}$ & $\begin{array}{l}r=-.31^{* *} \\
p<.01\end{array}$ & $\begin{array}{l}r=-.10 \\
p=.30\end{array}$ & $\begin{array}{l}r=-.17 \\
p=.09\end{array}$ \\
\hline
\end{tabular}




\begin{tabular}{|c|c|c|c|c|c|c|}
\hline $\begin{array}{l}\text { Not } \\
\text { correlated } \\
\text { or } \\
\text { negative } \\
\text { correlation }\end{array}$ & $\begin{array}{l}\text { ASI-3 } \\
\text { cognitive } \\
\text { concerns }\end{array}$ & $\begin{array}{l}r=.06 \\
p=.52\end{array}$ & $\begin{array}{l}r=.14 \\
p=.14\end{array}$ & $\begin{array}{l}r=-.26 * * \\
p=.01\end{array}$ & $\begin{array}{l}r=-.10 \\
p=.30\end{array}$ & $\begin{array}{l}r=-.17 \\
p=.08\end{array}$ \\
\hline $\begin{array}{l}\text { Not } \\
\text { correlated } \\
\text { or } \\
\text { negative } \\
\text { correlation }\end{array}$ & $\begin{array}{l}\text { ASI-3 } \\
\text { social } \\
\text { concerns }\end{array}$ & $\begin{array}{l}r=.15 \\
p=.13\end{array}$ & $\begin{array}{l}r=.08 \\
p=.44\end{array}$ & $\begin{array}{l}r=-.11 \\
p=.25\end{array}$ & $\begin{array}{l}r=-.10 \\
p=.30\end{array}$ & $\begin{array}{l}r=-.05 \\
p=.63\end{array}$ \\
\hline $\begin{array}{l}\text { Not } \\
\text { correlated } \\
\text { or } \\
\text { negative } \\
\text { correlation }\end{array}$ & $\begin{array}{l}\text { ASI-3 } \\
\text { physical } \\
\text { concerns }\end{array}$ & $\begin{array}{l}r=-.14 \\
p=.16\end{array}$ & $\begin{array}{l}r=.09 \\
p=.35\end{array}$ & $\begin{array}{l}r=-.30 * * \\
p<.01\end{array}$ & $\begin{array}{l}r=-.01 \\
p=.95\end{array}$ & $\begin{array}{l}r=-.17 \\
p=.09\end{array}$ \\
\hline
\end{tabular}




\section{APPENDICES}

\section{Appendix A}

Mindful Interoception Sampling Task (MIST) script. In a moment, you will begin a guided attention task. If you choose, you can close your eyes to better focus on the task, or if you prefer, you can leave your eyes open.

During this task, you will be asked to direct your attention to inner sensations within different regions of your body. As you attend to these regions of the body you may notice any number of inner sensations. Some people notice sensations such as tightness, looseness, coolness, warmth, or tingling. It does not matter which sensation you attend to, or whether it's a strong sensation or a weak sensation. Just focus on the sensations in your body as they are. (Brief pause....)

Now...in addition to inner physical sensations, your attention may also be drawn from time to time to thoughts or other mental events that come and go...we call this 'mind wandering', and it's a very common experience. Examples of mind wandering include internal conversations, daydreaming, or becoming distracted by a smell or sound.

During the task you may find that instances of mind wandering draw your attention away from the physical sensations you are experiencing in the present moment. Whenever this occurs, we ask that you refocus your attention on the internal sensations present in your body in that moment.

Throughout the task, you will periodically hear a signal that sounds like

this: . At that moment, we ask that you determine if your attention is focused on inner physical sensations or on something else, like thoughts. If your attention has wandered from physical sensations, please press the clicker in your hand. If your 
attention is presently on inner sensations, please continue focusing on the sensations and do not press the clicker. Other than pressing the clicker, you will not need to move your body during the task.

During this task, you may have thoughts about the sensations in your body (for example, 'I wonder if my stomach feels queasy because of the food I ate for breakfast'). Although these thoughts are related to the body, they have still shifted the attention away from sensations that are occurring in that moment. If you notice that you are having thoughts about inner sensations rather than focusing on the sensations themselves, consider this 'mind wandering'. It is important that you understand this distinction so that you are able to make the most accurate reports possible.

Before we practice, please let the facilitator know if you have any questions about this distinction or more generally about the task. (pause)

Okay, let's practice...now bringing your attention to the inside of the nose....just being aware of whatever inner sensations you are experiencing. ( 2 minutes of silence with 3 signals)

Please press the clicker to indicate that you are awake. Thank you.

The facilitator will now clear the count on your clicker in preparation for the full task. During this interval, please let your facilitator know if you have any further questions. (pause) Remember it is very important that you report instances of mind wandering as truthfully as possible. Thank you for your participation - let's begin. (pause)

Now bringing your attention to the abdomen, the center of the body....just being aware of whatever inner sensations you are experiencing. (2 minutes of silence with 3 signals) 
Please press the clicker to indicate that you are awake. Thank you.

Now, bringing your attention to the chest region of the body... just being aware of whatever inner sensations you are experiencing ( 2 minutes of silence with 3 signals)

Please press the clicker to indicate that you are awake. Thank you.

Now, bringing your attention to the muscles in your back... just being aware of whatever inner sensations you are experiencing ( 2 minutes of silence with 3 signals)

Please press the clicker to indicate that you are awake. Thank you.

Now, bringing your attention to the neck and throat... just being aware of whatever inner sensations you are experiencing ( 2 minutes of silence with 3 signals)

Please press the clicker to indicate that you are awake. Thank you.

This marks the end of this guided attention task. Please take your time redirecting your attention outwardly.

\section{Appendix B}

EKG protocol. Begin by rubbing a sterile, disposable sponge dipped in rubbing alcohol on the participant's wrist. The participant will be asked to sit still with his/her wrists facing up and the researcher will then attach two pre-gelled electrodes to the participant's left wrist and one pre-gelled electrode to the participant's right wrist. Using the Thought Technology Biograph Infiniti system, the researcher will attach the electrodes to the Thought Technology EKG equipment. The participant will be positioned to where he/she cannot see the EKG data on the computer screen.

The researcher will next test the EKG connection to determine if the electrodes have a good connection. If the signal is weak or not working, the participant will be instructed to adjust his/her arms until a signal appears. If a signal still does not appear and 
the participant is the same gender as the researcher, the researcher will offer to help assist with a torso placement, placing two electrodes under the clavicles and one electrode above the navel. If the participant is not the same gender as the researcher, the participant will be asked if he/she is willing to place the electrodes on his/her torso while the researcher leaves the room for privacy reasons. In this instance, the participant will be shown a diagram demonstrating the placement of the electrodes. If the participant declines at this time, this will end his/her involvement in the study and he/she will still receive course credit. Once an EKG signal is obtained either using the wrist or torso, the researcher will collect a baseline heart rate sample.

\section{Appendix C}

MIST protocol. Participants are seated and provided a clicker for counting instances of mind wandering. The researcher explains that the task involves listening to an audio recording and following directions. The researcher also explains that he/she will be seated out of view of the participant, but will be within hearing distance and available to answer questions. A visual barrier is placed between the researcher and the participant in order not to cause performance anxiety or expectations introduced by close observation.

The researcher begins the MIST audio recording. The audio recording provides opportunities for the participant ask questions and interact with the researcher, in a limited manner. For the full text of the audio recording, see Appendix A. If the participant does not respond to any one of the prompts querying whether the participant is awake, the participant is assumed to have fallen asleep and his/her data is excluded from 
the study. At the end of the audio recording, the researcher collects the clicker from the participant and then records the number of clicks as the participant's total MIST score.

\section{Appendix D.}

Schandry heartbeat detection task protocol. The administration of the

Schandry heartbeat detection task is based on the sequence described in the original Schandry heartbeat detection task paper (Schandry, 1981). Participants are instructed to count their heartbeats over a set amount of time as accurately as possible, after which they report that number to the researcher. The researcher indicates that a heartbeat detection period has begun by saying "Go"; the heartbeat detection period is finished when the researcher says "Stop." Participants are positioned to where they cannot see the EKG readout on the computer screen.

Once the participant indicates that he/she understands the directions, he/she is given 60 seconds of rest before the first detection period. The first detection period lasts 25 seconds. The ensuing rest period lasts 30 seconds. The second detection period lasts 35 seconds. The ensuing rest period lasts 30 seconds. The third detection period lasts 45 seconds. The final rest period lasts 60 seconds before transitioning to the MIST or to the self-report measures.

During each detection period, the researcher records actual heartbeats via the EKG. After the participant has completed the study and left the laboratory, the researcher counts the number of actual heartbeats for each detection period. He/she then records an error score for each detection period by calculating the difference between reported and actual heartbeats and dividing that value by actual heartbeats. The researcher then takes the absolute value of each detection period error score and adds these three values 
together. This sum score is then recorded as the participant's Schandry heartbeat detection task total score. A higher score thus correlates with a less accurate performance on the task.

\section{Appendix E}

Anxiety sensitivity index-3 (ASI-3). Please circle the number that best corresponds to how much you agree with each item. If any items concern something that you have never experienced (e.g., fainting in public) answer on the basis of how you think you might feel if you had such an experience. Otherwise, answer all items on the basis of your own experience. Be careful to circle only one number for each item and please answer all items.

\section{0 $=$ Very Little $\quad 1=$ A Little $2=$ Some $3=$ Much $4=$ Very Much}

1. It is important for me not to appear nervous.

$$
\begin{array}{lllll}
0 & 1 & 2 & 3 & 4
\end{array}
$$

2. When I cannot keep my mind on a task, I worry that I might be going crazy.

$$
\begin{array}{lllll}
0 & 1 & 2 & 3 & 4
\end{array}
$$

3. It scares me when my heart beats rapidly.

$$
\begin{array}{lllll}
0 & 1 & 2 & 3 & 4
\end{array}
$$

4. When my stomach is upset, I worry that I might be seriously ill.

$$
\begin{array}{lllll}
0 & 1 & 2 & 3 & 4
\end{array}
$$

5. It scares me when I am unable to keep my mind on a task.

$$
\begin{array}{lllll}
0 & 1 & 2 & 3 & 4
\end{array}
$$

6. When I tremble in the presence of others, I fear what people might think of me.

$$
\begin{array}{lllll}
0 & 1 & 2 & 3 & 4
\end{array}
$$

7. When my chest feels tight, I get scared that I won't be able to breathe properly.

$\begin{array}{lllll}0 & 1 & 2 & 3 & 4\end{array}$


8. When I feel pain in my chest, I worry that I am going to have a heart attack.

$$
\begin{array}{lllll}
0 & 1 & 2 & 3 & 4
\end{array}
$$

9. I worry that other people will notice my anxiety.

$$
\begin{array}{lllll}
0 & 1 & 2 & 3 & 4
\end{array}
$$

10. When I feel "spacey" or spaced out I worry that I may be mentally ill.

$$
\begin{array}{lllll}
0 & 1 & 2 & 3 & 4
\end{array}
$$

11. It scares me when I blush in front of people.

$$
\begin{array}{lllll}
0 & 1 & 2 & 3 & 4
\end{array}
$$

12. When I notice my heart skipping a beat, I worry that there is something seriously wrong with

me.

$$
\begin{array}{lllll}
0 & 1 & 2 & 3 & 4
\end{array}
$$

13. When I begin to sweat in a social situation, I fear people will think negatively of me.

$$
\begin{array}{lllll}
0 & 1 & 2 & 3 & 4
\end{array}
$$

14. When my thoughts seem to speed up, I worry that I might be going crazy.

$$
\begin{array}{lllll}
0 & 1 & 2 & 3 & 4
\end{array}
$$

15. When my throat feels tight, I worry that I could choke to death.

$$
\begin{array}{lllll}
0 & 1 & 2 & 3 & 4
\end{array}
$$

16. When I have trouble thinking clearly, I worry that there is something wrong with me.

$$
\begin{array}{lllll}
0 & 1 & 2 & 3 & 4
\end{array}
$$

17. I think it would be horrible for me to faint in public.

$$
\begin{array}{lllll}
0 & 1 & 2 & 3 & 4
\end{array}
$$

18. When my mind goes blank, I worry there is something terribly wrong with me.

$$
\begin{array}{lllll}
0 & 1 & 2 & 3 & 4
\end{array}
$$

Scoring:

Physical Concerns subscale prompts: $3,4,7,8,12,15$

Cognitive Concerns subscale prompts: 2, 5, 10, 14, 16, 18

Social Concerns subscale prompts: $1,6,9,11,13,17$

Sum each subscale for subscale scores. Add subscales for total score.

\section{Appendix F}




\section{Act with awareness subscale of the five-factor mindfulness questionnaire}

(FFMQ). Please rate each of the following statements using the scale provided. Write the number in the blank that best describes your own opinion of what is generally true for you.

$$
\begin{gathered}
1=\text { never or very rarely true } \\
4=\text { often true }
\end{gathered} \quad \begin{gathered}
2=\text { rarely true } \\
5=\text { very often or always true }
\end{gathered}
$$

1) When I do things, my mind wanders off and I'm easily distracted.

2) I don't pay attention to what I'm doing because I'm daydreaming, worrying, or otherwise distracted.

$\begin{array}{lllll}1 & 2 & 3 & 4 & 5\end{array}$

3) I am easily distracted.

$\begin{array}{lllll}1 & 2 & 3 & 4 & 5\end{array}$

4) I find it difficult to stay focused on what's happening in the present.

$\begin{array}{lllll}1 & 2 & 3 & 4 & 5\end{array}$

5) It seems I am "running on automatic" without much awareness of what I'm doing.

$\begin{array}{lllll}1 & 2 & 3 & 4 & 5\end{array}$

6) I rush through activities without being really attentive to them.

$\begin{array}{lllll}1 & 2 & 3 & 4 & 5\end{array}$

7) I do jobs or tasks automatically without being aware of what I'm doing.

$$
\begin{array}{lllll}
1 & 2 & 3 & 4 & 5
\end{array}
$$

8) I find myself doing things without paying attention.

$$
\begin{array}{lllll}
1 & 2 & 3 & 4 & 5
\end{array}
$$

Scoring: Reverse score all items and sum together.

\section{Appendix G}

Awareness scale of the Philadelphia mindfulness scale (PHLMS). Please indicate how often you experienced each of the following statements within the past week.

\begin{tabular}{lllll}
1 & 2 & 3 & 4 & 5 \\
\hline Never & rarely & sometimes & often & very often
\end{tabular}

1. I am aware of what thoughts are passing through my mind. 
3. When talking with other people, I am aware of their facial and body expressions.

5. When I shower, I am aware of how the water is running over my body.

7. When I am startled, I notice what is going on inside my body.

9. When I walk outside, I am aware of smells or how the air feels against.

11. When someone asks how I am feeling, I can identify my emotions easily.

13. I am aware of thoughts I'm having when my mood changes.

15. I notice changes inside my body, like my heart beating faster or my muscles getting tense.

17. Whenever my emotions change, I am conscious of them immediately.

19. When talking with other people, I am aware of the emotions I am experiencing.

Scoring:

The Awareness scale total score is the sum of the odd numbered prompts.

\section{Appendix H}

The Not-Worrying, Attention Regulation, and Body Listening Scales of the Multidimensional Assessment of Interoceptive Awareness (MAIA). Below you will

find a list of statements. Please indicate how often each statement applies to you generally in daily life.

Circle one number on each line

8. When I feel physical pain, I become upset. Never

0

2

34

Always

5

9. I start to worry that something is wrong if I feel any discomfort. Never 0

1

2

34

Always

10. I can notice an unpleasant body sensation without worrying about it.

Never

0
1

2
3
4 Always
5 
11. I can pay attention to my breath without being distracted by things happening around me.

Never

0

$2 \quad 3$

4

Always

12. I can maintain awareness of my inner bodily sensations even when there is a lot going on around me.

Never

0

1

2

3

4

Always

13. When I am in conversation with someone, I can pay attention to my posture.

Never

0

1

2

3

4

Always

14. I can return awareness to my body if I am distracted.

Never

0

1

2

3

4

Always

15. I can refocus my attention from thinking to sensing my body.

Never

0

1

2

3

4

5

Always

16. I can maintain awareness of my whole body even when a part of me is in pain or discomfort.

Never

0

1

2

3

4

Always

5

17. I am able to consciously focus on my body as a whole. Never

0

1

2

3

4

Always

27. I listen for information from my body about my emotional state.

Never

0

1

23

4

Always

28. When I am upset, I take time to explore how my body feels.

Never

0

1

2

3

4

Always

5

29. I listen to my body to inform me about what to do.

Never

0

1

2

3

4

Always

Scoring:

Take the average of the items on each scale.

Not-Worrying: Tendency not to worry or experience emotional distress with sensations of pain or discomfort 
Q8(reverse) + Q9(reverse) $+\mathrm{Q} 10$ $13=$

Attention regulation: Ability to sustain and control attention to body sensations

Q11. + Q12 + Q13 + Q14 + Q15 + Q16 + Q17 $17=$

Body Listening: Active listening to the body for insight $\mathrm{Q} 27 \ldots+\mathrm{Q} 28 \ldots$ Q29__ / 3= 


\section{CURRICULUM VITA}

NAME: Samuel J. Dreeben

ADDRESS: 14021 Canterbury Road

Spring Branch, TX 78070

DOB: $\quad$ San Antonio, TX - November 18, 1983

EDUCATION

\& TRAINING: $\quad$ B.A., Psychology

Williams College

2002-2006

M.A., Clinical Psychology

University of Louisville

2009-2011

AWARDS: Cum Laude, Williams College

2006

University Fellow, University of Louisville

2009-2011

PUBLICATIONS: $\quad$ Dreeben, S. J., Mamberg, M. H., \& Salmon, P. (2013). The MBSR Body Scan in Clinical Practice. Mindfulness, 4, 394-401.

Salmon, P. G., Sephton, S. E. \& Dreeben, S.J. (2010). Mindfulness-Based Stress Reduction. In J. D. Hebert \& E. Forman (Eds.), Acceptance and Mindfulness in Cognitive Behavior Therapy. Wiley. 